INSTITUTO DE PESQUISAS ENERGÉTICAS E NUCLEARES AUTARQUIA ASSOCIADA À UNIVERSIDADE DE SÃO PAULO

Avaliação da radioatividade natural e artificial em farinhas comercializadas na cidade de São Paulo por espectrometria gama de alta resolução

GRAZIELA MENDONÇA DA SILVA

Dissertação apresentada como parte dos requisitos para obtenção do grau de Mestre em Ciências na Área de Tecnologia Nuclear - Aplicações.

Orientador:

Dra. Brigitte Roxana Soreanu Pecequilo 
INSTITUTO DE PESQUISAS ENERGÉTICAS E NUCLEARES

Autarquia Associada à Universidade de São Paulo

Avaliação da radioatividade natural e artificial em farinhas comercializadas na cidade de São Paulo por espectrometria gama de alta resolução

Versão Corrigida

Versão Original disponível no IPEN

GRAZIELA MENDONÇA DA SILVA

Dissertação apresentada como parte dos requisitos para obtenção do Grau de Mestre em Ciências na Área de Tecnologia Nuclear - Aplicações

Orientadora:

Profa. Dra. Brigitte Roxana Soreanu

Pecequilo

\#

\# 
Fonte de Financiamento: CNEN-IPEN.

Autorizo a reprodução e divulgação total ou parcial deste trabalho, para fins de estudo e pesquisa, desde que citada a fonte.

Como citar:

SILVA, G. M. AVALIAÇÃO DA RADIOATIVIDADE NATURAL E ARTIFICIAL EM FARINHAS COMERCIALIZADAS NA CIDADE DE SÃO PAULO POR ESPECTROMETRÍA GAMA DE ALTA RESOLUÇÃO. 2020. 81 p. Dissertação (Mestrado em Tecnologia Nuclear), Instituto de Pesquisas Energéticas e Nucleares, IPEN-CNEN/SP, São Paulo. <www.teses.usp.br> (data de consulta no formato: $\mathrm{dd} / \mathrm{mm} /$ aaaa)

FICHA CATALOGRÁFICA

Mendonça da Silva, Graziela

AVALIAÇÃO DA RADIOATIVIDADE NATURAL E ARTIFICIAL EM FARINHAS COMERCIALIZADAS NA CIDADE DE SÃO PAULO POR ESPECTROMETRÍA GAMA DE ALTA RESOLUÇÃO / Graziela Mendonça da Silva; orientadora Brigitte Roxana Soreanu Pecequilo. - São Paulo, 2020. 83 p.

Dissertação (Mestrado) - Programa de Pós-Graduação em Tecnologia Nuclear (Aplicações) - Instituto de Pesquisas Energéticas e Nucleares, São Paulo, 2020.

1. Alimentos. 2. Radioatividade natural e artificial. 3. Espectrometria gama. 4. Concentração de atividade. 5. Dose efetiva. 


\section{Agradecimentos}

Agradeço a todos que contribuíram de alguma forma para o desenvolvimento deste projeto:

Agradeço aos meus familiares Mãe, Pitoco, Pai, em especial ao meu irmão Luilson Mendonça e minha cunhada Arine Mendonça, que de algum modo tiveram a paciência de me ouvir falar desse universo novo (área nuclear) mesmo sem entender nada, minha gratidão.

Agradeço a Profa. Dra. Brigitte Pecequilo, pela paciência e a oportunidade de realizar esse projeto.

Agradeço imensamente a Dra. Marcia Pires de Campos, por me apresentar a esse universo tão incrível que é o estudo das radiações e pela orientação no ingresso desse mundo novo.

As amizades que fiz durante o período de estudos no IPEN, Laíssa Bonifacio, Gleyca Damasceno, Heleine Almeida, Andressa Nery, Letícia, Vera Isiki, Guilherme Reis, Fábio Manocchi e Bruna Roque, por todos os momentos que passamos.

Ao Gabriel Beraldo pela amizade e companheirismo mesmo nas horas mais difíceis, sempre me apoiando e trocando seus conhecimentos comigo, e se tornar uma pessoa especial em minha vida.

Em especial a Dra. Sandra Regina Damatto, por se tornar uma amiga muito estimada, minha gratidão.

Ao senhor Décio por me trazer conhecimento durante os cafés, por todos os livros que me presenteou, foi um prazer conhecê-lo.

Aos Doutores Marcelo Bessa, Fernanda Cavalcante, Marcelo Máduar e Cátia Saueia e aos Mestres Marcos Medrado e Luiz Teixeira pelo apoio e paciência em me ajudar nos momentos de dúvidas, e ao Paulo Rene pela amizade, troca de livros e brincadeiras ao longo dos anos no LRA.

À Dra. Cibele Bugno Zamboni pela doação de algumas das amostras que foram analisadas. 
Ao Instituto de Pesquisas Energéticas e Nucleares (IPEN) e Laboratório de Radiometria Ambiental pelo uso das dependências e laboratórios.

À Comissão Nacional de Energia Nuclear (CNEN) pela bolsa de estudos fornecida. 
"A fé é um modo de já possuir o que ainda se espera, a convicção acerca de realidades que não se veem. “

- Hebreus 11,1-7 


\title{
AVALIAÇÃO DA RADIOATIVIDADE NATURAL E ARTIFICIAL EM FARINHAS COMERCIALIZADAS NA CIDADE DE SÃO PAULO POR ESPECTROMETRÍA GAMA DE ALTA RESOLUÇÃO
}

\author{
Graziela Mendonça da Silva
}

\begin{abstract}
RESUMO
Uma das contribuições mais relevantes para a dose efetiva recebida pelos seres humanos proveniente de fontes naturais de radiação é a dose por ingestão. As concentrações de radionuclídeos naturais em alimentos variam significativamente não apenas com os diferentes tipos de alimentos, mas também com níveis de radiação de fundo, clima e condições agrícolas. Na literatura, poucos trabalhos apresentam dados de dose efetiva pela ingestão de farinhas, amplamente utilizada como dieta de subsistência em todo o mundo. No presente trabalho, as concentrações de atividades de radionuclídeos naturais e artificiais foram analisadas por espectrometria gama de alta resolução em 38 amostras de farinha (trigo, milho, mandioca, arroz, soja, centeio, aveia e rosca) comumente comercializadas na cidade de São Paulo, Brasil. A partir dessas concentrações foram calculadas as doses efetivas por ingestão para os radionuclídeos considerados. Para os radionuclídeos naturais foram obtidas concentrações de atividade na faixa de $25 \mathrm{~Bq} \cdot \mathrm{kg}^{-1}$ a $663 \mathrm{~Bq} \cdot \mathrm{kg}^{-1}$ para o ${ }^{40} \mathrm{~K}$, de 0,97 Bq. $\mathrm{kg}^{-1}$ a 4,47 Bq. kg ${ }^{-1}$ para o ${ }^{226} \mathrm{Ra}$ e de 9,91 Bq. kg ${ }^{-1}$ a $42,41 \mathrm{~Bq} \cdot \mathrm{kg}^{-1}$ para o ${ }^{232} \mathrm{Th}$. As doses efetivas obtidas estão entre $0,34 \mu S v \cdot a^{-1}$ e $10,56 \mu S v \cdot a^{-1}$ para o ${ }^{40} \mathrm{~K}$, entre 0,67 $\mu S v . a^{-1}$ e $18,35 \mu S v . a^{-1}$ para o ${ }^{226}$ Ra e entre $5,62 \mu S v . a^{-1}$ a $114,02 \mu S v . a^{-1}$ para o ${ }^{232} \mathrm{Th}$. Os valores de dose efetiva recomendados pela UNSCEAR e IAEA por ingestão de alimentos contendo radionuclídeos naturais são de $140 \mu \mathrm{Sv} \cdot \mathrm{a}^{-1}$ e de $1 \mathrm{mSv} \cdot \mathrm{a}^{-1}$, respectivamente, para os indivíduos do público. Todos os radionuclídeos artificiais estudados, ${ }^{134} \mathrm{Cs},{ }^{137} \mathrm{Cs},{ }^{106} \mathrm{Ru},{ }^{103} \mathrm{Ru},{ }^{60} \mathrm{Co},{ }^{131} \mathrm{I}$ e ${ }^{241} \mathrm{Am}$, apresentaram valores de concentração de atividades abaixo da concentração mínima detectável (CMD), utilizada para o cálculo de dose efetiva. Os valores médios obtidos para ${ }^{134} \mathrm{Cs},{ }^{137} \mathrm{Cs}$, ${ }^{106} \mathrm{Ru},{ }^{103} \mathrm{Ru},{ }^{60} \mathrm{Co},{ }^{131} \mathrm{I}$ e ${ }^{241} \mathrm{Am}$ foram de $0,04 \mu S v . \mathrm{a}^{-1}, 0,03 \mu S v . \mathrm{a}^{-1}, 0,13 \mu \mathrm{Sv}_{\mathrm{a}} \mathrm{a}^{-1}, 0,001$ $\mu S v . a^{-1}, 0,01 \mu S v . a^{-1}, 0,05 \mu S v . a^{-1}$ e $0,4 \mu S v . a^{-1}$, respectivamente, para público adulto. Para público infantil os valores médios obtidos para os radionuclídeos artificiais recomendados foram de $0,04 \mu S v . a^{-1}, 0,03 \mu S v . a^{-1}, 0,01 \mu S v \cdot a^{-1}, 0,9 \mu S v . a^{-1}, 0,1$ $\mu S v \cdot a^{-1}, 0,4 \mu S v \cdot a^{-1}$ e $0,6 \mu S v \cdot a^{-1}$, para os radionuclídeos ${ }^{134} \mathrm{Cs},{ }^{137} \mathrm{Cs},{ }^{106} \mathrm{Ru},{ }^{103} \mathrm{Ru}$, ${ }^{60} \mathrm{Co},{ }^{131} \mathrm{I}$ e ${ }^{241} \mathrm{Am}$, respectivamente, inferiores aos valores recomendados pelo CODEX de $1 \mathrm{mSv} \cdot \mathrm{a}^{-1}$. Todas as amostras apresentaram valores de concentração de atividade na faixa dos valores da literatura e inferiores aos limites recomendados não apresentando riscos à saúde a partir da ingestão das farinhas analisadas.
\end{abstract}




\title{
EVALUATION OF NATURAL AND ARTIFICIAL RADIOACTIVITY IN FLOURS COMMERCIALIZED IN THE CITY OF SÃO PAULO BY HIGH RESOLUTION GAMMA SPECTROMETRY
}

\author{
Graziela Mendonça da Silva
}

\begin{abstract}
One of the most relevant contributions to the effective dose received by humans from natural sources of radiation is the dose by ingestion. The concentrations of natural radionuclides in food vary significantly not only with different types of food, but also with background radiation levels, climate and agricultural conditions. In the literature, few studies present data on effective dose for eating flour, which is widely used as a subsistence diet worldwide. In the present work, the activity concentrations of natural and artificial radionuclides were analyzed by high-resolution gamma spectrometry in 38 samples of flour (wheat, corn, manioc, rice, soy, rye, oats and breadcrumbs) commonly commercialized in the city of São Paulo, Brazil. From these concentrations, the effective doses per ingestion for the radionuclides considered were calculated. For natural radionuclides activity concentrations were obtained in the range of $25 \mathrm{~Bq} . \mathrm{kg}^{-1}$ to $663 \mathrm{~Bq} \cdot \mathrm{kg}^{-1}$ for ${ }^{40} \mathrm{~K}$, from $0.97 \mathrm{~Bq} \cdot \mathrm{kg}^{-1}$ to $4.47 \mathrm{~Bq} \cdot \mathrm{kg}^{-1}$ for ${ }^{226} \mathrm{Ra}$ and from $9.91 \mathrm{~Bq} \cdot \mathrm{kg}^{-}$ ${ }^{1}$ to $42.41 \mathrm{~Bq}^{-\mathrm{kg}^{-1}}$ for ${ }^{232} \mathrm{Th}$. The effective doses obtained are between $0.34 \mu \mathrm{Sv} \cdot \mathrm{y}^{-1}$ and $10.56 \mu \mathrm{Sv} . \mathrm{y}^{-1}$ for ${ }^{40} \mathrm{~K}$, between $0.67 \mu \mathrm{Sv} . \mathrm{y}^{-1}$ and $18.35 \mu \mathrm{Sv} \mathrm{y}^{-1}$ for ${ }^{226} \mathrm{Ra}$ and between $5.62 \mu \mathrm{Sv} . \mathrm{y}^{-1}$ to $114.02 \mu \mathrm{Sv} . \mathrm{y}^{-1}$ for ${ }^{232} \mathrm{Th}$. The effective dose values recommended by UNSCEAR and IAEA for foods containing natural radionuclides are $140 \mu \mathrm{Sv}_{\mathrm{y}} \mathrm{y}^{-1}$ and 1 $\mathrm{mSv} . \mathrm{y}^{-1}$, respectively, for individuals in the public. All artificial radionuclides studied, ${ }^{134} \mathrm{Cs},{ }^{137} \mathrm{Cs},{ }^{106} \mathrm{Ru},{ }^{103} \mathrm{Ru},{ }^{60} \mathrm{Co},{ }^{131} \mathrm{I}$ and ${ }^{241} \mathrm{Am}$, presented activity concentration values below the minimum detectable concentration (CMD) used to calculate the effective dose. The average values obtained for ${ }^{134} \mathrm{Cs},{ }^{137} \mathrm{Cs},{ }^{106} \mathrm{Ru},{ }^{103} \mathrm{Ru},{ }^{60} \mathrm{Co},{ }^{131} \mathrm{I}$ and ${ }^{241} \mathrm{Am}$ were $0.04 \mu$ Sv. $y^{-1}, 0.03 \mu$ Sv. $y^{-1}, 0.13 \mu S v \cdot y^{-1}, 0.001 \mu S v . y^{-1}, 0.01 \mu S v . y^{-1}, 0.05 \mu S v . y^{-}$ ${ }^{1}$ and $0.4 \mu \mathrm{Sv} . \mathrm{y}^{-1}$, respectively, for adult public. For children, the average values obtained for the recommended artificial radionuclides were $0.04 \mu S v \cdot y^{-1}, 0.03 \mu S v . y^{-1}$, $0.01 \mu$ Sv. $y^{-1}, 0.9 \mu$ Sv. $y^{-1}, 0.1 \mu S v . y^{-1}, 0.4 \mu S v . y^{-1}$ and $0.6 \mu S v . y^{-1}$, for radionuclides ${ }^{134} \mathrm{Cs},{ }^{137} \mathrm{Cs},{ }^{106} \mathrm{Ru},{ }^{103} \mathrm{Ru},{ }^{60} \mathrm{Co},{ }^{131} \mathrm{I}$ and ${ }^{241} \mathrm{Am}$, respectively, below the recommended values by the CODEX of $1 \mathrm{mSv} \cdot \mathrm{y}^{-1}$. All samples showed activity concentration values in the range of literature values and below the recommended limits, presenting no health risks from the intake of the analyzed flours.
\end{abstract}




\section{SUMÁRIO}

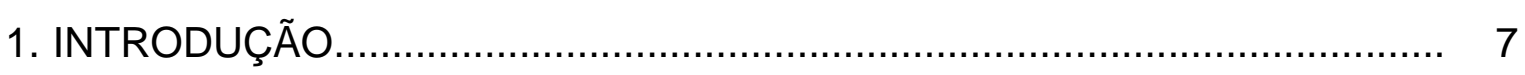

1.1 Radionuclídeos naturais e artificiais em alimentos....................... 11

1.2 Segurança alimentar....................................................... 15

1.3 Farinhas.................................................................... 16

1.4 Consumo de farinha no Brasil................................................... 17

1.5 Uso da farinha de trigo e milho na fortificação com ferro e ácido fólico....................................................................................... 20

1.6 Farinha de trigo.............................................................. 20

1.7 Farinha de milho................................................................... 22

1.8 Farinha de mandioca........................................................ 23

1.9 Farinha de arroz............................................................ 24

1.10 Farinha de soja............................................................... 24

1.11 Farinha de aveia............................................................... 25

1.12 Farinha de centeio........................................................... 26

1.13 Farinha de rosca............................................................ 26

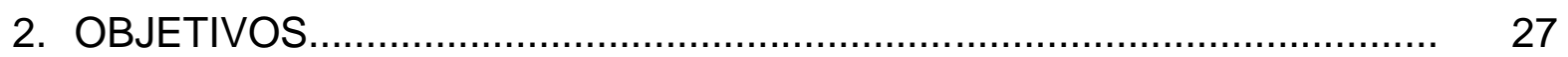

3. MATERIAIS E MÉTODOS............................................................ 27

3.1 Amostragem............................................................ 27

3.2 Preparo das amostras..................................................... 30

3.3 Espectrometria gama.................................................... 31

3.4 Tempo de contagem das amostras....................................... 33

3.5 Radionuclídeos analisados............................................... 35

3.6 Cálculo da concentração de atividade...................................... 37

3.7 Dose efetiva por ingestão de alimentos................................ 39

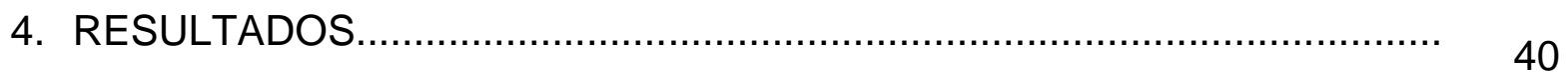

4.1 Concentração de atividade .................................................. 40

4.1.1 Concentração de atividade dos radionuclídeos naturais................ 40

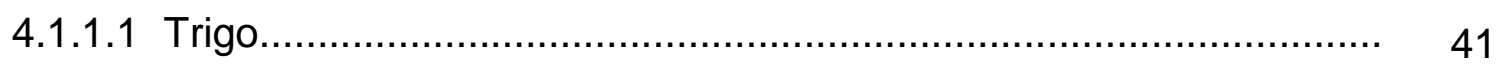

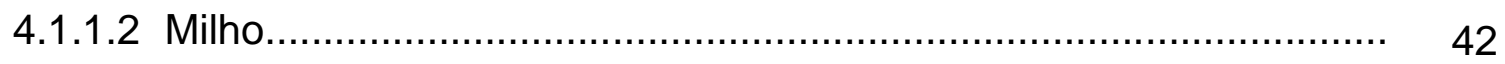

4.1 .1 .3 Mandioca....................................................................... 43

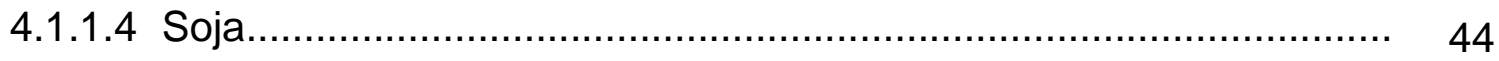




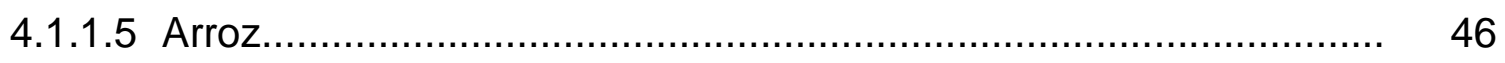

4.1.1.6 Centeio, Aveia e Rosca........................................................... 4

4.2 Concentração de Atividade e Concentração Mínima Detectável dos Radionuclídeos Naturais.

4.3 Concentração mínima detectável dos radionuclídeos artificiais...... 51

4.4 Dose efetiva...................................................................... 55

4.4.1 Dose efetiva para radionuclídeos naturais..................................... 55

4.4.1.1 Dose efetiva para indivíduo do público adulto................................. 55

4.4.1.2 Dose efetiva para indivíduo do público infantil.............................. 57

4.4.2 Dose efetiva para radionuclídeos artificiais................................... 59

4.4.2.1 Dose efetiva para indivíduo do público adulto............................... 59

4.4.2.2 Dose efetiva para indivíduo do público infantil............................... 60

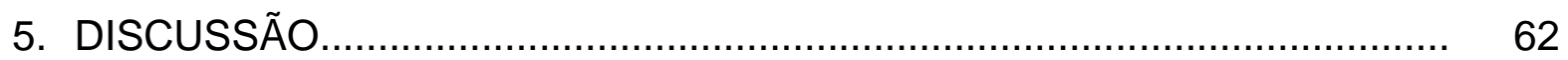

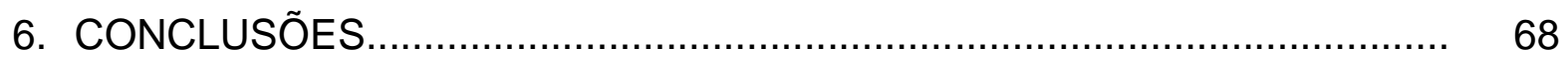

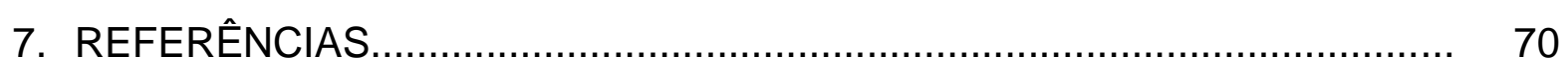




\section{LISTA DE FIGURAS}

1. Distribuição mundial de exposição à radiação.................................... 7

2. Série de decaimento Radioativo do Urânio......................................... 9

3. Série de decaimento Radioativo do Tório............................................ 10

4. Representação da incorporação dos radionuclídeos provenientes do fallout na dieta alimentar................................................................ 12

5. Consumo per capita de farinhas por grandes regiões do Brasil.............. 18

6. (a) Cápsula de porcelana utilizada para secar as amostras das farinhas,

(b) frascos de PEAD de $100 \mathrm{~mL}$ com tampa de rosca plana e batoque,

(c) amostras já secas, homogeneizadas, condicionadas e seladas no frasco de PEAD

7. Detector (HPGe) com pescoço de cisne e pré-amplificador, detalhes do interior da blindagem e arranjo para as amostras...

8. Derivadas das funções CMD em função do tempo de contagem para energias gama selecionadas.

9. Espectro bruto de uma amostra de farinha de e a identificação dos picos de emissão gama dos radionuclídeos naturais

10. Concentração de atividade de ${ }^{40} \mathrm{~K},{ }^{226} \mathrm{Ra}$ e ${ }^{232} \mathrm{Th}$ para as farinhas de trigo.

11. Concentração de atividade de ${ }^{40} \mathrm{~K},{ }^{226} \mathrm{Ra}$ e ${ }^{232} \mathrm{Th}$ para as farinhas de milho

12. Concentração de atividade de ${ }^{40} \mathrm{~K},{ }^{226} \mathrm{Ra}$ e ${ }^{232} \mathrm{Th}$ para as farinhas de mandioca.

13. Concentração de atividade de ${ }^{40} \mathrm{~K},{ }^{226} \mathrm{Ra}$ e ${ }^{232} \mathrm{Th}$ para as farinhas de soja.

14. Concentração de atividade de ${ }^{40} \mathrm{~K},{ }^{226} \mathrm{Ra}$ e ${ }^{232} \mathrm{Th}$ para as farinhas de arroz.

15. Concentração de atividade de ${ }^{40} \mathrm{~K},{ }^{226} \mathrm{Ra}$ e ${ }^{232} \mathrm{Th}$ para as farinhas de aveia, centeio e rosca.

16. Concentração de atividade e concentração mínima detectável de ${ }^{40} \mathrm{~K}$, ${ }^{226} \mathrm{Ra}$ e ${ }^{232} \mathrm{Th}$ para as farinhas de trigo.

17. Concentração de atividade e concentração mínima detectável de ${ }^{40} \mathrm{~K}$, ${ }^{226} \mathrm{Ra}$ e ${ }^{232} \mathrm{Th}$ para as farinhas de milho.

18. Concentração de atividade de ${ }^{40} \mathrm{~K},{ }^{226} \mathrm{Ra}$ e ${ }^{232} \mathrm{Th}$ para as farinhas de soja.

19. Concentração de atividade e concentração mínima detectável de ${ }^{40} \mathrm{~K}$, ${ }^{226} \mathrm{Ra}$ e ${ }^{232}$ Th para as farinhas de mandioca.

20. Concentração de atividade e concentração mínima detectável de ${ }^{40} \mathrm{~K}$, ${ }^{226} \mathrm{Ra}$ e ${ }^{232} \mathrm{Th}$ para as farinhas de arroz.

21. Concentração de atividade e concentração mínima detectável de ${ }^{40} \mathrm{~K}$, ${ }^{226} \mathrm{Ra}$ e ${ }^{232}$ Th para as farinhas de aveia, centeio e rosca

22. Concentração mínima detectável de ${ }^{134} \mathrm{Cs},{ }^{137} \mathrm{Cs},{ }^{103} \mathrm{Ru},{ }^{106} \mathrm{Ru},{ }^{60} \mathrm{Co},{ }^{131}$ I

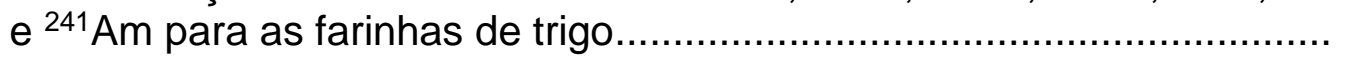

23. Concentração mínima detectável de ${ }^{134} \mathrm{Cs},{ }^{137} \mathrm{Cs},{ }^{103} \mathrm{Ru},{ }^{106} \mathrm{Ru},{ }^{60} \mathrm{Co},{ }^{131}$ | e ${ }^{241} \mathrm{Am}$ para as farinhas de milho

24. Concentração mínima detectável de ${ }^{134} \mathrm{Cs},{ }^{137} \mathrm{Cs},{ }^{103} \mathrm{Ru},{ }^{106} \mathrm{Ru},{ }^{60} \mathrm{Co},{ }^{131}$ I e ${ }^{241} \mathrm{Am}$ para as farinhas de soja. 
25. Concentração mínima detectável de ${ }^{134} \mathrm{Cs},{ }^{137} \mathrm{Cs},{ }^{103} \mathrm{Ru},{ }^{106} \mathrm{Ru},{ }^{60} \mathrm{Co},{ }^{131}$ । e ${ }^{241} \mathrm{Am}$ para as farinhas de mandioca.

26. Concentração mínima detectável de ${ }^{134} \mathrm{Cs},{ }^{177} \mathrm{Cs},{ }^{103} \mathrm{Ru},{ }^{106} \mathrm{Ru},{ }^{60} \mathrm{Co},{ }^{131}$ । $\mathrm{e}^{241} \mathrm{Am}$ para as farinhas de arroz

54

27. Concentração mínima detectável de ${ }^{134} \mathrm{Cs},{ }^{137} \mathrm{Cs},{ }^{103} \mathrm{Ru},{ }^{106} \mathrm{Ru},{ }^{60} \mathrm{Co},{ }^{131} \mid$ e ${ }^{241} \mathrm{Am}$ para as farinhas de aveia, centeio e rosca.

28. Valores de dose efetiva obtidos utilizando as concentrações de atividade e as concentrações mínimas detectáveis para as amostras de trigo (T), milho $(M)$, arroz $(A)$, mandioca $(M a)$, soja $(S)$, aveia $(A v)$, centeio $(C)$ e rosca $(R)$, para público adulto.

29. Valores de dose efetiva obtidos utilizando as concentrações de atividade e as concentrações mínimas detectáveis para as amostras de trigo $(T)$, milho $(M)$, arroz $(A)$, mandioca $(M a)$, soja $(S)$, aveia $(A v)$, centeio $(C)$ e rosca $(R)$, para público infantil

30. Valores de dose efetiva obtidos utilizando as concentrações mínimas detectáveis para as amostras de trigo $(\mathrm{T})$, milho $(\mathrm{M})$, arroz $(\mathrm{A})$, mandioca $(\mathrm{Ma})$, soja $(\mathrm{S})$, aveia $(\mathrm{Av})$, centeio $(\mathrm{C})$ e rosca $(\mathrm{R})$, para público adulto......

31. Valores de dose efetiva obtidos utilizando as concentrações mínimas detectáveis para as amostras de trigo $(\mathrm{T})$, milho $(\mathrm{M})$, arroz $(\mathrm{A})$, mandioca $(\mathrm{Ma})$, soja $(\mathrm{S})$, aveia $(\mathrm{Av})$, centeio $(\mathrm{C})$ e rosca $(\mathrm{R})$, para público infantil..... 


\section{LISTA DE TABELAS}

1. Doses efetivas anuais de radionuclídeos das séries naturais do urânio e tório em alimentos e água potável.

2. Consumo Per Capita de farinhas por grandes regiões e no Brasil.

3. Consumo de calorias diárias per capita na alimentação básica na região metropolitana de São Paulo.

4. Limites de tolerância para farinhas de trigo

5. Identificação e descrição das amostras de trigo.

6. Identificação e descrição das amostras de milho

7. Identificação e descrição das amostras de arroz, mandioca, soja, aveia, centeio e rosca.

8. Densidade média aparente das amostras analisadas.

9. Transições gama utilizadas para determinação das concentrações de atividade do ${ }^{226} \mathrm{Ra},{ }^{232} \mathrm{Th}$ e ${ }^{40} \mathrm{~K}$

10. Transições gama utilizadas para determinação das concentrações de atividade ${ }^{131}$, ${ }^{241} \mathrm{Am},{ }^{137} \mathrm{Cs},{ }^{60} \mathrm{Co}$ e ${ }^{103} \mathrm{Ru}$.

11. Coeficientes de conversão de dose para os radionuclídeos naturais público adulto e criança.

12. Coeficientes de conversão de dose para os radionuclídeos artificiais público adulto e criança.

13. Faixa de valores de dose efetiva calculada para ${ }^{40} \mathrm{~K},{ }^{226} \mathrm{Ra}$ e ${ }^{232} \mathrm{Th}$ para público adulto.

14. Faixa de valores de dose efetiva calculada para ${ }^{40} \mathrm{~K},{ }^{226} \mathrm{Ra}$ e ${ }^{232} \mathrm{Th}$ para público infantil.

15. Faixas de variação e valores da concentração de atividade dos radionuclídeos naturais ${ }^{40} \mathrm{~K},{ }^{232} \mathrm{Th}$ e ${ }^{226} \mathrm{Ra}$ no presente trabalho e na literatura, no Brasil e na Nigéria. (Entre parênteses, incertezas, quando disponíveis). 


\section{INTRODUÇÃO}

Os seres humanos estão expostos às fontes naturais de radiação ionizante de forma contínua as suas atividades. Essa exposição ocorre devido à presença de radionuclídeos na crosta terrestre, denominados radionuclídeos primordiais, que estão difundidos por todo meio ambiente, inclusive no próprio corpo humano, e aos radionuclídeos cosmogênicos, formados pela interação dos raios cósmicos com partículas presentes na atmosfera terrestre, promovendo uma cascata de partículas secundárias de alta energia, contribuindo para a exposição dos seres vivos com aproximadamente 2,4 mSv. $\mathrm{a}^{-1}$ dose anual (UNSCEAR, 2000). A Figura 1 apresenta a distribuição mundial de exposição à radiação (UNSCEAR, 2008a).

Figura 1. Distribuição mundial de exposição à radiação de $2,4 \mathrm{mSv}$ anuais (UNSCEAR, 2008a).

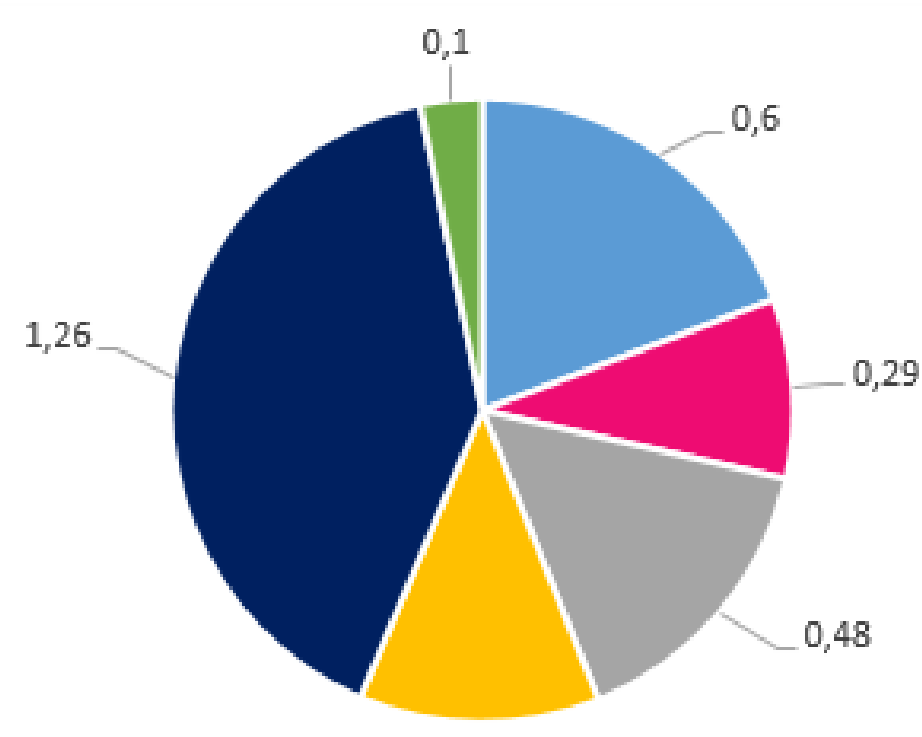

- Medicina | Ingestão " Radiação Terrestre " Radiação Cósmica " Radônio " Outros

Os radionuclídeos denominados primordiais são de origem terrestre e datam da formação da Terra, compondo as três séries radioativas naturais, do ${ }^{238} \mathrm{U}$, do ${ }^{235} \mathrm{U}$ e do ${ }^{232} \mathrm{Th}$. A maioria dos radionuclídeos que compõem essas séries possuem meias vidas curtas, terminando em isótopos estáveis de chumbo (EISENBUD, 1987), como apresentado nas Figuras 2 e 3. 
Além dos radionuclídeos primordiais e cosmogênicos, tem-se também a contribuição à exposição pelos radionuclídeos artificiais, que são produtos gerados por vazamentos em reatores nucleares e testes com bombas nucleares, e podem ser caracterizados por sua meia-vida e pela radiação que emitem. Os principais são ${ }^{137} \mathrm{Cs}$ e $0{ }^{90} \mathrm{Sr}$, quando liberados no meio ambiente irão se depositar diretamente sobre alimentos de consumo humano e animal, podendo ser absorvidos por ingestão.

Dentre as fontes de radiação, a radioatividade natural é a que tem maior contribuição da dose efetiva recebida pelos seres vivos, sendo os radionuclídeos das séries do ${ }^{238} \mathrm{U},{ }^{232} \mathrm{Th}$ e o radionuclídeo ${ }^{40} \mathrm{~K}$, a maior fonte de exposição interna e externa. A exposição interna ocorre pela ingestão e inalação desses elementos que estão presentes no ar e na dieta alimentar (UNSCEAR 2000, 2008a), assim como nos materiais de construção (FERREIRA, 2013, NISTI et al., 2013, AQUINO, 2015,). Já a exposição externa é oriunda dos raios cósmicos e radiação terrestre (EISENBUD, 1987).

O fato das fontes naturais contribuírem com a maior parcela de dose efetiva recebida pela população mostra a necessidade de uma avaliação adequada, para investigar os riscos que as radiações ionizantes podem induzir, e quando necessário, elaborar ações mitigadoras quanto à exposição aos seres vivos e ao meio ambiente. 
Figura 2. Série de decaimento Radioativo do Urânio (adaptado de IAEA, 2020).

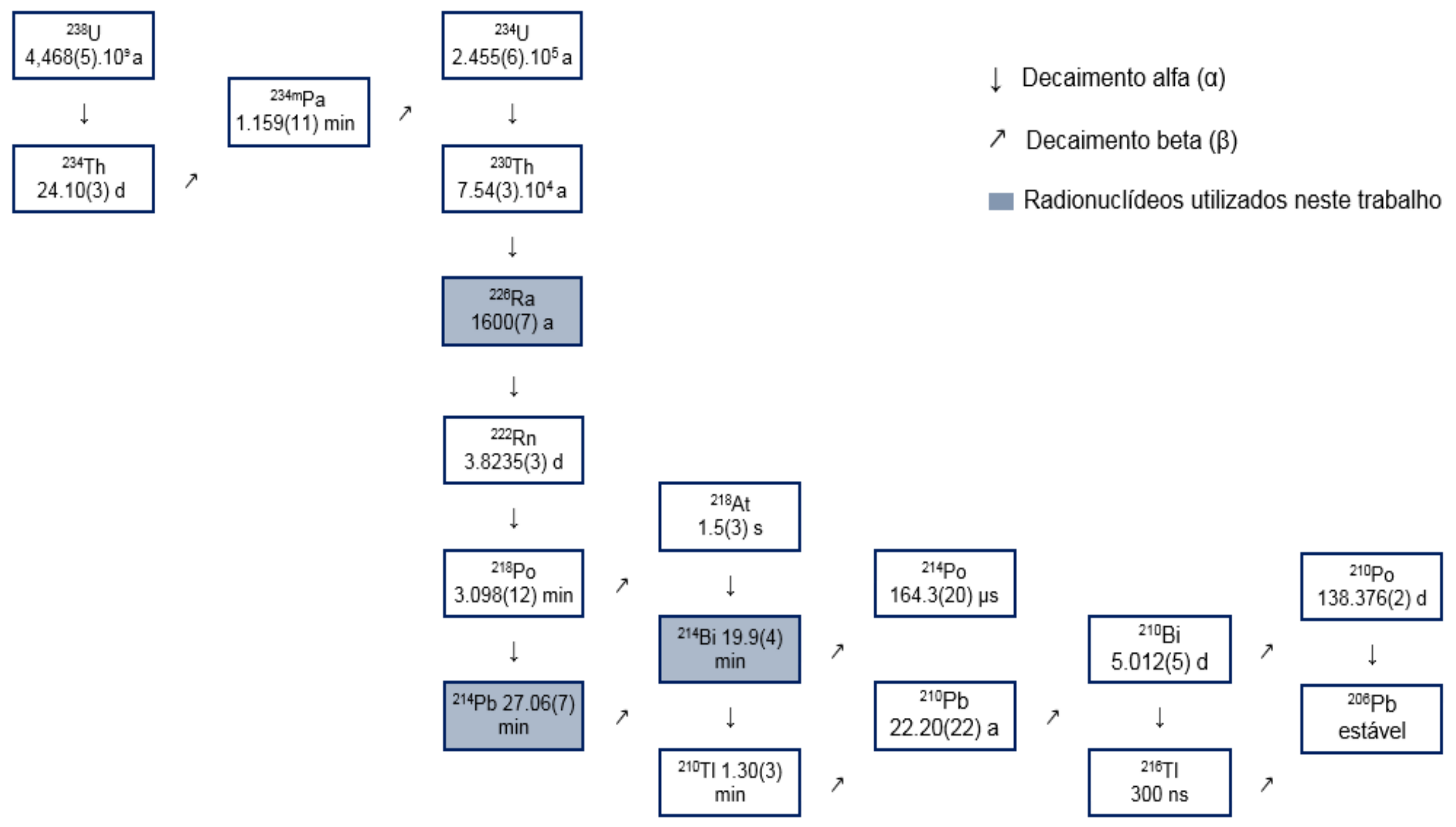


Figura 3. Série de decaimento Radioativo do Tório (adaptado de IAEA, 2020).
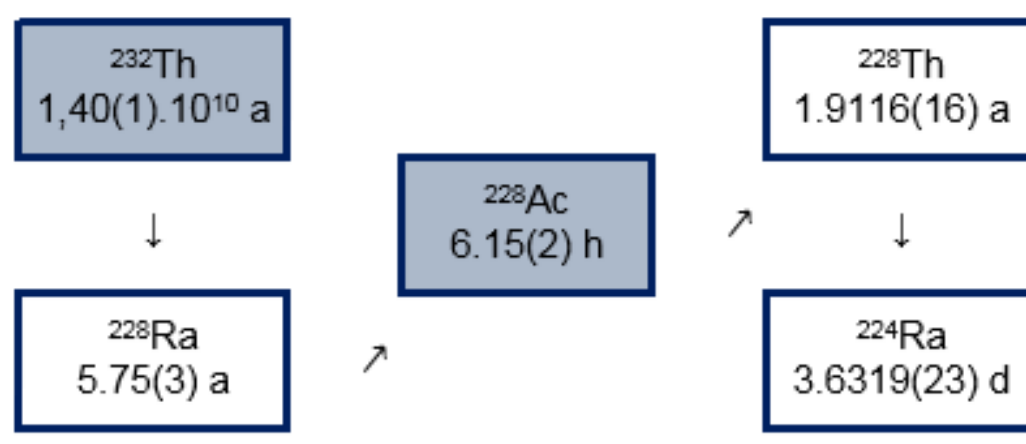

$\downarrow$ Decaimento alfa $(\alpha)$

$\nearrow$ Decaimento beta $(\beta)$

Radionuclídeos utilizados neste trabalho
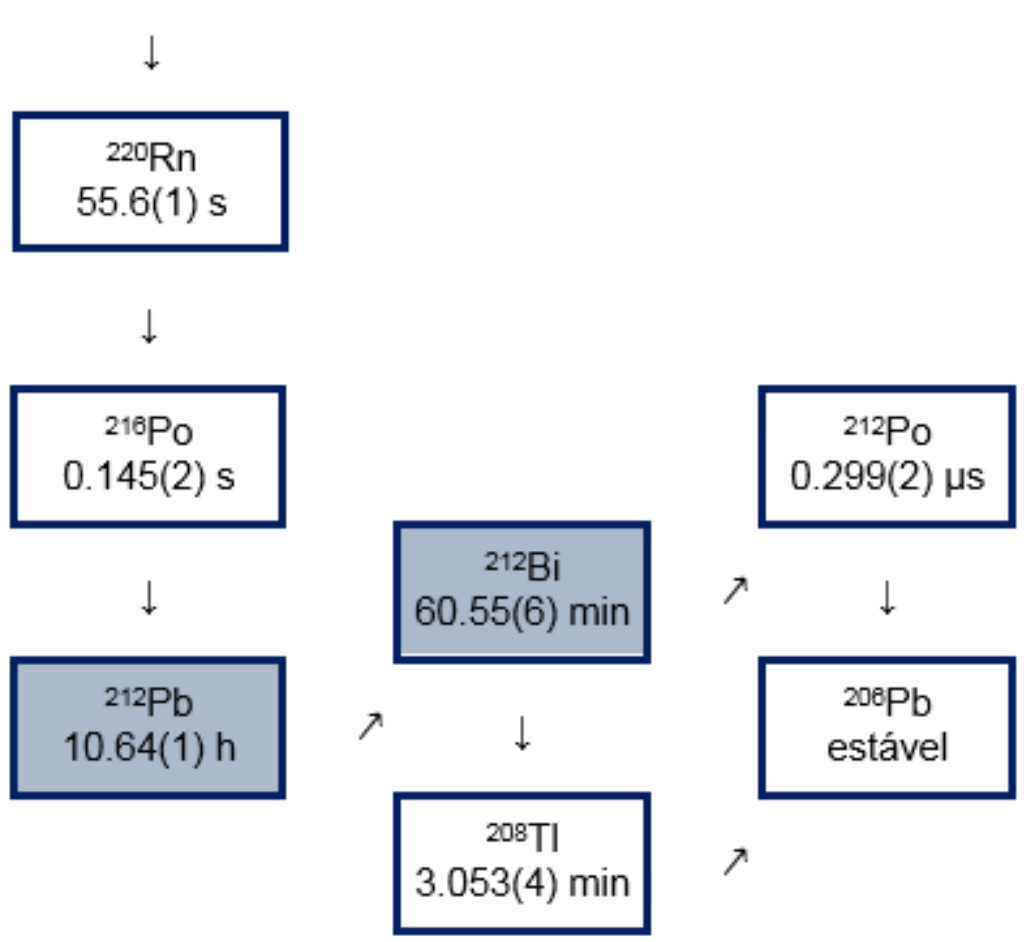
Uma das contribuições de maior relevância para a dose efetiva na população é a dose por ingestão de alimentos, calculada a partir das concentrações dos radionuclídeos naturais ${ }^{226} \mathrm{Ra},{ }^{232} \mathrm{Th}$ e ${ }^{40} \mathrm{~K}$ que variam significativamente como decorrência dos diferentes níveis de radiação de fundo e a variedade desses alimentos, clima, solo e condições agrícolas em que são cultivados (EISENBUD, 1987; UNSCEAR, 2000; ASADUZZAMAN et al., 2014).

Os limites de dose efetiva para público geral por ingestão de elementos radioativos presentes em alimentos estabelecidos pela United Nations Scientific Committee on the Effects of Atomic Radiation (UNSCEAR) e a International Atomic Energy Agency (IAEA), são de $140 \mu \mathrm{Sv}^{-\mathrm{a}^{-1}}$ e $1 \mathrm{mSv} \cdot \mathrm{a}^{-1}$ respectivamente (UNSCEAR 2000, IAEA, 2016).

Poucos trabalhos na literatura apresentam dados de dose por ingestão de alimentos que são amplamente utilizados na culinária brasileira, como por exemplo, as farinhas. De grande importância, as farinhas são basicamente utilizadas como dieta de subsistência em todo mundo (VENTURINI e SORDI, 1999; SANTOS et al., 2002a; SCHEIBEL, 2006). O presente trabalho avalia amostras que podem ser provenientes de áreas contaminadas, áreas anomalias radioativas ou de áreas não contaminadas. Uma vez que não se tem dados da origem dos insumos utilizados para produção dessas farinhas.

Com o grande uso dessas farinhas como matéria-prima para produção de diversos alimentos e a escassez de dados na literatura, é imprescindível verificar as concentrações de atividade dos radionuclídeos naturais e estimar as doses efetivas nas farinhas comumente utilizadas na dieta humana.

\subsection{Radionuclídeos naturais e artificiais em alimentos}

Na cadeia alimentar as plantas são receptoras primárias da contaminação radioativa, sujeita a contaminação direta ou indireta. A contaminação direta ocorre devido à deposição dos elementos radioativos diretamente na superfície das plantas. $\mathrm{Na}$ contaminação indireta, os elementos radioativos que contaminaram o solo serão sorvidos pelo sistema de raízes das plantas (EISENBUD,1987). 
Dos nutrientes que estão no solo, apenas uma fração será disponibilizada para a planta através da solução do solo, com isso a concentração dos radionuclídeos inicialmente encontrada no solo será diferente da disponibilizada para planta, que por sua vez, será diferente da concentração em cada espécie de planta devido suas características (EISENBUD, 1987; SCHEIBEL, 2006; NISTI, 2016; ROSA, 2018).

A contaminação radioativa do meio ambiente é atribuída à exposição dos seres humanos. Os radionuclídeos artificiais provenientes de vazamentos de reatores nucleares e testes com bombas, são incorporados na dieta alimentar assim como os naturais, por meio da precipitação no solo, alimentos e animais que podem ser consumidos pelos homens, por meio de precipitação, que é conhecida como "fallout (EISENBUD, 1987).

Uma vez incorporados metabolicamente às plantas quando estas retiram nutrientes do solo para seu desenvolvimento, os radionuclídeos ali presentes serão incorporados ao seu metabolismo, e consequentemente ingeridos, elevando a contribuição de dose efetiva como representado na Figura 4.

Figura 4. Representação da incorporação dos radionuclídeos provenientes do fallout na dieta alimentar (MELQUIADES, 2004).

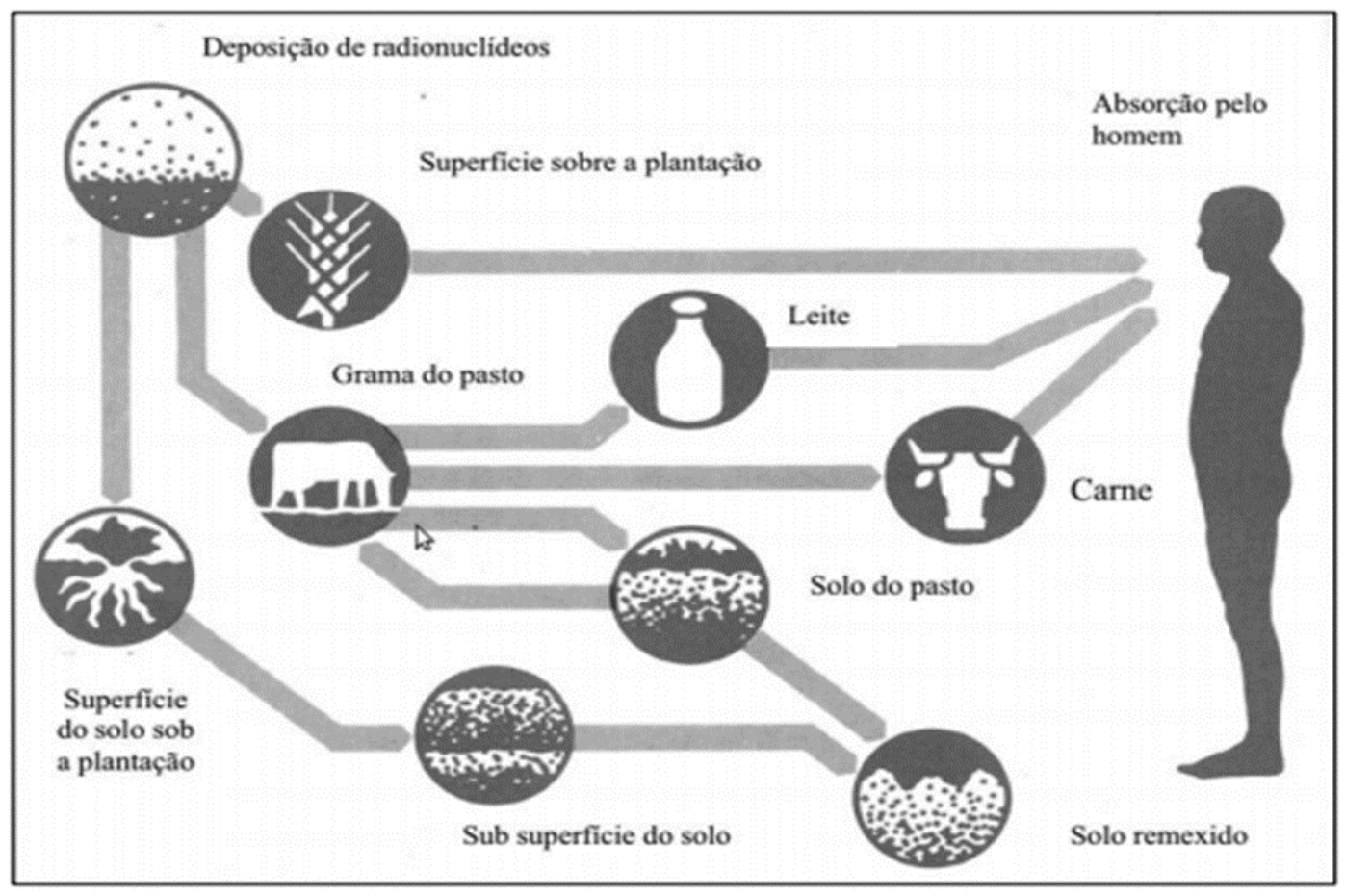


Quanto à ingestão de radionuclídeos naturais incorporados à dieta alimentar, alguns têm uma relevância maior devido suas características físicas, químicas e biológicas no metabolismo dos seres humanos. Um dos radionuclídeos naturais de maior interesse é o rádio, devido a sua radiotoxicidade $\left({ }^{226} \mathrm{Ra}\right.$ e $\left.{ }^{228} \mathrm{Ra}\right)$; uma vez incorporado ao organismo dos seres humanos, ele tente a se acumular nos ossos e músculos, pois apresenta um comportamento químico semelhante ao cálcio, que é um elemento essencial para o funcionamento desses sistemas (PAIVA, 2008; CNEN, 2014; ROSA, 2018).

Já o radionuclídeo ${ }^{40} \mathrm{~K}$, sendo um macronutriente essencial para o equilíbrio homeostático, regulando as funções corporais, não apresenta relevância quando se trata de dose por ingestão, pois sua abundância de 0,01\% em relação aos isótopos não radioativos ${ }^{39} \mathrm{~K}$ e ${ }^{41} \mathrm{~K}$, é muito inferior, e consequentemente a sua concentração na dieta alimentar. Avaliar as concentrações desse radionuclídeo é importante para registro dos níveis (background) desse elemento nos diferentes tipos de alimentos (PAIVA, 2008; WHO, 2012; IAEA, 2016).

Os radionuclídeos artificiais, assim como os naturais, também são considerados de acordo com suas características físicas, químicas e biológicas no metabolismo dos seres humanos, sendo os principais, ${ }^{137} \mathrm{Cs},{ }^{60} \mathrm{Co},{ }^{106} \mathrm{Ru},{ }^{103} \mathrm{Ru},{ }^{131} \mathrm{I} \mathrm{e}$ ${ }^{241} \mathrm{Am}$ (IAEA, 2016). Esses radionuclídeos são provenientes de vazamentos de reatores nucleares e testes com bombas, e são incorporados na dieta alimentar assim como os naturais, por meio da precipitação no solo, alimentos e animais que podem ser consumidos pelos homens.

Nos casos da presença de radionuclídeos artificiais em alimentos, a posição regulatória da Comissão Nacional de Energia Nuclear (CNEN-3.01/006) recomenda valores de concentração de atividade de radionuclídeos artificiais presente apenas em alimentos para comercialização (CNEN, 2005). Nos casos em que a população local está sujeita aos níveis de ação e controle, se aplica a posição regulatória, somente se houver suprimentos alternativos de alimentos. Os níveis de orientação aplicam-se aos radionuclídeos presentes nos alimentos destinados ao consumo humano e comercializados internacionalmente, que foram potencialmente contaminados após uma emergência nuclear ou radiológica. Os níveis de dose 
recomendados não se aplicam aos alimentos secos ou concentrados, e são baseados em um nível de isenção de intervenção de 1 mSv por ano (CODEX, 2009).

Segundo dados da IAEA (TEC-DOC 1788/2016), os valores de doses anuais individuais para as séries do urânio e tório na dieta total são $0,20 \mathrm{mSv}$ e $0,26 \mathrm{mSv}$, para crianças e adultos, respectivamente. O valor de dose mais elevado é atribuído aos componentes da dieta alimentar, pois a dose anual individual devido o consumo de água potável é da ordem de 0,01 mSv, ou seja, dez vezes inferior ao nível de orientação da WHO de 0,1 mSv (WHO, 2016). A Tabela 1 apresenta os valores de dose efetiva anual para os radionuclídeos das séries naturais do urânio e tório (IAEA, 2016).

Tabela 1. Doses efetivas anuais de radionuclídeos das séries naturais do urânio e tório em alimentos e água potável (IAEA, 2016).

\begin{tabular}{lccc}
\hline \hline & \multicolumn{3}{c}{ Dose efetiva $\left(\mathrm{mSv} \cdot \mathrm{a}^{-1}\right)$} \\
\hline \hline & Criança & Adulto & $\begin{array}{c}\text { Ponderação por } \\
\text { idade }\end{array}$ \\
\cline { 2 - 4 } Dieta total & 0.20 & 0.26 & 0.14 \\
Água potável & 0.007 & 0.012 & 0.009 \\
$\begin{array}{l}\text { Relação da contribuição de } \\
\text { dose entre água e alimento }\end{array}$ & $6.1 \%$ & $6.1 \%$ & $6 \%$ \\
\hline \hline
\end{tabular}

Para o radionuclídeo ${ }^{40} \mathrm{~K}$ os valores de dose anual estimado para crianças e adultos são $0,165 \mathrm{mSv}$ e $0,185 \mathrm{mSv}$, respectivamente. Porém, não há controle quanto à ingestão desse radionuclídeo, uma vez que o potássio é um elemento essencial para as funções metabólicas dos seres humanos. Com isso os seres humanos recebem uma dose anual de radiação de 0,3 mSv devido aos radionuclídeos naturais presentes na dieta, que representa aproximadamente $10 \%$ da dose média anual de $3 \mathrm{mSv}$ de todas as fontes a que o indivíduo está exposto (UNSCEAR, 2008a; WHO, 2012). 
Quanto aos radionuclídeos artificiais presentes na dieta, devem ser considerados os radionuclídeos com maior relevância liberados no meio ambiente em uma emergência nuclear ou radiológica. Nesses casos o ${ }^{137} \mathrm{Cs}$ tem uma maior atenção na exposição de adultos e crianças, devido seu comportamento químico ser semelhante ao do potássio (LOPES, 2018). Durante o primeiro ano após a contaminação com esse radionuclídeo, considerando que 10\% dos alimentos da dieta anual contenham esse radionuclídeo, foram estimadas doses de $0,7 \mathrm{mSv}$ para adultos e de $0,4 \mathrm{mSv}$ para crianças, valores significativamente menores que o valor de $1 \mathrm{mSv}$ recomendado como nível de orientação pela Codex Alimentarius Commission (CODEX, 2009).

\subsection{Segurança alimentar}

Com a grande demanda mundial referente à produção de alimentos, tornase essencial que produtos alimentícios sejam produzidos em quantidade suficientes para assegurar o acesso de todos, como também garantir sua qualidade. Com a globalização, a segurança alimentar está diretamente ligada a questões socioeconômicas e políticas. Diversos estudos tentam correlacionar alimentos, nutrição e saúde, assim como redução de doenças com a melhoria da dieta, e é evidente que a carência nutricional, assim como a dificuldade de acesso a alimentos está associada a diversas doenças.

Segundo o Conselho Nacional de Segurança Alimentar (CONSEA),

"A segurança alimentar é direito de todos ao acesso regular e permanente a alimentos de qualidade, em quantidade suficiente, sem comprometer o acesso a outras necessidades essenciais, tendo como base práticas alimentares promotoras da saúde, que respeitem a diversidade cultural e que sejam ambiental, cultural, econômica e socialmente sustentáveis".

Outro conceito não menos importante é referente à qualidade desses alimentos, de forma que sejam livres de qualquer tipo de risco por contaminantes, 
assim como, problemas decorrentes da produção e distribuição desses alimentos (CAISAN, 2018).

Com a necessidade de se garantir a segurança alimentar, a pesquisa sobre o risco associado a contaminantes como radionuclídeos, toxinas e agrotóxicos, requer um controle por órgãos públicos, assegurando que os níveis dessas substâncias nesses alimentos não tragam riscos à saúde humana (BRASIL, 1969; BELIK, 2003, AWUDU et al., 2012; CARNEIRO et al., 2012; ROSA, 2018).

\subsection{Farinhas}

As farinhas são o produto obtido pela moagem de parte comestível de vegetais e são qualificadas de acordo com suas características, sendo classificadas em dois grupos, $\boldsymbol{a}$ e $\boldsymbol{b}$. No grupo $\boldsymbol{a}$, denominado farinha simples, o produto é obtido a partir da moagem dos grãos, rizomas, frutos ou tubérculos de uma só espécie vegetal. No grupo $\boldsymbol{b}$, denominado farinha mista, o produto é obtido a partir da mistura de diferentes espécies vegetais (ANVISA, 1978).

As farinhas devem ser fabricadas a partir de matérias primas e limpas, isentas de matéria terrosa e parasitos, não devem apresentar umidade, estar fermentadas ou rançosas. A farinha é um pó desidratado rico em amido, obtida geralmente de cereais moídos. Os cereais mais utilizados para produção de farinhas são: trigo, milho, arroz, aveia, cevada, sorgo e centeio. Entre as farinhas mais usadas, incluem-se: farinha de alfarroba, farinha de amendoim, farinha de arroz, farinha de aveia, farinha de centeio, farinha de fruta, farinha de glúten, farinha integral, farinha de mandioca, farinha de milho, farinha de raspa de mandioca, farinha de soja, farinha de trigo, farinha de milho ou fubá. No rótulo das embalagens para comercialização dessas farinhas deve constar a classificação do produto de acordo com sua qualificação e especificações (ANVISA, 1978).

Cereais são sementes que se reproduzem quando plantadas, sendo constituídos de três partes: embrião ou germe, a fonte de alimento chamada endosperma e uma coberta protetora que origina o farelo. Durante o processo de moagem, esses três componentes podem ou não serem separados, reduzindo o 
endosperma em partículas pequenas, denominada farinha. A moagem desses três componentes juntos formará a farinha conhecida como integral. Já para as farinhas denominadas refinadas, as cascas dos grãos são retiradas durante o processo de produção (EMBRAPA, 2010).

Além dos cereais utilizados para produção de farinha, outras espécies também podem ser utilizadas com essa finalidade, como no caso da mandioca, que é uma raiz e um dos ingredientes essenciais na dieta da população brasileira, principalmente nas regiões Norte e Nordeste (EMBRAPA, 2006).

\subsection{Consumo de farinha no Brasil}

As farinhas mais consumidas no Brasil são as farinhas de trigo, milho e mandioca, segundo dados do IBGE conforme apresentado na Tabela 2 (IBGE, 2010).

Porém esse trabalho abrange farinhas de soja, arroz, aveia, centeio e rosca, que apresentam baixo consumo pela população.

Tabela 2. Consumo Per Capita de farinhas por grandes regiões e no Brasil (IBGE, 2010).

\begin{tabular}{c|c|ccccc}
\hline \multicolumn{1}{c}{} & \multicolumn{5}{c}{ Consumo anual per capita farinhas } \\
\hline \hline & \multirow{2}{*}{$\begin{array}{c}\text { Brasil } \\
\text { (Ton/a) }\end{array}$} & \multicolumn{5}{c}{ Grandes Regiões (kg/a) } \\
\cline { 3 - 7 } & Norte & Nordeste & Sudeste & Sul & Centro-Oeste \\
\hline Farinhas & 9,018 & 25,811 & 11,027 & 3,894 & 12,919 & 4,38 \\
\hline Trigo & 3,397 & 1,962 & 1,02 & 2,464 & 11,798 & 2,831 \\
Mandioca & 5,33 & 23,537 & 9,674 & 1,173 & 0,812 & 1,286 \\
Fubá de milho & 2,303 & 1,692 & 4,562 & 1,41 & 1,514 & 0,961 \\
Floco de milho & 0,612 & 0,282 & 1,394 & 0,287 & 0,365 & 0,316 \\
Rosca & 0,061 & 0,032 & 0,027 & 0,08 & 0,109 & 0,025 \\
Flocos de Aveia & 0,074 & 0,075 & 0,084 & 0,073 & 0,071 & 0,048 \\
Farinhas vitaminadas & 0,091 & 0,098 & 0,139 & 0,063 & 0,056 & 0,121 \\
Outras farinhas & 0,139 & 0,182 & 0,167 & 0,114 & 0,144 & 0,117 \\
\hline \hline
\end{tabular}


A Figura 5 apresenta o consumo per capita de farinhas por grandes regiões do Brasil (IBGE, 2010).

Figura 5. Consumo per capita de farinhas por grandes regiões do Brasil

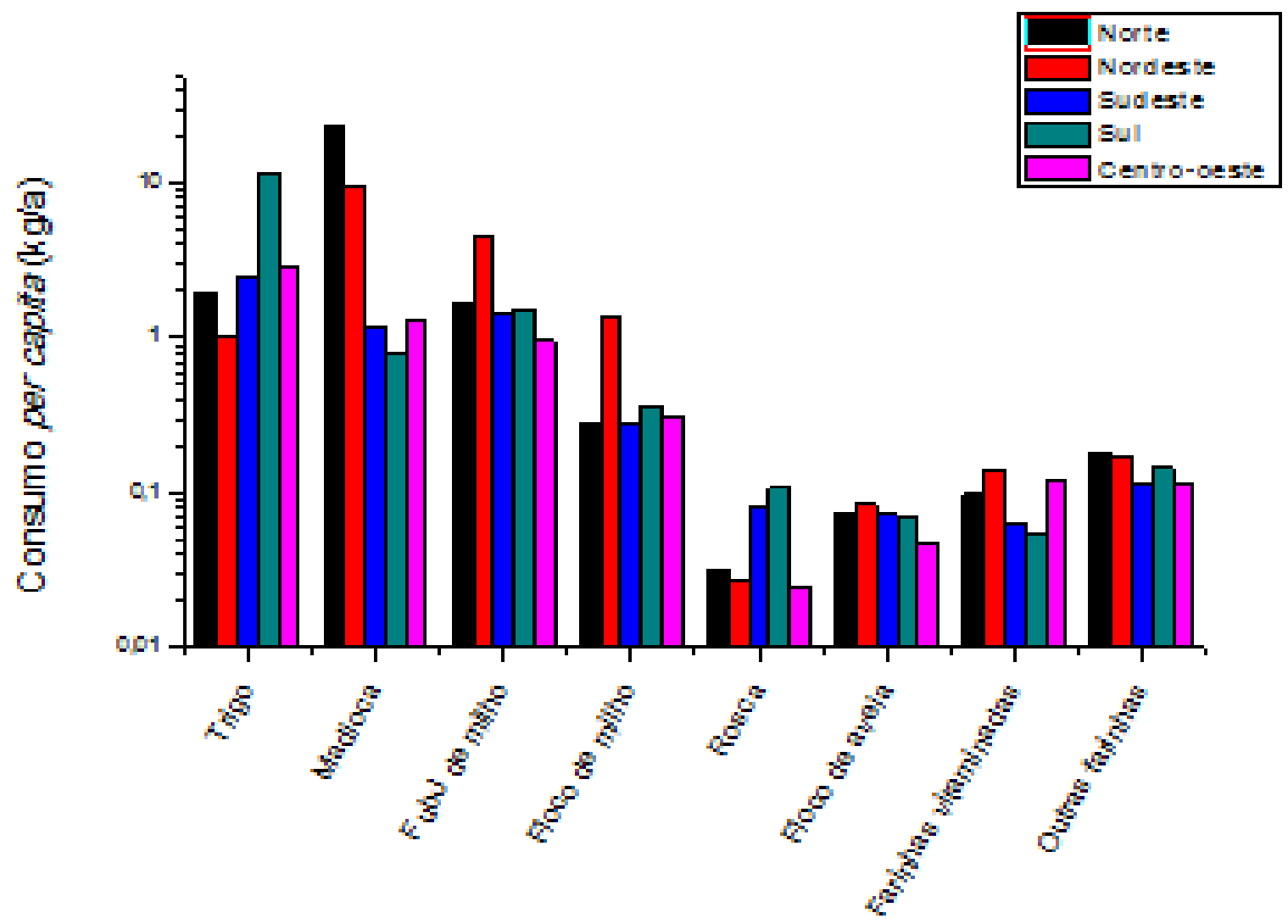

Segundo o Sindicato da Indústria do Trigo no Estado de São Paulo, da região sudeste, o estado de São Paulo é o maior consumidor de farinha de trigo (SINDUSTRIGO, 2019), na região norte e nordeste as farinhas mais consumidas são de mandioca e fubá de milho. As farinhas de rosca, aveia e outras farinhas tem um consumo inferior quando comparadas com as de trigo, mandioca e milho (IBGE, 2010). A Tabela 3 apresenta dados do consumo diário de calorias para alimentos básicos, permitindo observar que alguns dos produtos considerados na alimentação básica têm como matéria prima a farinha de trigo e milho para sua produção, consequentemente aumentando o consumo dessas farinhas (IBGE, 2010). 
Tabela 3. Consumo de calorias diárias per capita na alimentação básica na região metropolitana de São Paulo (IBGE, 2010).

\begin{tabular}{|c|c|}
\hline Alimentos & \\
\hline & Total (\%) \\
\hline Cereais e derivados & 36,60 \\
\hline Arroz polido & 15,84 \\
\hline Pão francês & 9,20 \\
\hline Biscoito & 3,79 \\
\hline Macarrão & 2,70 \\
\hline Farinha de Trigo & 1,16 \\
\hline Outros & 3,92 \\
\hline Feijões e outras leguminosas & 4,22 \\
\hline Raízes, tubérculos e derivados & 1,60 \\
\hline Carnes & 11,91 \\
\hline Leites e derivados & 7,25 \\
\hline Ovos & 0,74 \\
\hline Frutas e sucos naturais & 2,91 \\
\hline Verduras e legumes & 1,00 \\
\hline Óleos e gorduras vegetais & 12,46 \\
\hline Gorduras animais & 1,56 \\
\hline Açúcar de mesa e refrigerantes & 11,73 \\
\hline Bebidas alcoólicas & 0,73 \\
\hline Oleaginosas & 0,17 \\
\hline Condimentos & 0,47 \\
\hline Refeições prontas e misturas industrializadas & 6,66 \\
\hline
\end{tabular}




\subsection{Uso da farinha de trigo e milho na fortificação com ferro e ácido fólico}

A importância de analisar as farinhas deve-se ao grande consumo como alimento básico na dieta mundial. As farinhas são utilizadas como meio de intervenção, a fim de erradicar a anemia por deficiência de ferro e ácido fólico que é um problema epidemiológico em vários países, atingindo toda população e os grupos materno/infantil. O Ministério da Saúde - MS atendendo às recomendações da World Health Organization (WHO), e por meio da RDC № 344 da Agência Nacional de Vigilância Sanitária (ANVISA), determinou em 2002 a fortificação mandatória das farinhas de trigo e milho com ferro e ácido fólico no Brasil (WHO, 2001; ANVISA 2002; ISMAEL, 2011; WHO, 2016, NEVES, 2017).

A deficiência de ferro e ácido fólico, além de prejudicar o desenvolvimento cognitivo, diminui o desempenho do indivíduo adulto e a capacidade de aprendizagem de crianças na idade escolar, podendo comprometer o sistema imune, deixando o indivíduo mais suscetível a infecções, e ainda pode trazer consequências socioeconômicas negativas para o país (WHO, 2001; HORTON \& ROSS, 2003).

A implementação da fortificação da farinha de trigo e milho é uma estratégia simples, eficaz e de baixo custo como oferta de vitaminas e minerais na dieta alimentar, suprindo essa deficiência em grandes grupos populacionais (WHO, 2016).

\subsection{Farinha de trigo}

Dentre as farinhas produzidas, a farinha de trigo é a matéria-prima básica em centenas de produtos alimentícios, sendo a mais consumida do que qualquer outra farinha de cereais. Isto se deve ao fato do trigo não sofrer alterações decorrentes das variações climáticas, podendo ser cultivado em condições amplamente variáveis (EMBRAPA, 2010; BARTABURU, 2016; ABITRIGO, 2019).

Segundo a legislação brasileira (ANVISA, 1978) e a Associação Brasileira da Indústria de Trigo (ABITRIGO), definem-se como farinha de trigo os produtos obtidos a partir da espécie do gênero Triticum aestivum, pelo processo de moagem do grão. A farinha obtida poderá ser acrescida com outros componentes de acordo 
com a norma legal vigente. Nesses casos, deverá ser identificada com nomes que indicam o produto adicionado, seguido por sua classificação (BRASIL, 2005; COSTA et al., 2008).

O cultivo, a colheita, a secagem, o armazenamento dos grãos de trigo, o processo de moagem, transporte e armazenamento, são fatores que influenciam diretamente nas características nutricionais das farinhas de trigo, sendo necessária uma padronização dos produtos obtidos (ZARDO, 2010).

As farinhas de trigo podem ser integrais, especial ou de primeira, farinha comum ou de segunda. No caso da farinha integral, o grão de trigo é processado por inteiro obtendo-se um alto teor de fibras. Já a farinha especial ou de primeira, possui uma tonalidade mais clara e granulometria mais fina, pois é extraída da parte central do endosperma tendo uma quantidade mais elevada de glúten. A farinha comum ou de segunda, possui uma tonalidade mais escura, pois é obtida da parte mais externa do endosperma, tendo um teor de glúten menor, e sua granulometria mais espessa (ZARDO, 2010).

Os fatores que determinam a qualidade da farinha estão atrelados ao processo de produção, em que a umidade, as cinzas, a quantidade de glúten e a cor, determinarão sua classificação, sendo as cinzas o fator determinante na qualidade do produto final.

A fim de melhorar a qualidade do produto final e padronizá-lo, alguns elementos podem ser acrescentados durante sua produção, tais como branqueadores, antioxidantes, enzimas e emulsificantes; estes são alguns ingredientes utilizados no processo (EMBRAPA, 2010, ZARDO, 2010). Análise de alveografia, teor de glúten, teor de cinzas, cor, umidade e número de quedas avaliam a qualidade e padronização do produto final estabelecidas pela Instrução Normativa 8/2005 do Ministério da Agricultura, Pecuária e Abastecimento. A Tabela 4 apresenta limites de tolerância do teor de cinza, granulometria, teor de proteínas, acidez graxa, e umidade para farinhas de trigo (BRASIL, 2005). 
Tabela 4. Limites de tolerância para farinhas de trigo.

\begin{tabular}{cccccc}
\hline \hline \multicolumn{6}{c}{ Limites de tolerância para farinhas de trigo } \\
\hline \hline Tipos & $\begin{array}{c}\text { Teor de } \\
\text { cinza (\%) }\end{array}$ & Granulometria & $\begin{array}{c}\text { Teor de } \\
\text { Proteína } \\
\text { (mínimo) }\end{array}$ & $\begin{array}{c}\text { Acidez } \\
\text { Graxa } \\
\text { (mg de } \\
\text { KOH/100g } \\
\text { do produto) } \\
\text { (máximo) }\end{array}$ & $\begin{array}{c}\text { Umidade } \\
\text { (máximo) }\end{array}$ \\
\hline \hline Integral & $2,5 \%$ & $\begin{array}{c}\text { 95\% do } \\
\text { produto deve } \\
\text { passar pela } \\
\text { peneira com } \\
\text { abertura de } \\
250 \text { um }\end{array}$ & $8,0 \%$ & 100 & $15 \%$ \\
Cospecial ou tipo 1 & $0,8 \%$ & $8,0 \%$ & 100 & $15 \%$ \\
\hline \hline
\end{tabular}

Para comercialização dessas farinhas, os valores obtidos por meio dos processos de avaliação devem ficar abaixo dos valores estabelecidos pelo Ministério da Agricultura Pecuária e Abastecimento.

\subsection{Farinha de milho}

O milho é um cereal de grande aplicação agrícola e pode ser utilizado para diversos fins, desde o consumo humano, até aplicações como fonte de combustível para produção de etanol. Seus derivados podem ser empregados em vários setores industriais, entre eles, alimentícia e química.

No setor alimentício os derivados do milho produzem amido, dextrina, glicose, óleo, margarina, fermento, entre outros produtos, assim como no setor de bebidas, com a produção de licores, refrigerantes, vinhos, etc. No setor químico e mecânico, os derivados do milho são utilizados na fundição de metais e plásticos, e para composição de rações para consumo animal na forma de grão moído, farelo e gérmen.

Em sua etapa produtiva, o milho pode ser vendido diretamente in natura, por pequenos produtores, ou após processamento em grandes empresas de diversos segmentos (CARDOSO et al. 2011). 
Assim como trigo, o grão de milho possui endosperma, composto basicamente de amido, glúten, e pequena porcentagem de gordura, uma película que recobre o grão, germe que é a parte vegetativa do grão, e a água que corresponde a aproximadamente $16 \%$ da composição do grão (ABIMILHO, 2019).

Para produção da farinha de milho ou fubá, o grão de milho (Zea mays, L.) é moído, desgerminado ou não. O grão deve ser torrado, desgerminado ou não, e previamente macerado, socado e peneirado (ANVISA, 1978). A farinha obtida pode ser utilizada para produção de diferentes alimentos, servindo de matéria prima de diversos pratos culinários de grande consumo nacional, como por exemplo, cuscuz, polenta, angu, bolos, canjicas, mingaus, cremes, entre outros (CARDOSO et al. 2011; ABIMILHO, 2019).

\subsection{Farinha de mandioca}

A farinha de mandioca é obtida a partir do processamento de plantas da família Euphorbiaceae, gênero Manihot (BRASIL, 1996). O espécime da mandioca cultivada para fins alimentícios é o Manihot esculenta Crantz, que pode ser classificada como brava ou mansa de acordo com seu teor de glicosídios cianogênicos que liberam o ácido cianídrico e quando sofre ação enzimática torna-se tóxica (CÂMARA et al., 1982; ARAÚJO, 1999; BRASIL, 2011).

A definição do espécime quanto brava ou mansa é feita de acordo com a quantidade de ácido cianídrico presentes no vegetal. Sua classificação é determinada

pelo órgão oficial credenciado pelo Ministério da Agricultura, Pecuária e Abastecimento, por meio de certificação (EMBRAPA, 2006).

Em países em desenvolvimento a farinha é considerada o principal produto processado derivado da mandioca, sendo maior parte para o comércio interno, onde $70 \%$ do cultivo mundial de mandioca são destinados ao processamento para obtenção de farinha (LIMA, 1982; CHUZEL, G. et al., 1995; DIAS, 2002).

No Brasil a farinha de mandioca é de grande consumo, fazendo parte das refeições diárias dos brasileiros, principalmente na região norte e nordeste do Brasil, além de ser ingrediente para produção de diversos produtos industriais (SCHEIBEL, 
2006; ÁLVARES, 2014). Devido sua importância, a farinha de mandioca também é utilizada como meio de intervenção da anemia nutricional, assim como as farinhas de trigo e milho. A farinha é o principal subproduto obtido da mandioca e grande parte da sua produção é para o comércio interno, não tendo relevância como produto de exportação.

\subsection{Farinha de arroz}

Para produção de produtos sem glúten, a farinha de arroz é uma das mais indicadas. Por apresentar baixos níveis de sódio, conter carboidratos de fácil digestão e ser hipoalergênica, torna-se uma nova fonte de matéria-prima livre de glúten, resultando em produtos que apresentem boa aceitação pelo consumidor, principalmente os portadores da doença celíaca (POLANCO et al., 1995; TORRES et al., 1999; SIVARAMAKRISHNAN et al., 2004).

A farinha é obtida a partir do beneficiamento industrial do arroz, por meio de moagem dos grãos; nesse processo de cisalhamento em rolos raiados, a granulometria do grão é reduzida, e, por meio de peneiramento, as partículas com granulometrias maiores são retiradas, ajudando a reduzir ou eliminar sujeiras e possíveis contaminações microscópicas, para que o produto final esteja dentro dos padrões tecnológicos, garantindo sua qualidade nutricional (KENNEDY et al. 2002; SILVA, 2007).

\subsection{Farinha de soja}

Devido as suas características, a soja é amplamente utilizada pela indústria de alimentos como base para produtos de panificação, misturas pré-preparadas, bebidas e na fabricação de alimentos dietéticos e infantis (EMBRAPA, 2007). Segundo a Organização Mundial de Saúde (OMS), a soja contém a única proteína vegetal que engloba todos os aminoácidos essenciais necessários ao desenvolvimento do organismo. Com sua grande vantagem nutricional, a farinha de soja pode ser utilizada como um ingrediente para aumentar o valor proteico de muitos alimentos (HE e CHEN, 2013), trazendo, desta forma, inúmeros benefícios à saúde. 
A estrutura da planta da soja varia, dependendo das condições ambientais, influenciando em sua floração, e consequentemente em seu ciclo. Essa variação é classificada de acordo com a região de cultivo (EMPRAPA, 2007). A temperatura, assim como, a disponibilidade hídrica são os fatores climáticos que mais afetam o desenvolvimento e a produtividade da soja.

A água constitui aproximadamente $90 \%$ do peso da planta, atuando em praticamente todos os processos fisiológicos e bioquímicos, desempenhando a função de solvente, através dos quais gases, minerais e outros solutos movem-se através da planta (EMPRAPA, 2007). Essa dinâmica da água no sistema solo - planta atmosfera, ocorre em função da Demanda Evaporativa da Atmosfera (DEA) e pode determinar a intensidade da perda de água e, consequentemente, a necessidade de absorção pelas raízes (BERGAMASCHI, 1999) alterando essa absorção devido à capacidade de armazenamento de água disponível no solo. Solos com baixa Capacidade de Armazenamento de Água (CAD) são impróprios para o cultivo da soja, uma vez que o sistema hídrico é essencial para todas as fases do desenvolvimento da planta (EMBRAPA, 2007). Para obtenção da farinha de soja, os grãos são torrados, moídos e peneirados até uma granulometria específica (HE e CHEN, 2013).

\subsection{Farinha de aveia}

Dentre as diferentes espécies de aveia, a branca é a mais conhecida. Seu uso pode ser empregado desde a produção para consumo humano e ração animal, como para produção de produtos de higiene (EMBRAPA, 2020).

A farinha de aveia é obtida a partir da moagem da semente Avenasativa, L. beneficiada, contém componentes indispensáveis aos seres humanos, como por exemplo, os aminoácidos, ácidos graxos e sais minerais, assim como as fibras alimentares (ANVISA, 1978; WEBER et al., 2002).

O processo de moagem da aveia é diferente do processo da moagem do trigo devido a sua estrutura anatômica (EMBRAPA, 2020). Após os grãos serem limpos, descascados e classificados, esses são submetidos ao vapor por dois a três minutos para inativação de enzimas, que poderiam afetar a qualidade do grão, tornando-o rançoso. Em seguida esses grãos são tostados para redução de umidade, 
permitindo que sejam estocados por um período maior. Posteriormente é feita a flocagem, produzindo flocos grandes ou inteiros, médios e finos.

Ao serem moídos, esses flocos tornam-se a farinha e o farelo, que podem ser utilizados na produção de produtos de panificação, confeitaria e alimentos infantis. Existe uma variedade de produtos elaborados com aveia na sua composição, melhorando os teores de proteínas e fibra alimentar (GUTKOSKI et al., 2007).

\subsection{Farinha de centeio}

O centeio (Secale cereale L.) pode ser cultivado em condições climáticas diversas. Originário do Sudoeste da Ásia é um dos cereais mais utilizados na produção de produtos de panificação no mundo. Além de produção de produtos forneados (pães, biscoitos, etc.), o centeio pode ser utilizado na produção de produtos dietéticos e bebidas destiladas claras, como também para produção de produtos não alimentícios, por exemplo, em misturas adesivas e colas, fármacos, cosméticos, álcool, etc., assim como para produtos de alimentação animal (DE MORI et al., 2013).

Dentre suas características uma de maior destaque é o baixo uso de insumos agrícolas, incluindo agrotóxicos, tornando-se um cereal com propriedades ecológicas e orgânicas importantes.

Rico em fibras, sais minerais e aminoácidos essenciais, o cereal é indicado para diversas dietas alimentares, sendo indicado para diabéticos e hipertensos, além de reduzir problemas de mau funcionamento intestinal, auxilia na prevenção do desenvolvimento de obesidade, reduz e previne à diabetes, auxilia na redução do risco de doenças cardiovasculares e de câncer (NYGREN et al., 1984).

\subsection{Farinha de rosca}

A farinha de rosca é definida como o produto obtido, pela moagem do pão, obrigatoriamente, torrado. Geralmente o tipo de pão utilizado para confecção dessa farinha é o francês, e ela é utilizada na confecção de empanados ou para engrossar alimentos (ACIOLI, 2000). Uma vez que o pão tem como matéria prima a farinha de 
trigo, e a farinha de rosca é confeccionada a partir do pão, deve-se levar em consideração a analise esta farinha. Para garantir as características mínimas de qualidade deste produto, seguem-se as mesmas especificações utilizadas para garantir a qualidade dos pães, considerando a necessidade de ações de controle de alimentos, visando à proteção à saúde da população.

\section{OBJETIVOS}

Os objetivos do presente trabalho de mestrado são:

- Determinar a concentração de atividade dos radionuclídeos naturais e artificiais presentes nas farinhas comercializadas na cidade de São Paulo, por espectrometria gama de alta resolução, contribuindo para formação de um banco de dados.

- A partir das concentrações de atividades obtidas, estimar os valores de dose efetiva por ingestão, comparando os valores obtidos com os resultados disponíveis na literatura.

\section{MATERIAIS E MÉTODOS}

\subsection{Amostragem}

No total, foram adquiridas 38 amostras, sendo 18 de farinhas de trigo (integral e tradicional), 8 de milho (fubá e floco de milho), 3 de mandioca (fina e grossa), 3 de arroz (fina e flocada), 3 de soja (tostada), 1 de centeio, 1 de aveia e 1 de rosca, de diferentes produtores, comercializadas na cidade de São Paulo.

A quantidade de amostras adquiridas varia em quantidade e tipo devido a tendência de consumo, assim, as farinhas de trigo e milho, apresentam um número maior de amostras. As demais farinhas analisadas ainda apresentam baixo consumo 
e consequentemente, menor quantidade de fabricantes, dificultando à busca pela variedade disponível no comércio.

As amostras de farinhas foram identificadas por letras representando o tipo do produto (T para trigo, M para milho, Ma para mandioca, A para arroz, S para soja, C para centeio, Av para aveia e $\mathrm{R}$ para rosca), seguido por uma numeração que identifica cada fabricante.

As Tabelas 5, 6, e 7 apresentam a identificação e descrição das amostras de acordo com as instruções normativas do Ministério da Agricultura, Pecuária e Abastecimento (BRASIL, 1996).

Tabela 5. Identificação e descrição das amostras de trigo (BRASIL, 1996).

\begin{tabular}{|c|c|c|c|}
\hline Amostra & Identificação & Numeração & Descrição \\
\hline \multirow{18}{*}{ Trigo } & \multirow{18}{*}{$\mathrm{T}$} & $\mathrm{T} 1$ & tipo 1 \\
\hline & & $\mathrm{T} 2$ & tipo 1 \\
\hline & & T3 & tipo 1 \\
\hline & & $\mathrm{T} 4$ & tipo 1 \\
\hline & & T5 & tipo 2 \\
\hline & & T6 & tipo 1 \\
\hline & & $\mathrm{T} 7$ & tipo 1 \\
\hline & & T8 & tipo 1 \\
\hline & & T9 & puríssima tipo 1 \\
\hline & & $\mathrm{T} 10$ & integral \\
\hline & & $\mathrm{T} 11$ & tipo 1 \\
\hline & & $\mathrm{T} 12$ & integral \\
\hline & & $\mathrm{T} 13$ & tipo 1 \\
\hline & & $\mathrm{T} 14$ & tipo 1 \\
\hline & & $\mathrm{T} 15$ & tipo 1 \\
\hline & & $\mathrm{T} 16$ & tipo 1 \\
\hline & & $\mathrm{T} 17$ & integral \\
\hline & & $\mathrm{T} 18$ & integral \\
\hline
\end{tabular}


Tabela 6. Identificação e descrição das amostras de milho (BRASIL, 1996).

\begin{tabular}{cccc}
\hline \hline Amostra & Identificação & Numeração & Descrição \\
\hline \multirow{3}{*}{ Milho } & M1 & fubá \\
& M2 & fubá \\
& M3 & fubá \\
& $M 4$ & fubá \\
& M5 & floco \\
& M6 & fubá \\
& M7 & floco \\
& M8 & floco \\
\hline \hline
\end{tabular}

Tabela 7. Identificação e descrição das amostras de arroz, mandioca, soja, aveia, centeio e rosca (BRASIL, 1996).

\begin{tabular}{|c|c|c|c|}
\hline Amostra & Identificação & Numeração & Descrição \\
\hline \multirow{3}{*}{ Arroz } & \multirow{3}{*}{$A$} & $\mathrm{~A} 1$ & fina \\
\hline & & $\mathrm{A} 2$ & fina \\
\hline & & A3 & floco \\
\hline \multirow{3}{*}{ Mandioca } & \multirow{3}{*}{$\mathrm{Ma}$} & Ma1 & fina \\
\hline & & Ma2 & grossa \\
\hline & & Ma3 & fina \\
\hline \multirow{3}{*}{ Soja } & \multirow{3}{*}{$S$} & S1 & fina \\
\hline & & $\mathrm{S} 2$ & fina \\
\hline & & S3 & fina \\
\hline Aveia & $A v$ & Av1 & fina \\
\hline Centeio & C & $\mathrm{C} 1$ & fina \\
\hline Rosca & $R$ & $\mathrm{R} 1$ & grossa \\
\hline
\end{tabular}




\subsection{Preparo das amostras}

Todas as amostras foram secas em estufa no laboratório a uma temperatura de $50^{\circ}$, por aproximadamente 24 horas, para eliminar possível umidade na amostra. Após esse período, as amostras foram homogeneizadas e fechadas em frascos de $100 \mathrm{~mL}$ de polietileno de alta densidade (PEAD) com tampa de rosca e batoque, selados hermeticamente com fita isolante (Fig. 6) para assegurar que o ${ }^{222} \mathrm{Rn}$ $\mathrm{e}^{220} \mathrm{Rn}$ não escapem da amostra. As amostras foram medidas após aproximadamente 4 semanas de armazenamento, para garantir o equilíbrio radioativo secular (EVANS, 1972), pois as concentrações de atividade do ${ }^{226} \mathrm{Ra}$ são inferidas pelas concentrações de atividade do ${ }^{214} \mathrm{~Pb}$ e ${ }^{214} \mathrm{Bi}$ e as concentrações de atividade de ${ }^{232} \mathrm{Th}$ pelas concentrações de atividade do ${ }^{228} \mathrm{Ac},{ }^{212} \mathrm{~Pb}$ e ${ }^{212} \mathrm{Bi}$ (ver FIGS. 2 e 3, Introdução).

Figura 6. (a) Cápsula de porcelana utilizada para secar as amostras das farinhas, (b) frascos de PEAD de $100 \mathrm{~mL}$ com tampa de rosca plana e batoque, (c) amostras já secas, homogeneizadas, condicionadas e seladas no frasco de PEAD.

(a)

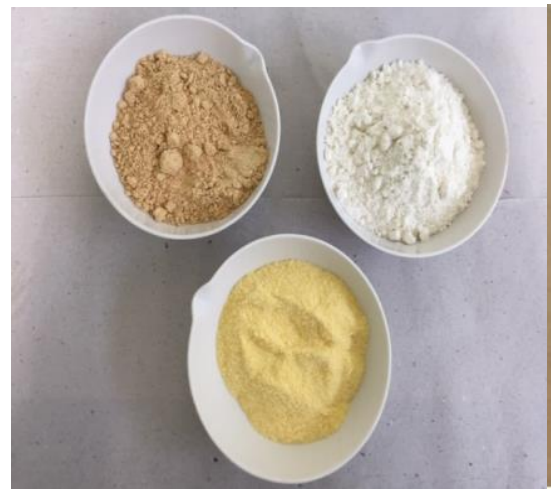

(b)

(c)

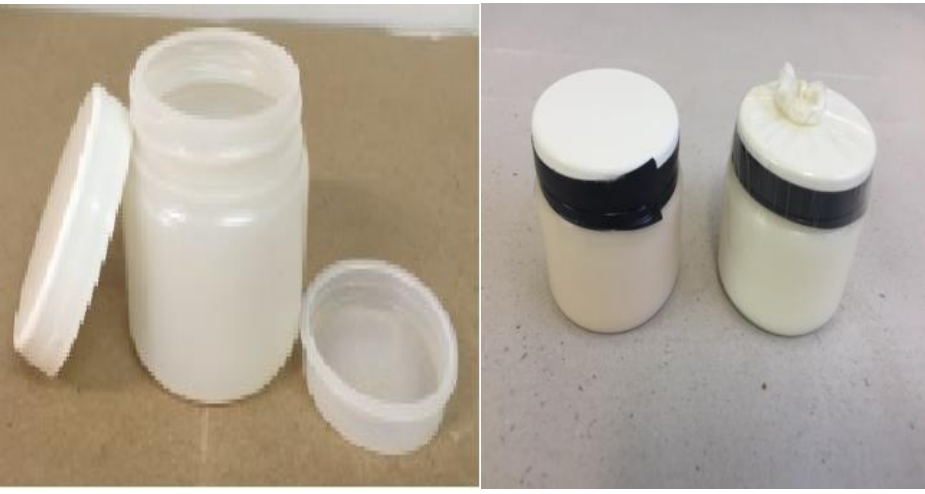

A densidade média aparente das amostras de farinha foi obtida pesando as amostras após secagem e homogeneização, utilizando uma balança semianalítica GEHAKA BK6000. Como todas as densidades das farinhas analisadas estão na faixa de $0,6 \mathrm{~g} \cdot \mathrm{cm}^{-3}$ a $0,9 \mathrm{~g} \cdot \mathrm{cm}^{-3}$, portanto inferiores à da solução padrão aquosa $\left(1 \mathrm{~g} \cdot \mathrm{cm}^{-3}\right)$, não houve necessidade de realizar correções na eficiência devido à autoatenuação 
das transições gama nas amostras (BARROS e PECEQUILO, 2014). A densidade média aparente para cada tipo de farinha é apresentada na Tabela 8.

Tabela 8. Densidade média aparente das amostras analisadas.

\begin{tabular}{cc}
\hline Amostra & $\begin{array}{c}\text { Densidade média aparente } \\
\left(\mathrm{g} \cdot \mathrm{cm}^{-3}\right)\end{array}$ \\
\hline Trigo & 0,86 \\
Milho & 0,89 \\
Arroz & 0,84 \\
Mandioca & 0,66 \\
Soja & 0,68 \\
Centeio & 0,75 \\
Aveia & 0,74 \\
Rosca & 0,59 \\
\hline \hline
\end{tabular}

\subsection{Espectrometria gama}

A espectrometria gama é um método analítico amplamente utilizado em laboratórios de medidas ambientais por ser um ensaio não destrutivo, e por efetuar analise de diversos radionuclídeos presentes nas amostras em uma mesma medida (GILMORE e HEMINGWAY, 1995; KNOLL, 2000).

Os fótons ao incidirem no detector perdem sua energia formando pulsos elétricos que são amplificados, analisados e então registrados. A altura do pulso formado é proporcional à energia gama do fóton incidente no detector, assim, os pulsos formam o pico de absorção total, o conjunto desses picos é o espectro de raios gama da amostra (KNOLL, 2000).

O equipamento utilizado para obtenção dos espectros foi um detector de germânio hiperpuro (HPGe) Canberra GX4020 (CANBERRA, 2019), "pescoço de cisne", de faixa estendida, alta resolução e baixa radiação de fundo (Fig. 7), acomodado numa blindagem especial, de baixa radiação de fundo, com as paredes internas cobertas de cobre. 
No sistema utilizado, o cristal está encapsulado hermeticamente em um mecanismo cilíndrico vertical isolado do pré-amplificador por uma blindagem, assegurando um baixo nível de radiação de fundo. O cristal possui uma janela fina de carbono na entrada, permitindo medir energias baixas (até $3 \mathrm{keV}$ ). O detector está ligado a uma fonte de alta tensão e a um pré-amplificador, que envia o sinal para um amplificador, seguindo para um analisador multicanal de alturas de pulsos e por fim, para um sistema de registro de dados. Posteriormente todos os espectros foram analisados com o software InterWinner 6.0 (INTERWINNER, 2004).

Figura 7. Detector (HPGe) com pescoço de cisne e pré-amplificador, detalhes do interior da blindagem e arranjo para as amostras.

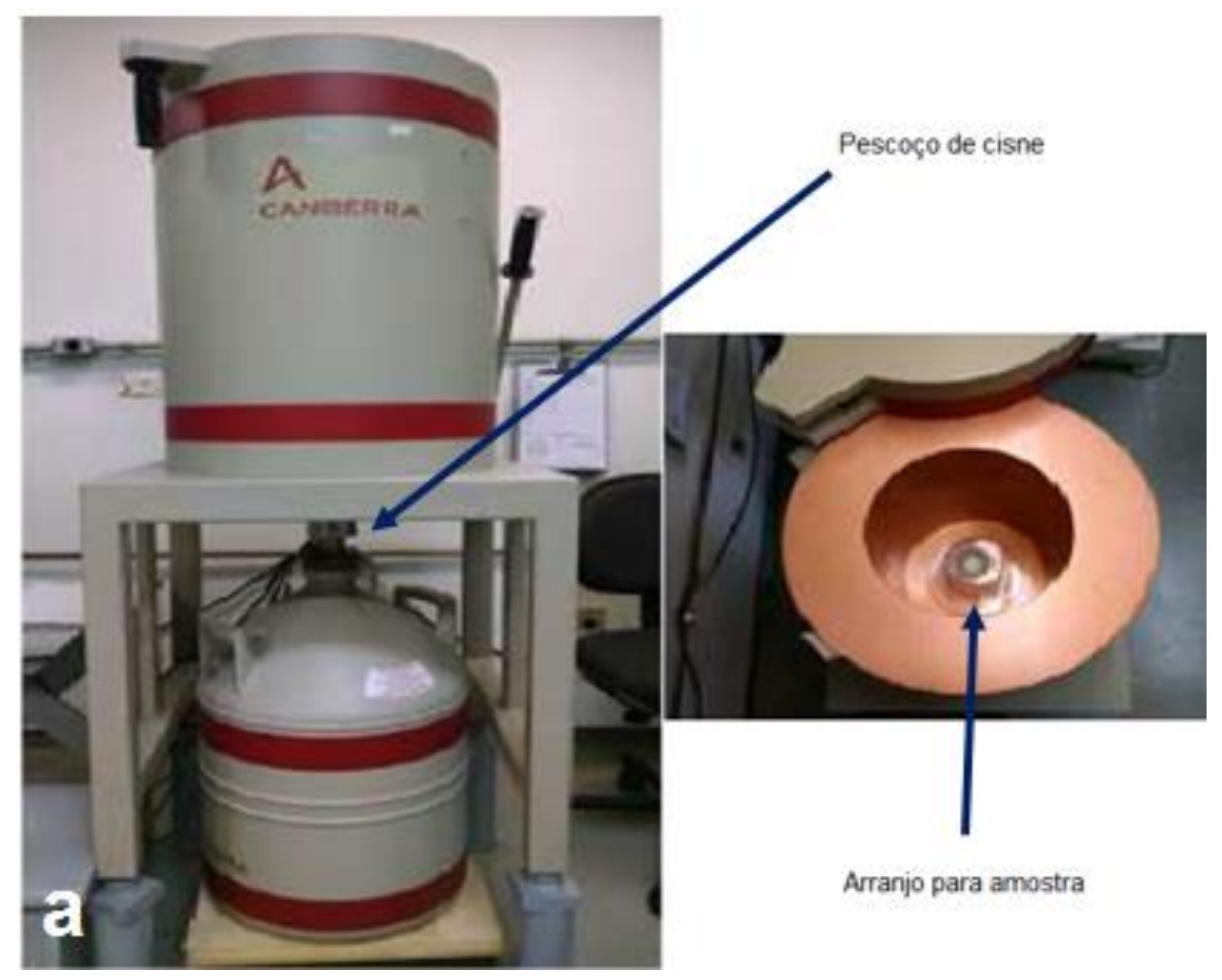


A calibração em eficiência do detector foi feita utilizando uma solução aquosa padrão multielemental e a radiação de fundo determinada com água ultrapura, ambas na mesma geometria das amostras (BARROS e PECEQUILO, 2014). A curvas de calibração em eficiência são regularmente verificadas por testes do Programa Nacional de Intercomparação, realizado pelo Instituto de Radioproteção e Dosimetria (IRD - CNEN) (PNI, 2019).

Os radionuclídeos investigados neste trabalho possuem tempos de meiavida significativamente maiores que o tempo de contagem, ou seja, suas atividades continuaram praticamente invariáveis durante as análises não há necessidade de correções (EVANS, 1972).

\subsection{Tempo de contagem das amostras}

A sensibilidade do método analítico em detectar a presença de um elemento (radionuclídeo) é designado Limite de Detecção (LD) e é um dos parâmetros essenciais para que se determine o tempo de contagem das amostras analisadas, assim como o Limite Crítico (LC) que identifica o patamar do sinal acima do sinal bruto que pode ser considerado como contagem em relação ao sinal de fundo do sistema de detecção. Por fim, o Limite de Detecção (LD) é apontado como o sinal acima do qual a precisão do sistema de medida é considerada boa o suficiente para determinações quantitativas (CURRIE, 1968; NISTI et al., 2009; MÁDUAR, 2010).

As Concentrações Mínimas Detectáveis (CMD) são determinadas pela área líquida da radiação de fundo para cada transição gama considerada, pela massa da amostra, pelo tempo de contagem, pela eficiência de contagem para a energia da transição gama considerada, assim como sua intensidade absoluta da transição gama considerada, e por uma constante que expressa o nível de confiança associado (\%), conforme a equação 1 (CURRIE, 1968).

$$
\mathrm{CMD}=4,66 \frac{\sqrt{\text { área }}}{\text { Ef.m.t.I }}
$$


Em que:

- CMD: concentração mínima detectável (Bq. $\left.\mathrm{kg}^{-1}\right)$;

- Área: área líquida da radiação de fundo para a transição gama considerada (contagens);

- m: massa da amostra $(\mathrm{kg})$;

- $\mathrm{t}$ : tempo de contagem (s);

- I $\gamma$ : intensidade absoluta da transição gama considerada (\%);

- 4,66: número que expressa o nível de confiança associado de 95\%.

Neste trabalho foi adotado o tempo de contagem das amostras em 150.000 segundos, onde estudo realizado por NISTI et al. (2009) demonstrou que esse tempo é ideal para medidas ambientais, portanto, otimiza-se o processo por meio da geometria e tempo de contagem de modo que se tenham limites de detecção aceitáveis (SHWEIKANI, 2015). Segundo CAVALCANTE (2017) após levantamento dos valores de Concentração Mínima Detectável (CMD) e seguindo os procedimentos sugeridos pelos autores citados, os valores obtidos apresentam pontos a partir dos quais os valores de CMD são aproximadamente nulos e constantes em função do tempo de contagem, indicando que 150.000 segundos são suficientes para as amostras analisadas.

Cavalcante (2017), realizando levantamento dos valores de Concentração Mínima Detectável (CMD) em função do tempo de contagem para as energias gama dos radionuclídeos ${ }^{214} \mathrm{~Pb}(351,9 \mathrm{keV}),{ }^{214} \mathrm{Bi}(609,3 \mathrm{keV}),{ }^{228} \mathrm{Ac}(911,1 \mathrm{keV})$ e ${ }^{40} \mathrm{~K}$ (1460,8 keV) observou pontos a partir dos quais os valores derivados de cada função exponencial obtida são aproximadamente nulos e constantes, como apresentado na Figura 8. 
Figura 8. Derivadas das funções CMD em função do tempo de contagem para energias gama selecionadas (CAVALCANTE, 2017).

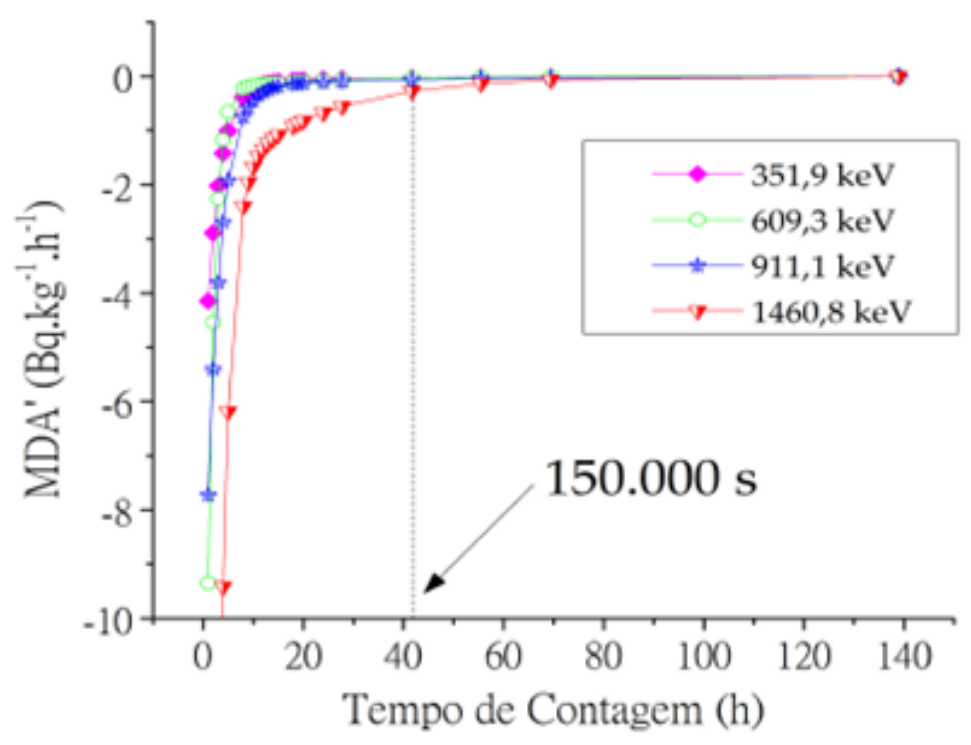

\subsection{Radionuclídeos analisados}

Foram avaliados os radionuclídeos das séries naturais ${ }^{226} \mathrm{Ra}$ e ${ }^{232} \mathrm{Th}$, e o radionuclídeo ${ }^{40} \mathrm{~K}$, e também os radionuclídeos artificiais que normalmente são avaliados em amostras de alimentos para consumo humano, tais como: ${ }^{131} \mathrm{I},{ }^{241} \mathrm{Am}$, ${ }^{137} \mathrm{Cs},{ }^{60} \mathrm{Co},{ }^{103} \mathrm{Ru}$ e ${ }^{106} \mathrm{Ru}$, (IAEA, 1996; IAEA, 2016; CNEN, 2005; CODEX, 2009).

No método empregado, as concentrações de atividade dos radionuclídeos das séries naturais foram obtidas por meio do equilíbrio radioativo, a partir das concentrações de atividades dos filhos de maior probabilidade de emissão gama. A Tabela 9 apresenta as transições gama utilizadas para determinação das concentrações de atividade do ${ }^{40} \mathrm{~K},{ }^{226} \mathrm{Ra}$ e ${ }^{232} \mathrm{Th}$ (LNHB, 2019). Para os radionuclídeos artificiais as concentrações de atividade são inferidas diretamente por suas emissões gama (Tabela 10). A figura 9 apresenta o espectro bruto e a identificação dos picos de emissão gama dos radionuclídeos naturais considerados neste trabalho. 
Tabela 9. Transições gama utilizadas para determinação das concentrações de atividade do ${ }^{226} \mathrm{Ra},{ }^{232} \mathrm{Th}$ e ${ }^{40} \mathrm{~K}$ (LNHB, 2019).

\begin{tabular}{cccc}
\hline \hline Radionuclídeo & Radionuclídeo filho & Energia (keV) & $\begin{array}{c}\text { Intensidade } \\
(\%)\end{array}$ \\
\hline \hline \multirow{2}{*}{${ }^{226} \mathrm{Ra}$} & ${ }^{214} \mathrm{~Pb}$ & 295,21 & 18,42 \\
& & 351,92 & 35,60 \\
\cline { 2 - 4 } & & 609,32 & 45,49 \\
\hline${ }^{214} \mathrm{Bi}$ & 338,4 & 11,27 \\
${ }^{232} \mathrm{Th}$ & ${ }^{228} \mathrm{Ac}$ & 911,07 & 25,80 \\
& & 968,9 & 15,80 \\
& & 238,63 & 43,60 \\
& ${ }^{212} \mathrm{~Pb}$ & 300,09 & 3,30 \\
\hline${ }^{40} \mathrm{~K}$ & ${ }^{212} \mathrm{Bi}$ & 727,33 & 6,74 \\
\hline
\end{tabular}

Figura 9. Espectro bruto de uma amostra e a identificação dos picos de emissão gama dos radionuclídeos naturais.

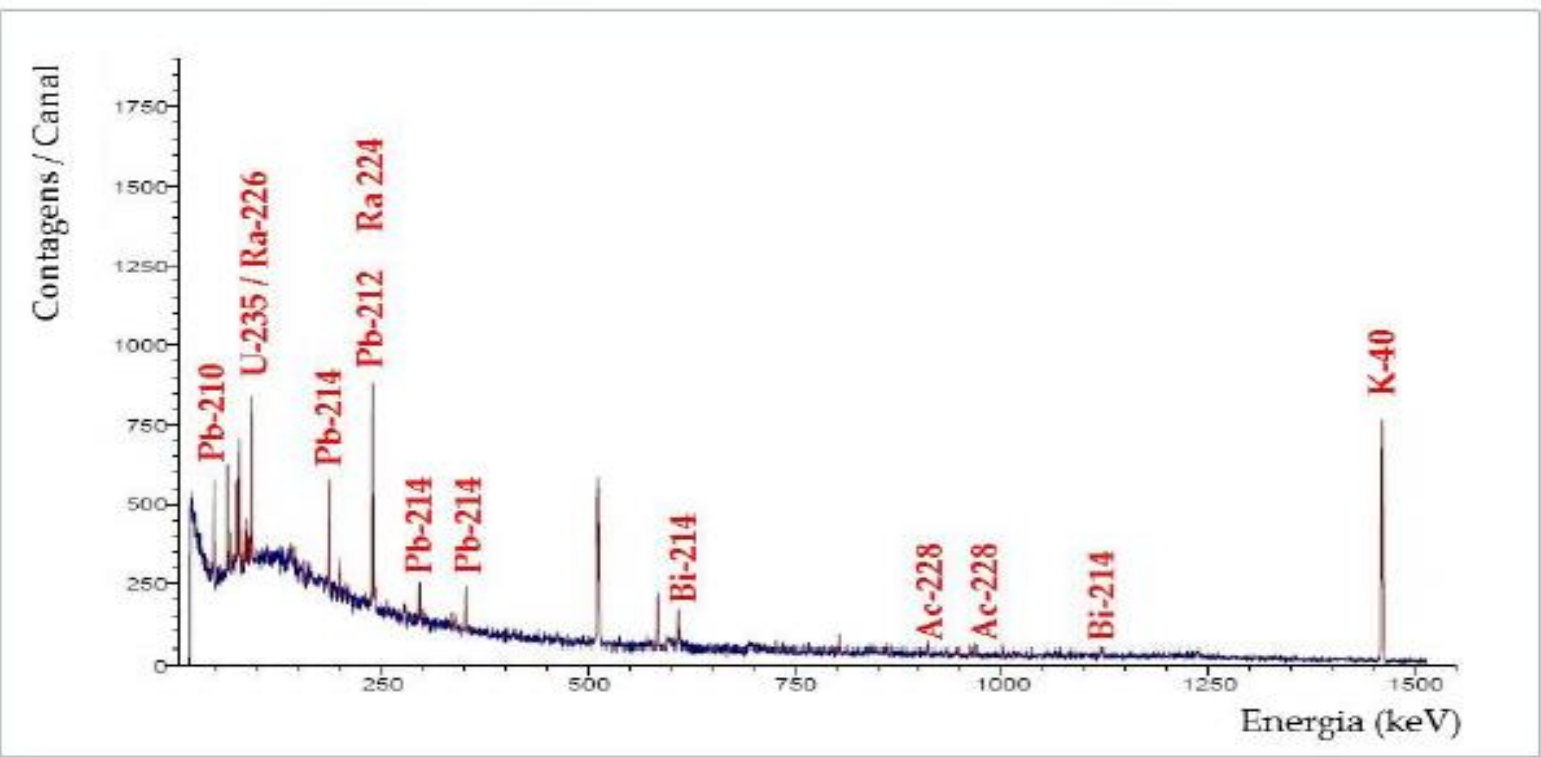


Tabela 10. Transições gama utilizadas para determinação das concentrações de atividade ${ }^{131} \mathrm{I},{ }^{241} \mathrm{Am},{ }^{137} \mathrm{Cs}$, ${ }^{60} \mathrm{Co}$ e ${ }^{103} \mathrm{Ru}$, (CNEN, 2005; CODEX, 2009; LNHB, 2019).

\begin{tabular}{|c|c|c|c|}
\hline Radionuclídeo & $\begin{array}{l}\text { Radionuclídeo } \\
\text { filho }\end{array}$ & Energia (keV) & Intensidade (\%) \\
\hline${ }^{137} \mathrm{Cs}$ & & 661,65 & 94,36 \\
\hline \multirow{2}{*}{${ }^{60} \mathrm{Co}$} & & 1173,23 & 99,89 \\
\hline & & 1332,50 & 99,98 \\
\hline${ }^{131} \mid$ & & 364,49 & 83,1 \\
\hline${ }^{103} \mathrm{Ru}$ & & 497,08 & 86,04 \\
\hline \multirow{2}{*}{${ }^{106} \mathrm{Ru}$} & \multirow{2}{*}{${ }^{106} \mathrm{Rh}$} & 621,92 & $9,8 \%$ \\
\hline & & 1050,36 & $1,53 \%$ \\
\hline${ }^{241} \mathrm{Am}$ & & 59,54 & 35,9 \\
\hline
\end{tabular}

\subsection{Cálculo da concentração de atividade}

A concentração de atividade para $0{ }^{40} \mathrm{~K}$ foi calculada pela sua transição gama única de 1460,83 keV, por meio da equação 2 (KNOLL, 2000; BARROS e PECEQUILO, 2013).

$$
A_{i}\left(E_{\gamma i}\right)=\frac{C_{\gamma i}}{\varepsilon_{\gamma i} \cdot \mathrm{I}_{\gamma i} \cdot t_{l} \cdot m}
$$

Em que:

- A $\left(E_{\mathrm{ri}}\right)$ : atividade da transição gama considerada do radionuclídeo na amostra (Bq. $\left.\mathrm{kg}^{-1}\right)$;

- $C_{y i}$ área líquida do pico da transição gama;

- $\varepsilon_{y i}$ : eficiência do detector para a transição gama considerada;

- Iyi: probabilidade de emissão da transição gama com energia (\%);

- $\mathrm{t}$ : tempo de contagem (s);

- m: massa da amostra (kg). 
A concentração de atividade do ${ }^{226} \mathrm{Ra}$ foi determinada pela média ponderada das transições gama do ${ }^{214} \mathrm{~Pb}$ e ${ }^{214} \mathrm{Bi}$, como na equação 3 , e a atividade de ${ }^{232} \mathrm{Th}$ pela média ponderada de ${ }^{212} \mathrm{~Pb},{ }^{212} \mathrm{Bi}$ e ${ }^{228} \mathrm{Ac}$ por meio da equação 4 (KNOLL, 2000).

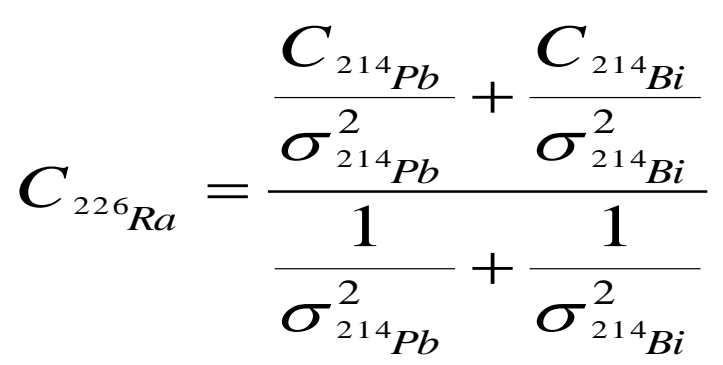

Em que:

- $\mathrm{C}^{226} \mathrm{Ra}$ : Concentração de atividade do ${ }^{226} \mathrm{Ra}\left(\mathrm{Bq} \cdot \mathrm{kg}^{-1}\right)$;

- $\quad \mathrm{C}^{214} \mathrm{~Pb}$ : Concentração de atividade do ${ }^{214} \mathrm{~Pb}\left(\mathrm{~Bq} \cdot \mathrm{kg}^{-1}\right)$;

- $\quad \sigma^{214} \mathrm{~Pb}$ : Incerteza da concentração de atividade do ${ }^{214} \mathrm{~Pb}\left(\mathrm{~Bq} \cdot \mathrm{kg}^{-1}\right)$;

- $\mathrm{C}^{214} \mathrm{Bi}$ : Incerteza da concentração da atividade do ${ }^{214} \mathrm{Bi}\left(\mathrm{Bq} \cdot \mathrm{kg}^{-1}\right)$;

- $\sigma^{214} \mathrm{Bi}$ : Incerteza da concentração da atividade do ${ }^{214} \mathrm{Bi}\left(\mathrm{Bq} \cdot \mathrm{kg}^{-1}\right)$.

Em que:

$$
C_{{ }^{232} \mathrm{Th}}=\frac{\frac{C_{212} \mathrm{~Pb}}{\sigma_{212}^{2} P b}+\frac{C_{212}^{2} B i}{\sigma_{212}^{2}}+\frac{C_{228} A c}{\sigma_{228}^{2}}}{\frac{1}{\sigma_{212}^{2} P b}+\frac{1}{\sigma_{212}^{2}}+\frac{1}{\sigma_{228}^{2}}}
$$

- $\quad \mathrm{C}^{232} \mathrm{Th}$ : Concentração de atividade do ${ }^{232} \mathrm{Th}\left(\mathrm{Bq} \cdot \mathrm{kg}^{-1}\right)$;

- $\quad \mathrm{C}^{212} \mathrm{~Pb}$ : Concentração de atividade do ${ }^{212} \mathrm{~Pb}\left(\mathrm{~Bq} \cdot \mathrm{kg}^{-1}\right)$;

- $\quad \sigma^{212} \mathrm{~Pb}$ : Incerteza da concentração de atividade do ${ }^{212} \mathrm{~Pb}\left(\mathrm{~Bq} \cdot \mathrm{kg}^{-1}\right)$;

- $\quad \mathrm{C}^{212} \mathrm{Bi}$ : Incerteza da concentração da atividade do ${ }^{212} \mathrm{Bi}\left(\mathrm{Bq} \cdot \mathrm{kg}^{-1}\right)$;

- $\quad \sigma^{212} \mathrm{Bi}$ : Incerteza da concentração da atividade do ${ }^{212} \mathrm{Bi}\left(\mathrm{Bq} \cdot \mathrm{kg}^{-1}\right)$;

- $\quad \mathrm{C}^{228} \mathrm{Ac}$ : Incerteza da concentração da atividade do ${ }^{228} \mathrm{Ac}\left(\mathrm{Bq} \cdot \mathrm{kg}^{-1}\right)$;

- $\sigma^{228} \mathrm{Ac}$ : Incerteza da concentração da atividade do ${ }^{228} \mathrm{Ac}\left(\mathrm{Bq} \cdot \mathrm{kg}^{-1}\right)$. 


\subsection{Dose efetiva por ingestão de alimentos}

A dose efetiva é uma grandeza que avalia a dose absorvida (interna e externa) por diferentes tipos de tecidos de um indivíduo, considerando o tipo de radiação e a radiossensibilidade desses tecidos. Para calcularmos a dose por ingestão, além da dose absorvida é necessária a taxa de consumo anual do referido alimento $\left(\mathrm{kg} \cdot \mathrm{a}^{-1}\right)$, assim como o coeficiente de conversão de dose para cada radionuclídeo avaliado. A estimativa de dose por ingestão de alimentos é feita a partir do cálculo da dose efetiva por ano de ingestão $\left(D_{E}\right)$ em Sv.a ${ }^{-1}$, dada pela equação 5 (ICRP, 1991):

$$
D_{E}=e(g) \cdot A \cdot T
$$

Em que:

- $D_{E}$ : dose efetiva por unidade de ingestão $\left(S v \cdot a^{-1}\right)$;

- $\mathrm{e}(\mathrm{g})$ : coeficiente de dose efetiva $\left(\mathrm{Sv}_{\mathrm{Bgq}}{ }^{-1}\right)$;

- A: atividade media do radionuclídeo (Bq. $\left.\mathrm{kg}^{-1}\right)$;

- $\mathrm{T}$ : taxa de consumo anual $\left(\mathrm{kg} \cdot \mathrm{a}^{-1}\right)$ do referido alimento.

Os valores dos coeficientes de conversão de dose para os radionuclídeos naturais e artificiais são apresentados nas Tabelas 11 e 12.

Tabela 11. Coeficientes de conversão de dose para os radionuclídeos naturais público adulto e criança (ICRP, 1991).

\begin{tabular}{|c|c|c|}
\hline & \multicolumn{2}{|c|}{ (Sv/Bq) } \\
\hline & Adulto & Criança \\
\hline${ }^{40} \mathrm{~K}$ & $6,2 \times 10^{-09}$ & $4,2 \times 10^{-08}$ \\
\hline${ }^{226} \mathrm{Ra}$ & $2,8 \times 10^{-07}$ & $9,6 \times 10^{-07}$ \\
\hline${ }^{232} \mathrm{Th}$ & $2,3 \times 10^{-07}$ & $4,5 \times 10^{-07}$ \\
\hline
\end{tabular}


Tabela 12. Coeficientes de conversão de dose para os radionuclídeos artificiais público adulto e criança (ICRP, 1991).

\begin{tabular}{ccc}
\hline \hline & \multicolumn{2}{c}{$(\mathrm{Sv} / \mathrm{Bq})$} \\
\hline \hline & Adulto & Criança \\
\cline { 2 - 3 }${ }^{134} \mathrm{Cs}$ & $1,9 \times 10^{-08}$ & $1,6 \times 10^{-08}$ \\
${ }^{137} \mathrm{Cs}$ & $1,3 \times 10^{-08}$ & $1,2 \times 10^{-08}$ \\
${ }^{103} \mathrm{Ru}$ & $7,3 \times 10^{-10}$ & $4,6 \times 10^{-09}$ \\
${ }^{106} \mathrm{Ru}$ & $7,0 \times 10^{-09}$ & $4,9 \times 10^{-08}$ \\
${ }^{60} \mathrm{Co}$ & $3,4 \times 10^{-09}$ & $2,7 \times 10^{-08}$ \\
${ }^{131} \mathrm{I}$ & $2,2 \times 10^{-08}$ & $1,8 \times 10^{-07}$ \\
${ }^{241} \mathrm{Am}$ & $2,0 \times 10^{-07}$ & $3,7 \times 10^{-07}$ \\
\hline \hline
\end{tabular}

Os valores recomendados de dose efetiva por ingestão pela UNSCEAR e IAEA para os indivíduos do público, são de $140 \mu \mathrm{Sv}^{\mathrm{a}} \mathrm{a}^{-1}$ e de $1 \mathrm{mSv} \cdot \mathrm{a}^{-1}$, respectivamente (UNSCEAR, 2000; IAEA, 2016). A dose efetiva anual devido à exposição do indivíduo adulto às fontes naturais de radiação é de 2,4 mSv.a ${ }^{-1}$, desse valor 0,29 mSv. $\mathrm{a}^{-1}$ é devido à ingestão.

Para o cálculo de dose para crianças, os coeficientes de conversão de dose para cada radionuclídeo avaliado são mais restritivos. Os valores para os coeficientes de dose efetiva são baseados em modelos metabólicos usados pela avaliação da UNSCEAR, e os coeficientes de dose efetiva são disponibilizados pela ICRP (ICRP, 1991, UNSCEAR, 2008b).

\section{RESULTADOS}

\subsection{Concentração de atividade}

\subsubsection{Concentração de atividade dos radionuclídeos naturais}




\subsubsection{Trigo}

Foram analisadas 18 amostras de farinha de trigo, nomeadas de T1 a T18 (ver Item 3.1, tabela 5).

Todas as amostras de farinha de trigo analisadas apresentaram concentração de atividade acima da concentração mínima detectável (CMD) para ${ }^{40} \mathrm{~K}$. Para o ${ }^{232} \mathrm{Th}$, as farinhas de trigo T7, T11, T12 e T18 apresentaram concentração de atividade acima da concentração mínima detectável (CMD). Para o ${ }^{266} \mathrm{Ra}$, as amostras de farinha de trigo T1, T3, T5, T6, T7, T8, T9, T10, T11, T14 e T18 apresentaram valores de concentração de atividade acima da concentração mínima detectável para o ${ }^{226} \mathrm{Ra}$, conforme apresentado na Figura 10.

Figura 10. Concentração de atividade de ${ }^{40} \mathrm{~K},{ }^{226} \mathrm{Ra}$ e ${ }^{232} \mathrm{Th}$ para as farinhas de trigo.

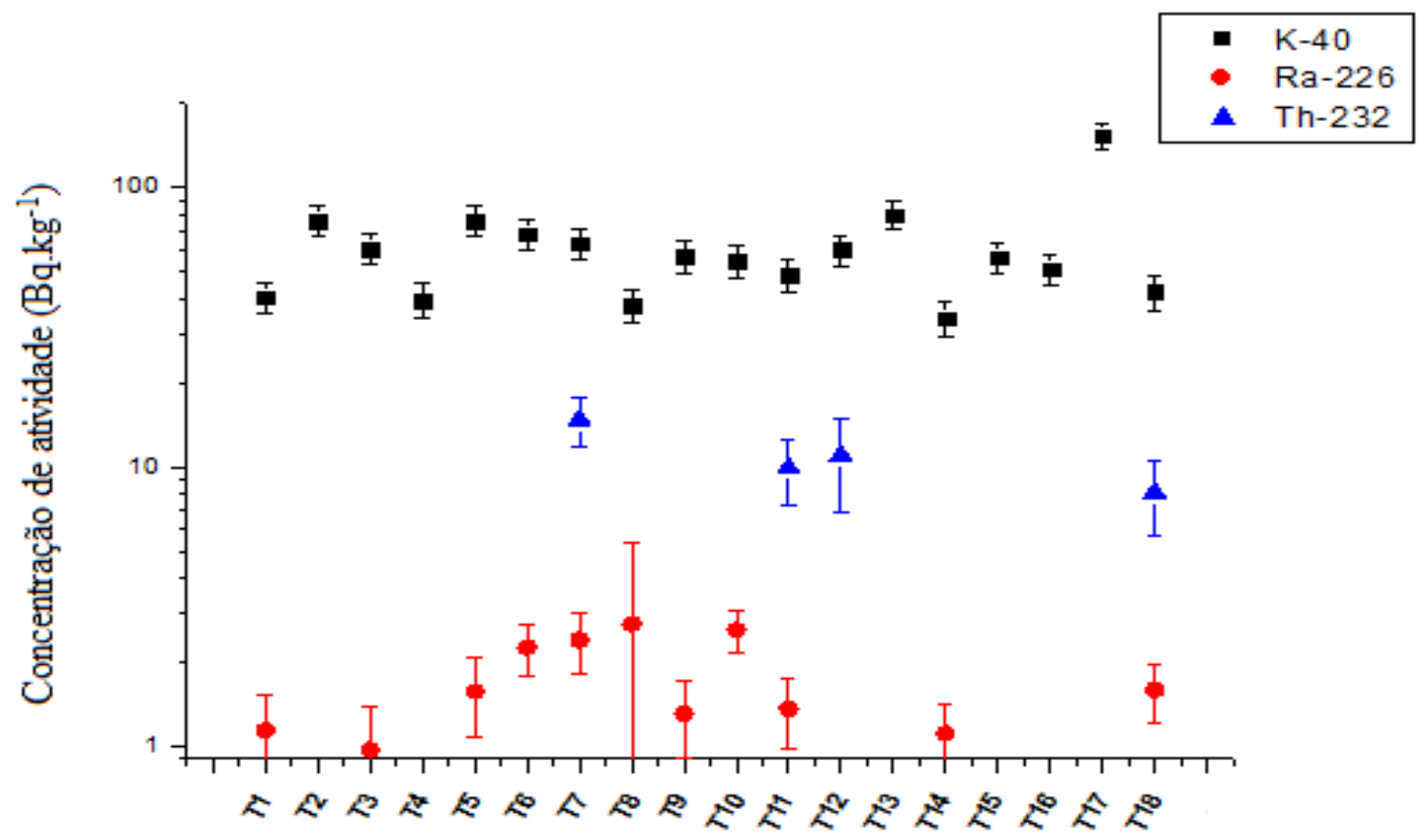

Os valores de concentração de atividade para $0{ }^{40} \mathrm{~K}$ ficaram entre $34 \pm 4$ Bq.kg-1 (amostra T14) e $153 \pm 2$ Bq. kg ${ }^{-1}$ (amostra T17). Para o ${ }^{226} \mathrm{Ra}$, os valores de concentração de atividade obtidos ficaram entre 0,9 \pm 1 Bq. $\mathrm{kg}^{-1}$ (amostra T3) e 2,6 $\pm 1 \mathrm{~Bq} \cdot \mathrm{kg}^{-1}$ (amostra T10). Os valores de concentração de atividade obtidos para o ${ }^{232} \mathrm{Th}$ ficaram entre $10 \pm 3$ Bq. $\mathrm{kg}^{-1}$ (amostra T11) e 14,7 $\pm 3,0$ Bq. kg-1 (amostra T7). 
Dentre as amostras de farinha de trigo analisadas, podemos observar que as concentrações de atividade de ${ }^{232}$ Th são mais elevadas que as concentrações de atividade para o ${ }^{226} \mathrm{Ra}$. E os valores de concentração de atividade de ${ }^{40} \mathrm{~K}$ são bem mais elevados quando comparados com o ${ }^{226} \mathrm{Ra}$ e ${ }^{232} \mathrm{Th}$.

\subsubsection{Milho}

Foram analisadas 8 amostras de farinha de milho, nomeadas de M1 a M8 (ver Item 3.1, tabela 6).

Todas as amostras de milho analisadas apresentaram concentração de atividade acima da concentração mínima detectável (CMD) para ${ }^{40} \mathrm{~K}$. Para $0{ }^{232} \mathrm{Th}$ apenas a amostra de trigo M8 apresentou concentração de atividade acima da concentração mínima detectável (CMD). Para o ${ }^{266} \mathrm{Ra}$, apenas as amostras de milho M4 e M8 apresentaram valores de concentração de atividade acima da concentração mínima detectável, conforme apresentado na Figura 11.

Figura 11. Concentração de atividade de ${ }^{40} \mathrm{~K},{ }^{226} \mathrm{Ra}$ e ${ }^{232} \mathrm{Th}$ para as farinhas de milho.

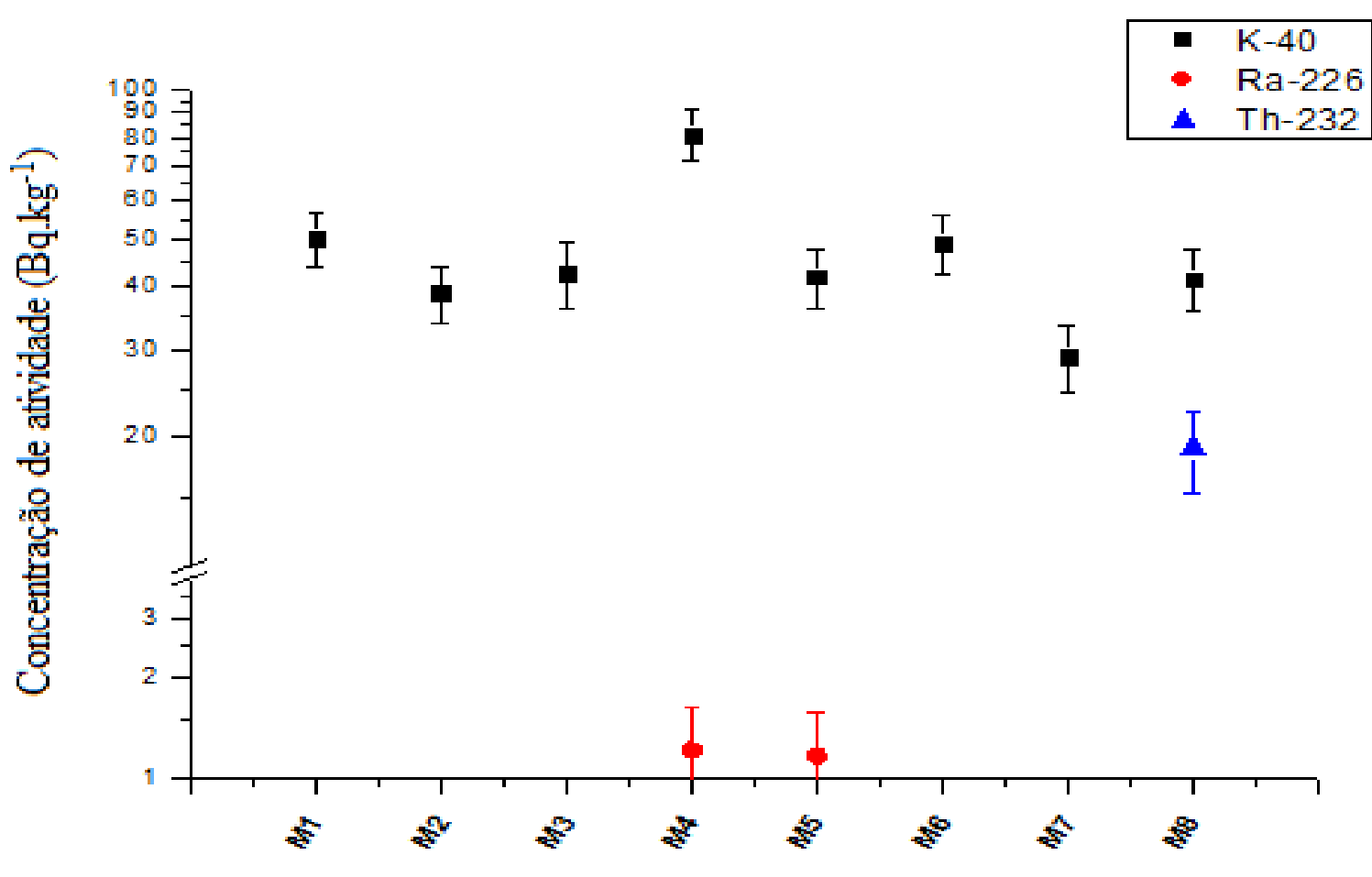


Os valores de concentração de atividade para $0{ }^{40} \mathrm{~K}$ ficaram entre $29 \pm 4$ Bq. kg-1 (amostra M7) e $81 \pm 9$ Bq. kg-1 (amostra M4). Para o ${ }^{226} \mathrm{Ra}$, os valores de concentração de atividade obtidos ficaram entre 1,1 $\pm 1 \mathrm{~Bq}^{\mathrm{kg}}{ }^{-1}$ (amostra M5) e 1,2 $\pm 1 \mathrm{~Bq} \cdot \mathrm{kg}^{-1}$ (amostra M4). Apenas a farinha de milho M8 apresentou concentração de atividade para o ${ }^{232} \mathrm{Th}$ de $19 \pm 4$ Bq.kg ${ }^{-1}$.

Foi possível observar que as concentrações de atividade de ${ }^{40} \mathrm{~K}$ são mais elevadas se comparadas com as amostras que apresentaram concentrações de atividade para $0{ }^{232} \mathrm{Th}$ e ${ }^{226} \mathrm{Ra}$, seguindo a mesma tendência apresentada pelas concentrações das farinhas de trigo.

\subsubsection{Mandioca}

Foram analisadas 3 amostras de farinha de mandioca, nomeadas de Ma1, Ma2 e Ma3 (ver Item 3.1, tabela 7).

Todas as amostras de farinha de mandioca analisadas apresentaram concentração de atividade acima da concentração mínima detectável (CMD) para ${ }^{40} \mathrm{~K}$. Para o ${ }^{232}$ Th apenas a amostra de mandioca Ma3 apresentou concentração de atividade acima da concentração mínima detectável (CMD). Para o ${ }^{266} \mathrm{Ra}$, nenhuma das farinhas apresentou valores de concentração de atividade acima da concentração mínima detectável para o ${ }^{226} \mathrm{Ra}$, conforme apresentado na Figura 12. 
Figura 12. Concentração de atividade de ${ }^{40} \mathrm{~K},{ }^{226} \mathrm{Ra}$ e ${ }^{232} \mathrm{Th}$ para as farinhas de mandioca.

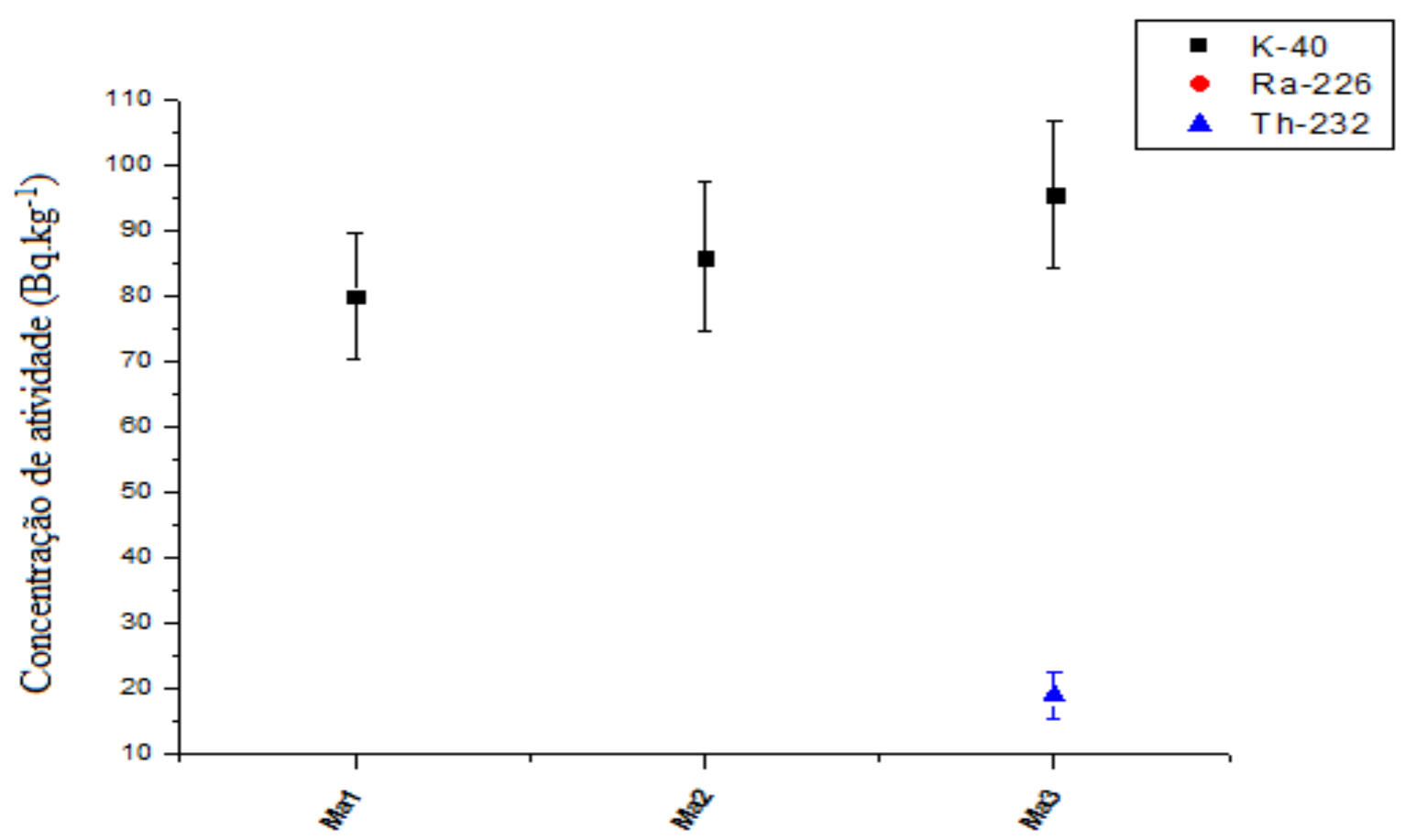

Os valores de concentração de atividade para o ${ }^{40} \mathrm{~K}$ ficaram entre $80 \pm 1$ Bq. $\mathrm{kg}^{-1}$ (amostra Ma1) e $95 \pm 1$ Bq. kg-1 (amostra Ma3). Apenas a farinha de mandioca Ma3 apresentou concentração de atividade para $0{ }^{232} \mathrm{Th}$ de $19 \pm 4$ Bq. $\mathrm{kg}^{-1}$.

\subsubsection{Soja}

Foram analisadas 3 amostras de farinha de soja, nomeadas de S1, S2 e S3 (ver Item 3.1, tabela 7).

Todas as amostras de farinha de soja analisadas apresentaram concentração de atividade acima da concentração mínima detectável (CMD) para ${ }^{40} \mathrm{~K}$, ${ }^{232}$ Th e ${ }^{266} \mathrm{Ra}$, conforme apresentado na Figura 13. 
Figura 13. Concentração de atividade de ${ }^{40} \mathrm{~K},{ }^{226} \mathrm{Ra}$ e ${ }^{232} \mathrm{Th}$ para as farinhas de soja.

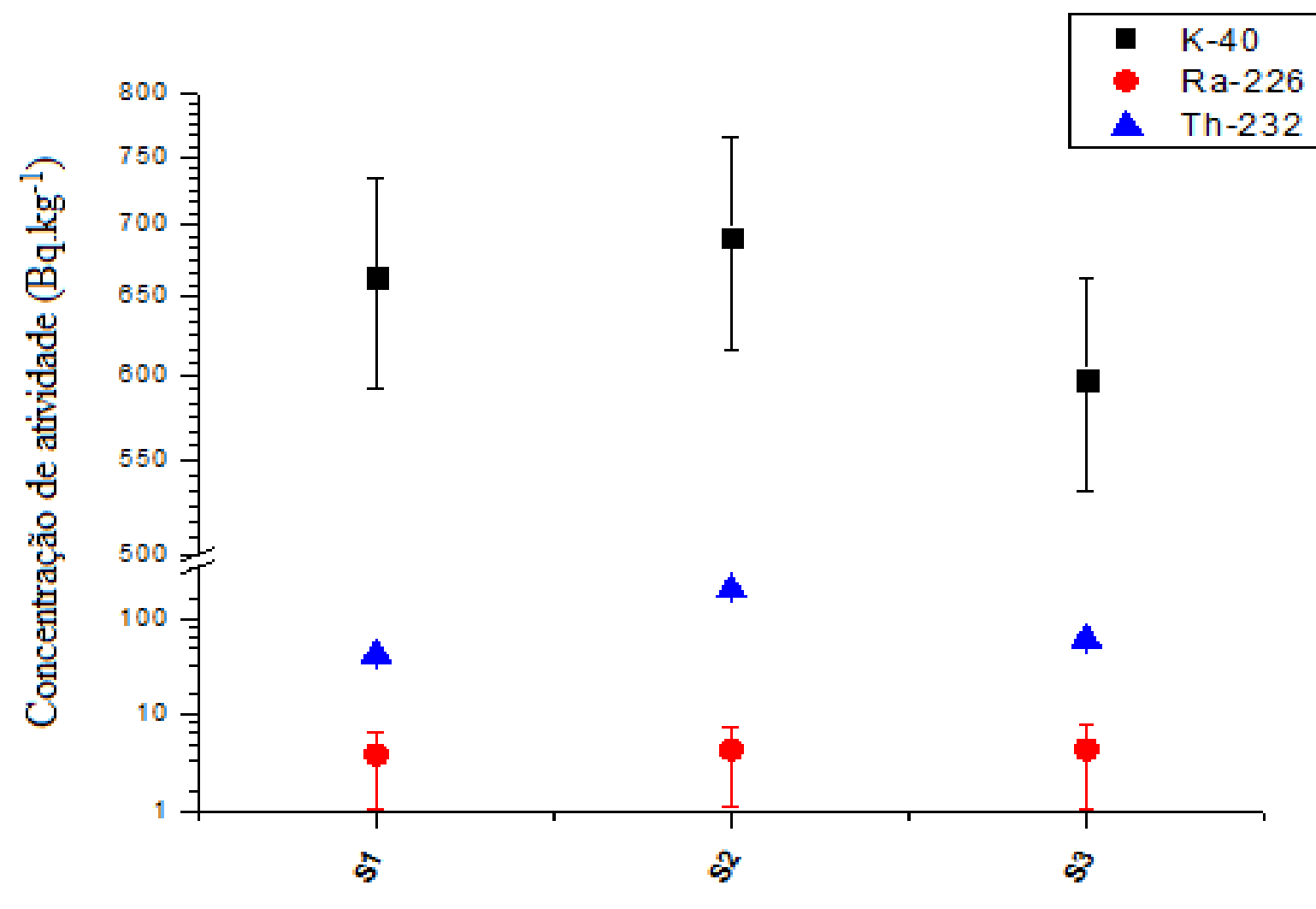

Os valores de concentração de atividade de ${ }^{40} \mathrm{~K}$ para as amostras de farinhas de soja S1, S2 e S3 foram $663 \pm 7$ Bq.kg-1, $691 \pm 74$ Bq. $\mathrm{kg}^{-1}$ e $598 \pm 6 \mathrm{~Bq} \cdot \mathrm{kg}^{-1}$, respectivamente. As concentrações de atividade para o ${ }^{232} \mathrm{Th}$ foram de 42,4 $\pm 6 \mathrm{~Bq} \cdot \mathrm{kg}^{-1}$ para a amostra S1, de $201 \pm 2 \mathrm{~Bq} \cdot \mathrm{kg}^{-1}$ para a amostra S2, e $60 \pm 8 \mathrm{~Bq} \cdot \mathrm{kg}^{-1}$ para amostra S3. As concentrações de atividade para o ${ }^{226} \mathrm{Ra}$ foram de 3,9 \pm 3 Bq. $\mathrm{kg}^{-1}, 4,3 \pm 3 \mathrm{~Bq} \cdot \mathrm{kg}^{-1}$ e 4,4 $\pm 3 \mathrm{~Bq} \cdot \mathrm{kg}^{-1}$ para as amostras de farinha S1, S2 e S3, respectivamente.

Os valores de concentração de atividade obtidos para as farinhas de soja são mais elevados quando comparados com farinhas de outros tipos, e dentre as amostras analisadas foi a única que apresentou concentração de atividade acima das concentrações mínimas detectáveis para ${ }^{40} \mathrm{~K},{ }^{226} \mathrm{Ra}$ e ${ }^{232} \mathrm{Th}$. 


\subsubsection{Arroz}

Foram analisadas 3 amostras de farinha de arroz, nomeadas de A1, A2 e A3 (ver Item 3.1, tabela 7).

Todas as amostras de farinha de arroz analisadas apresentaram concentração de atividade acima da concentração mínima detectável (CMD) para ${ }^{40} \mathrm{~K}$. Para o 232Th, nenhuma das amostras de farinha de arroz apresentou concentração de atividade acima da concentração minima detectável. Para o ${ }^{266} \mathrm{Ra}$, apenas a amostra A3 apresentou concentração de atividade acima da concentração mínima detectável, conforme apresentado na Figura 14.

Figura 14. Concentração de atividade de ${ }^{40} \mathrm{~K},{ }^{226} \mathrm{Ra}$ e ${ }^{232} \mathrm{Th}$ para as farinhas de arroz.

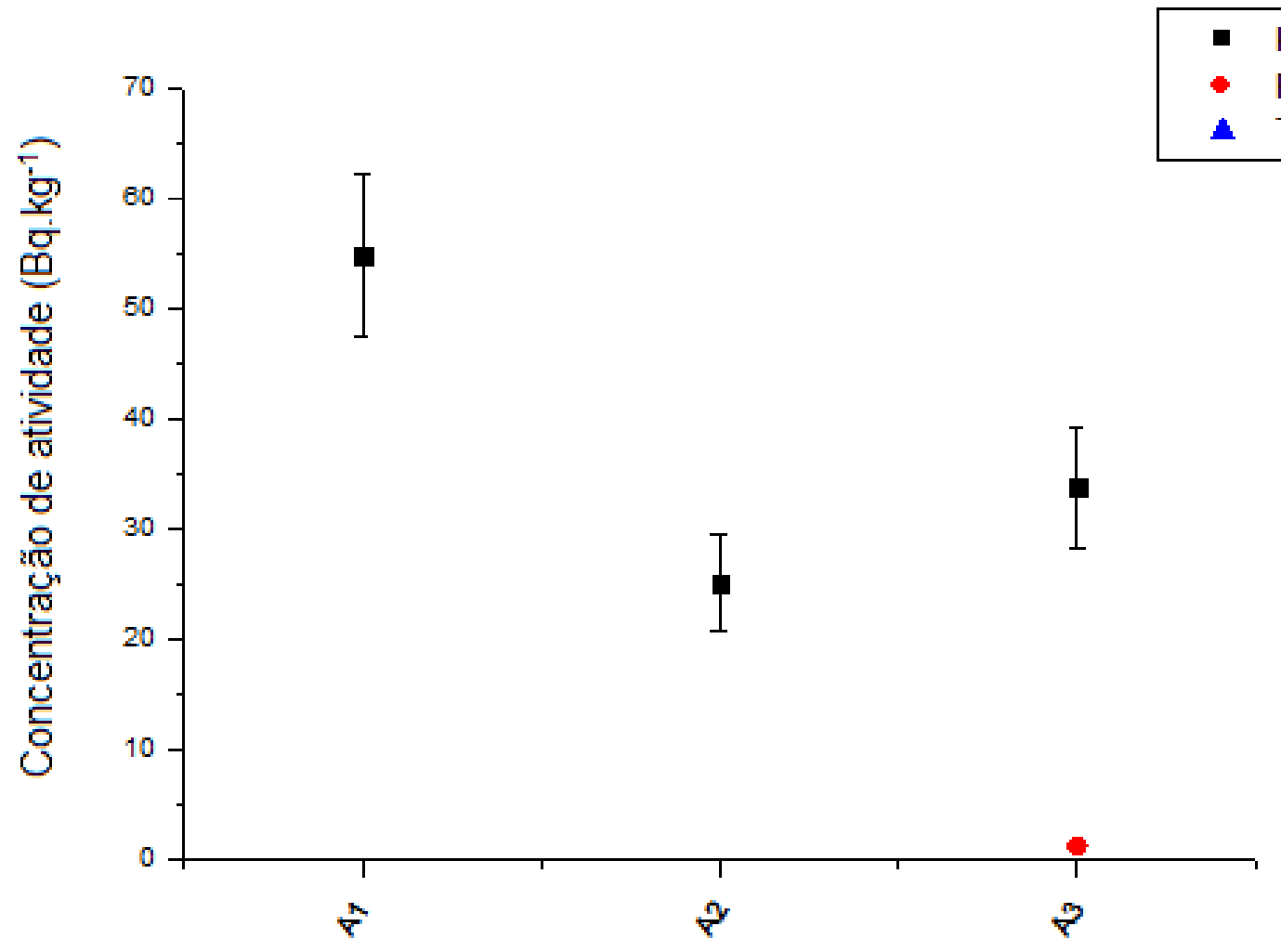

Para $0{ }^{40} \mathrm{~K}$ as amostras de farinha de arroz $\mathrm{A} 1, \mathrm{~A} 2$ e $\mathrm{A} 3$ apresentaram concentração de atividade de $54 \pm 7 \mathrm{~Bq} \cdot \mathrm{kg}^{-1}, 25 \pm 4 \mathrm{~Bq} \cdot \mathrm{kg}^{-1}$, e de $33 \pm 5 \mathrm{~Bq} \cdot \mathrm{kg}^{-1}$ para ${ }^{40} \mathrm{~K}$, respectivamente. Para ${ }^{226} \mathrm{Ra}$ o valor obtido foi de $1,3 \pm 1 \mathrm{~Bq} \cdot \mathrm{kg}^{-1}$. 


\subsubsection{Aveia, Centeio e Rosca}

Foram analisadas uma única amostra de farinha de aveia, centeio e rosca, nomeadas de Av1, C1 e R1 (ver Item 3.1, tabela 7).

As amostras de aveia, centeio e rosca analisadas apresentaram concentração de atividade acima da concentração mínima detectável (CMD) para ${ }^{40} \mathrm{~K}$. Nenhuma das amostras das farinhas de aveia, centeio e rosca apresentaram concentrações de atividade acima da concentração mínima detectável para ${ }^{226} \mathrm{Ra} e$ ${ }^{232} \mathrm{Th}$, conforme apresentado na Figura 15.

Figura 15. Concentração de atividade de ${ }^{40} \mathrm{~K},{ }^{226} \mathrm{Ra}$ e ${ }^{232} \mathrm{Th}$ para as farinhas de aveia, centeio e rosca.

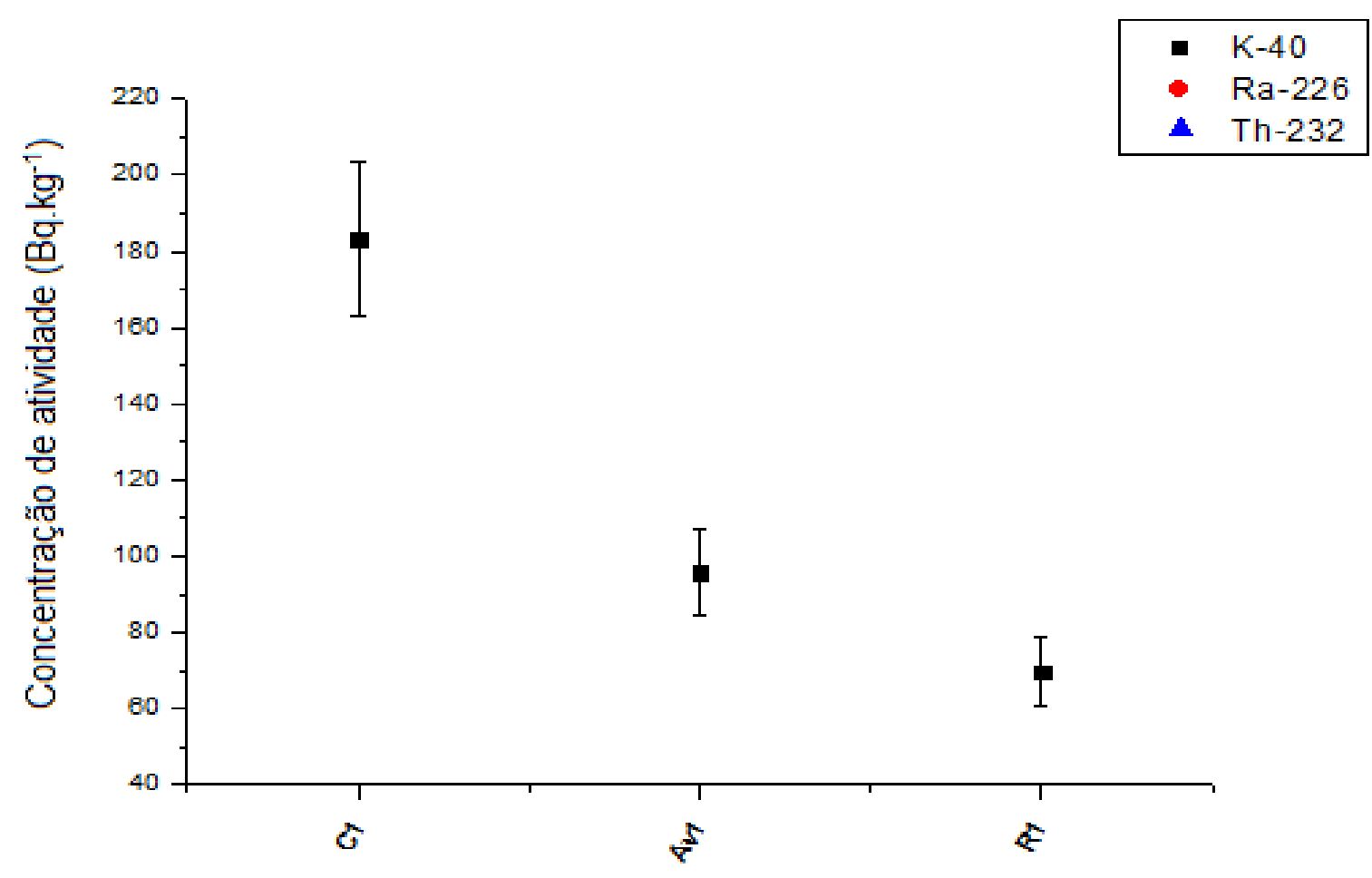

As concentrações de atividade obtidas para o ${ }^{40} \mathrm{~K}$ foram de $95 \pm 1 \mathrm{~Bq} \cdot \mathrm{kg}^{-1}$ para farinha de aveia, de $183 \pm 2 \mathrm{~Bq} \cdot \mathrm{kg}^{-1}$ para farinha de centeio, e de $69 \pm 9 \mathrm{~Bq} \cdot \mathrm{kg}^{-1}$ para farinha de rosca. 


\subsection{Concentração de atividade e concentração mínima detectável dos radionuclídeos naturais}

As figuras 16, 17, 18, 19, 20 e 21 apresentam os valores das concentrações de atividade obtidas para as farinhas de trigo, milho, soja, mandioca, arroz, centeio, rosca e aveia, e as concentrações mínimas detectáveis para cada uma dessas amostras de farinha que não apresentaram valores de concentração de atividade para cálculo de dose. Os valores das concentrações mínimas detectáveis foram utilizados para estimar a dose efetiva por ingestão para os radionuclídeos naturais.

Os limites recomendados para os radionuclídeos naturais na dieta total anual são de 22 Bq. $\mathrm{kg}^{-1}$ para o ${ }^{226} \mathrm{Ra}$ e de $1,7 \mathrm{~Bq} \cdot \mathrm{kg}^{-1}$ para o ${ }^{232} \mathrm{Th}$. Para o ${ }^{40} \mathrm{~K}$ não é aplicado um limite, pois esse elemento é essencial para a manutenção homeostática dos seres humanos. Os valores obtidos para esse radionuclídeo ficam como registro, possibilitando verificar se ocorrerá uma alteração nos valores ao longo do tempo.

Figura 16. Concentração de atividade e concentração mínima detectável de ${ }^{40} \mathrm{~K}$, ${ }^{226} \mathrm{Ra}$ e ${ }^{232} \mathrm{Th}$ para as farinhas de trigo.

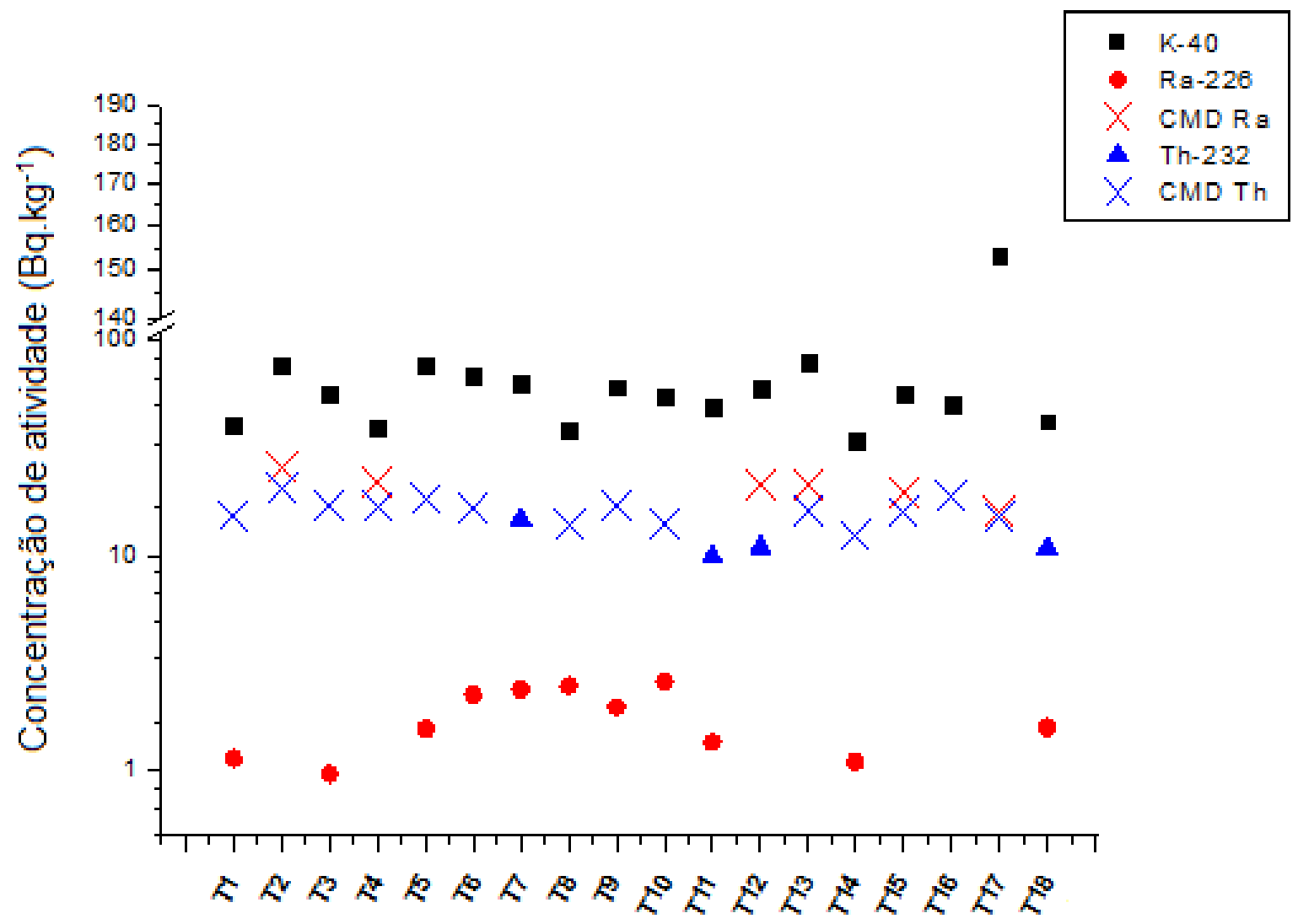


Figura 17. Concentração de atividade e concentração mínima detectável de ${ }^{40} \mathrm{~K}$, ${ }^{226} \mathrm{Ra}$ e ${ }^{232} \mathrm{Th}$ para as farinhas de milho.

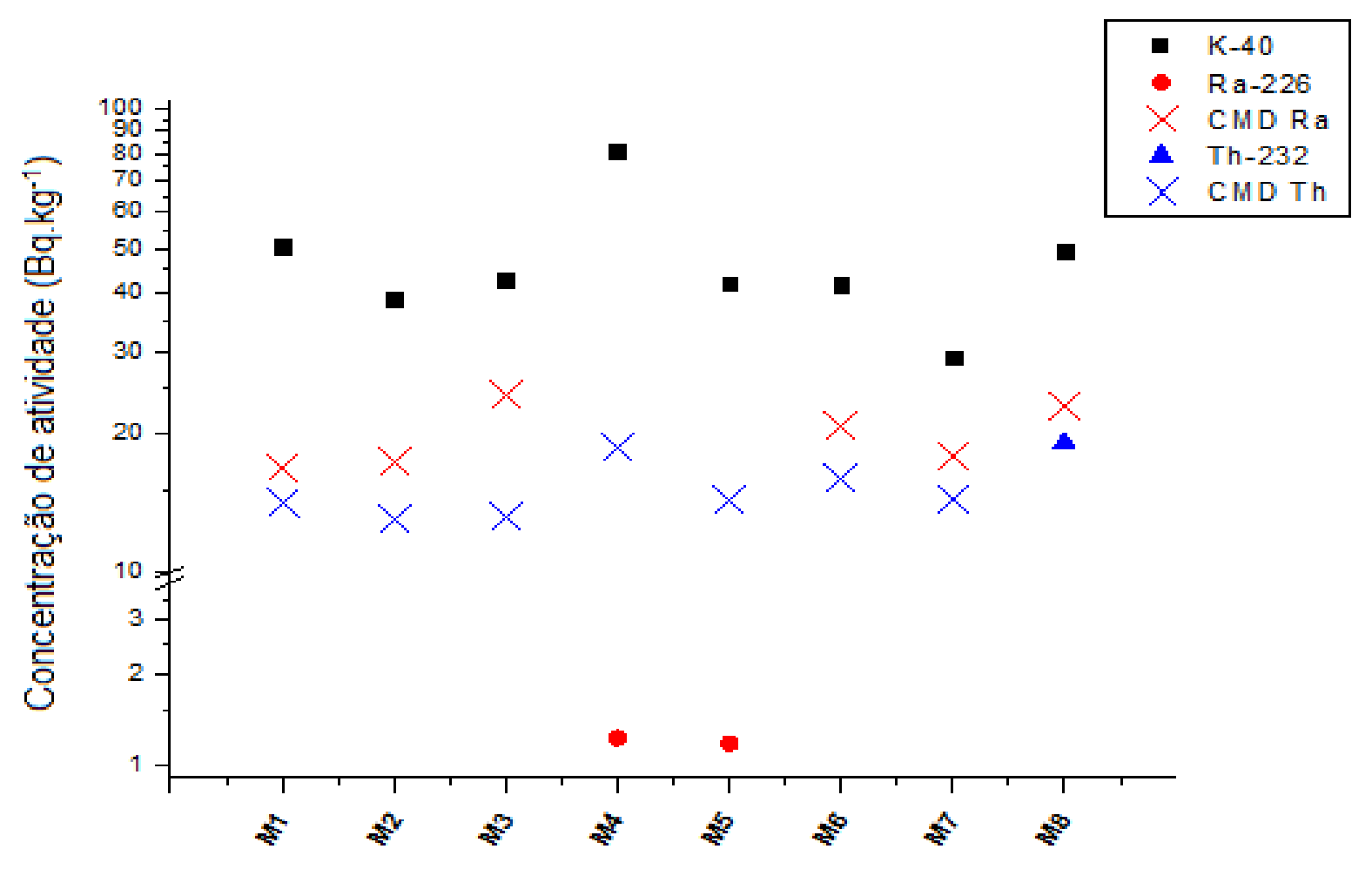

Figura 18. Concentração de atividade de ${ }^{40} \mathrm{~K},{ }^{226} \mathrm{Ra}$ e ${ }^{232} \mathrm{Th}$ para as farinhas de soja.

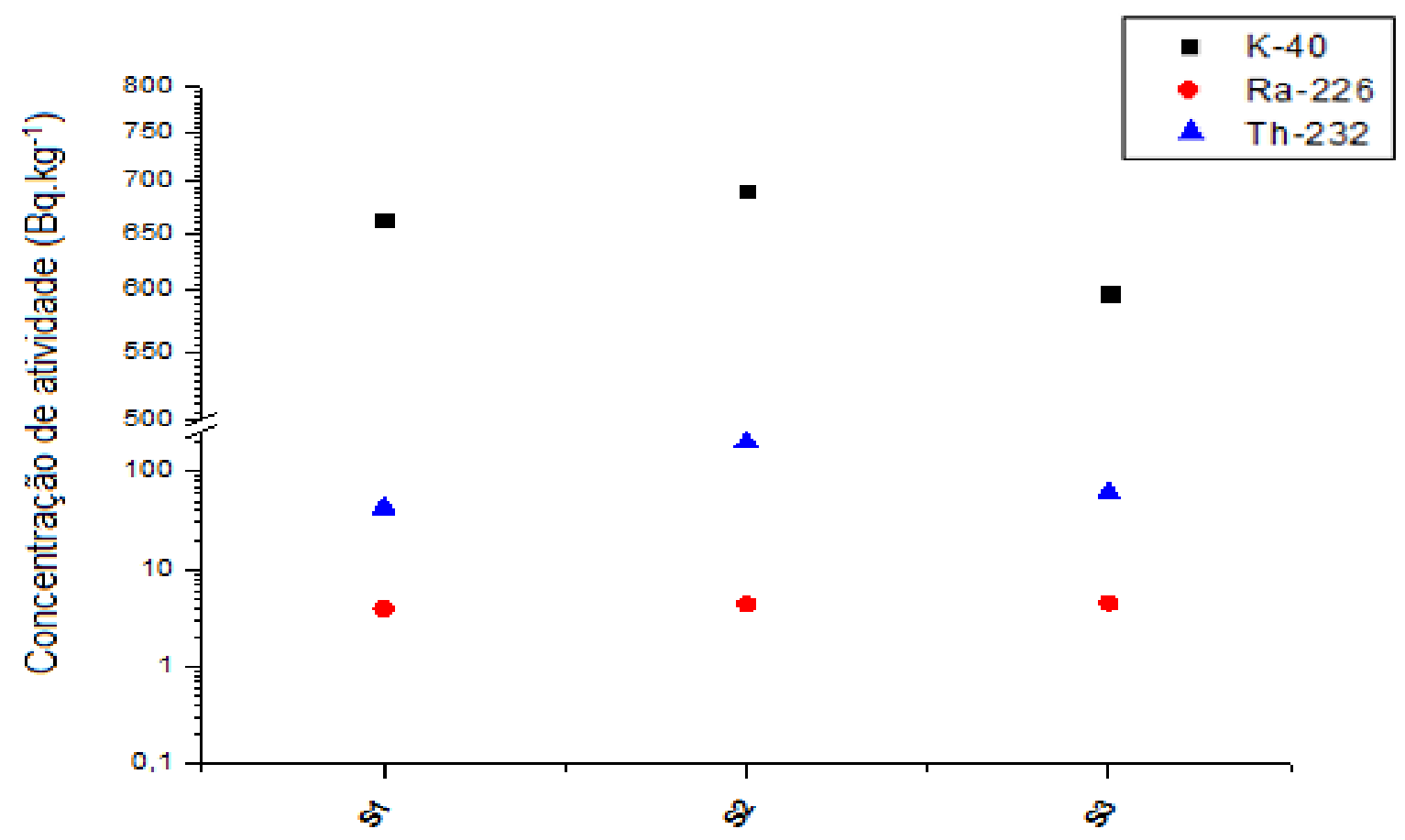


Figura 19. Concentração de atividade e concentração mínima detectável de ${ }^{40} \mathrm{~K}$, ${ }^{226} \mathrm{Ra}$ e ${ }^{232} \mathrm{Th}$ para as farinhas de mandioca.

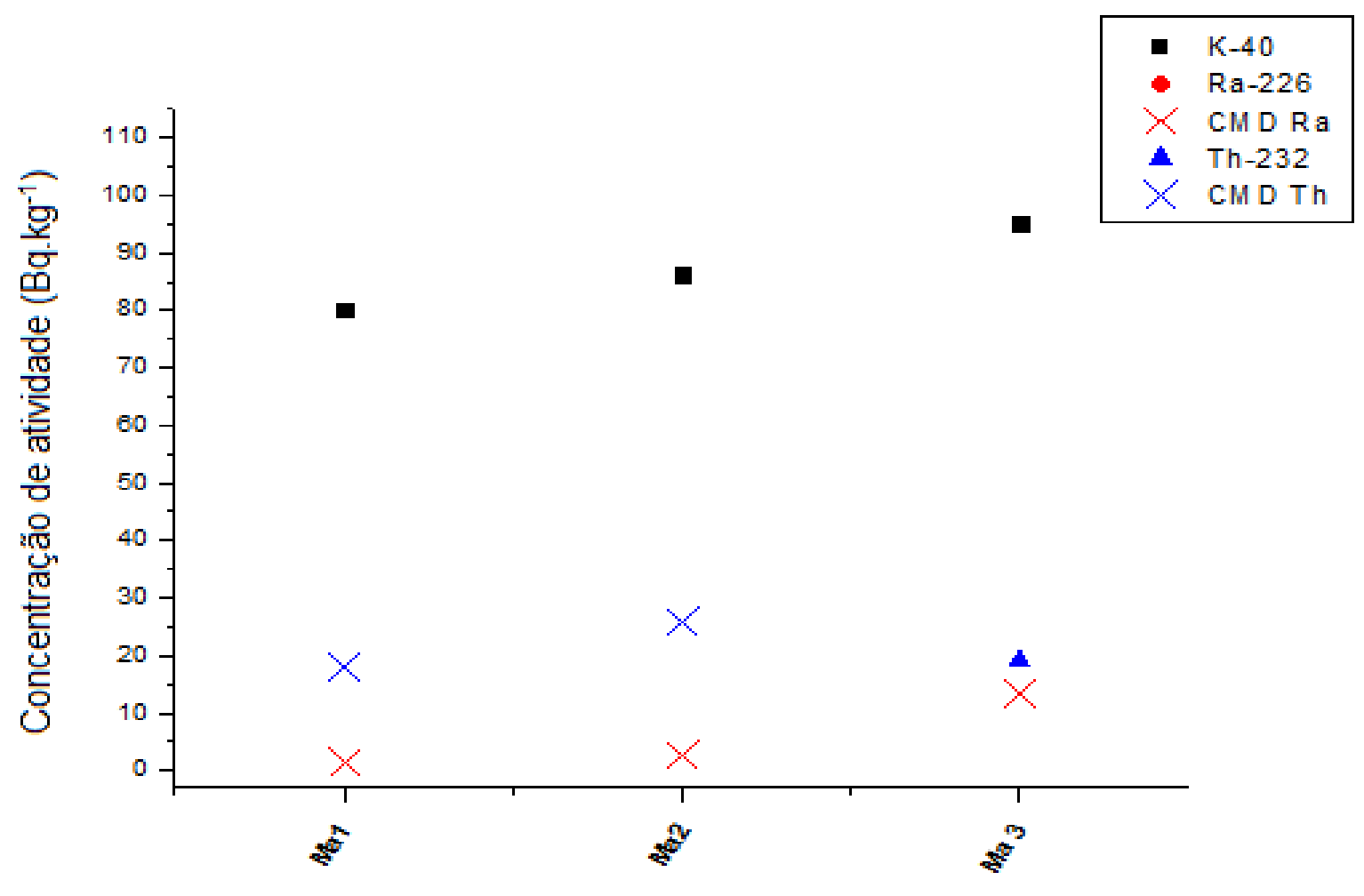

Figura 20. Concentração de atividade e concentração mínima detectável de ${ }^{40} \mathrm{~K}$, ${ }^{226} \mathrm{Ra}$ e ${ }^{232} \mathrm{Th}$ para as farinhas de arroz.

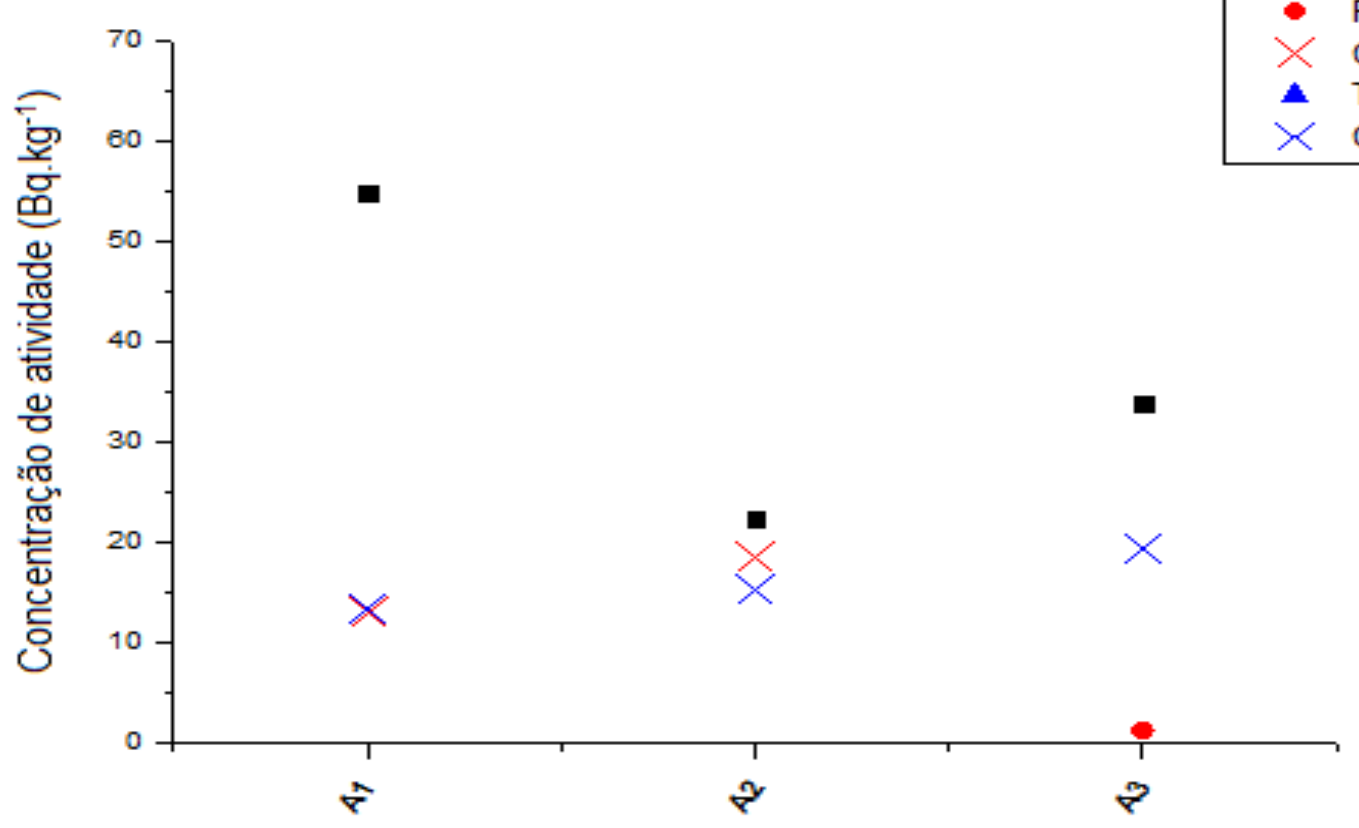

- K-40

- Ra-226 CMD Ra

Th-232 CMD Th 
Figura 21. Concentração de atividade e concentração mínima detectável de ${ }^{40} \mathrm{~K}$, ${ }^{226} \mathrm{Ra}$ e ${ }^{232} \mathrm{Th}$ para as farinhas de aveia, centeio e rosca.

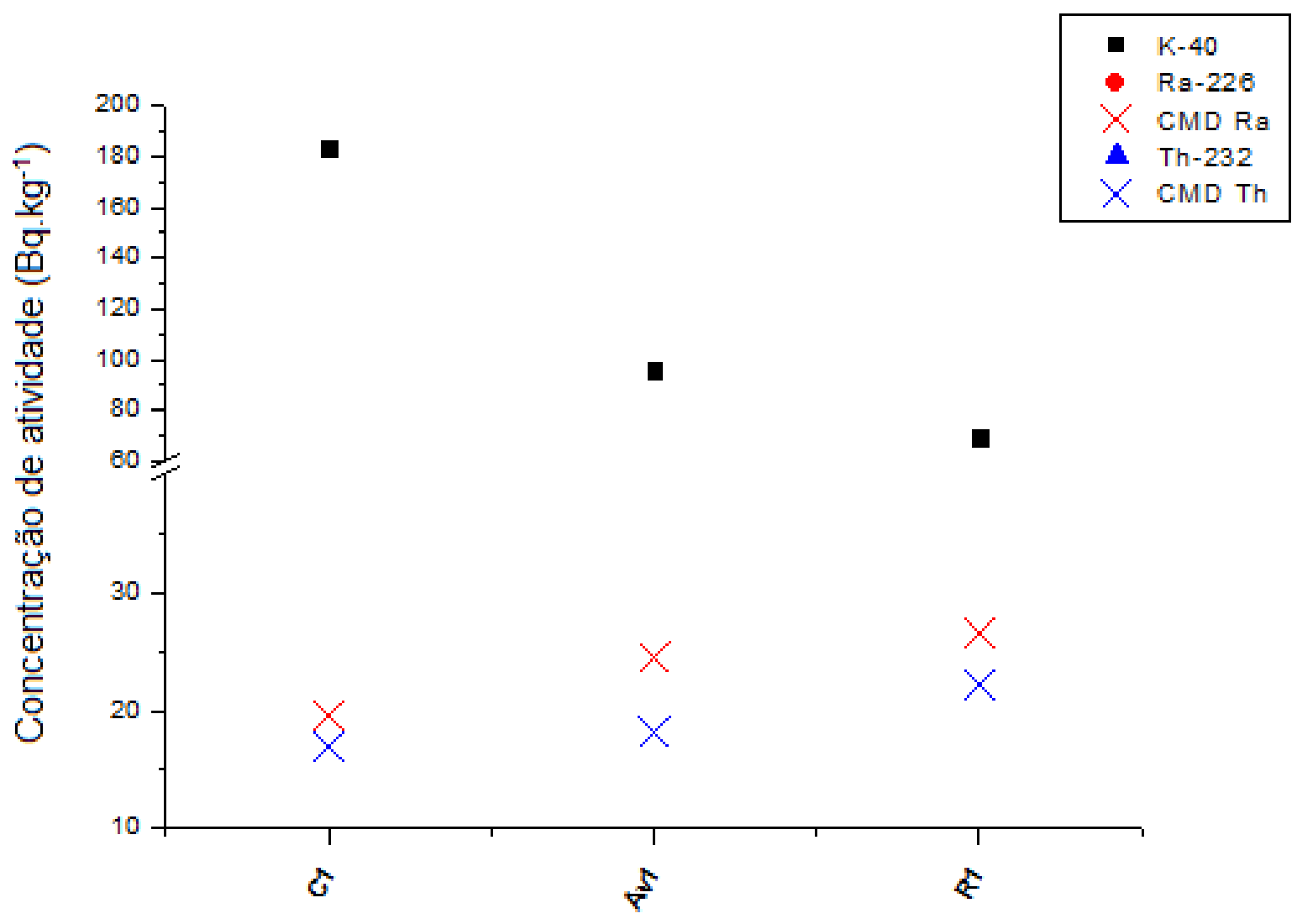

\subsection{Concentração mínima detectável dos radionuclídeos artificiais}

Para os radionuclídeos artificiais ${ }^{134} \mathrm{Cs},{ }^{137} \mathrm{Cs},{ }^{103} \mathrm{Ru},{ }^{106} \mathrm{Ru},{ }^{60} \mathrm{Co},{ }^{131} \mathrm{I} \mathrm{e}$ ${ }^{241} \mathrm{Am}$, em nenhuma das amostras analisadas foi encontrada concentração de atividade acima da concentração mínima detectável. Os valores das concentrações mínimas detectáveis foram utilizados para estimar a dose efetiva por ingestão para os radionuclídeos artificiais. As Figuras, 22, 23, 24, 25, 26 e 27 apresentam as concentrações mínimas detectáveis para as farinhas de trigo, milho, soja, mandioca, arroz, centeio, rosca e aveia, respectivamente.

O limite recomendado de concentração de atividade para ${ }^{134} \mathrm{Cs},{ }^{137} \mathrm{Cs}$, ${ }^{103} \mathrm{Ru}$ e ${ }^{60} \mathrm{Co}$ é de $1000 \mathrm{~Bq} \cdot \mathrm{kg}^{-1}$. Para o ${ }^{106} \mathrm{Ru}$ e ${ }^{131} \mathrm{I}$, o valor recomendado é de 100 Bq. $\mathrm{kg}^{-1}$ e para o ${ }^{241} \mathrm{Am}$ o valor recomendado é de $10 \mathrm{~Bq} \cdot \mathrm{kg}^{-1}$ para adultos e crianças. 
Figura 22. Concentração mínima detectável de ${ }^{134} \mathrm{Cs},{ }^{137} \mathrm{Cs},{ }^{103} \mathrm{Ru},{ }^{106} \mathrm{Ru},{ }^{60} \mathrm{Co},{ }^{131} \mathrm{I}$ e ${ }^{241} \mathrm{Am}$ para as farinhas de trigo.

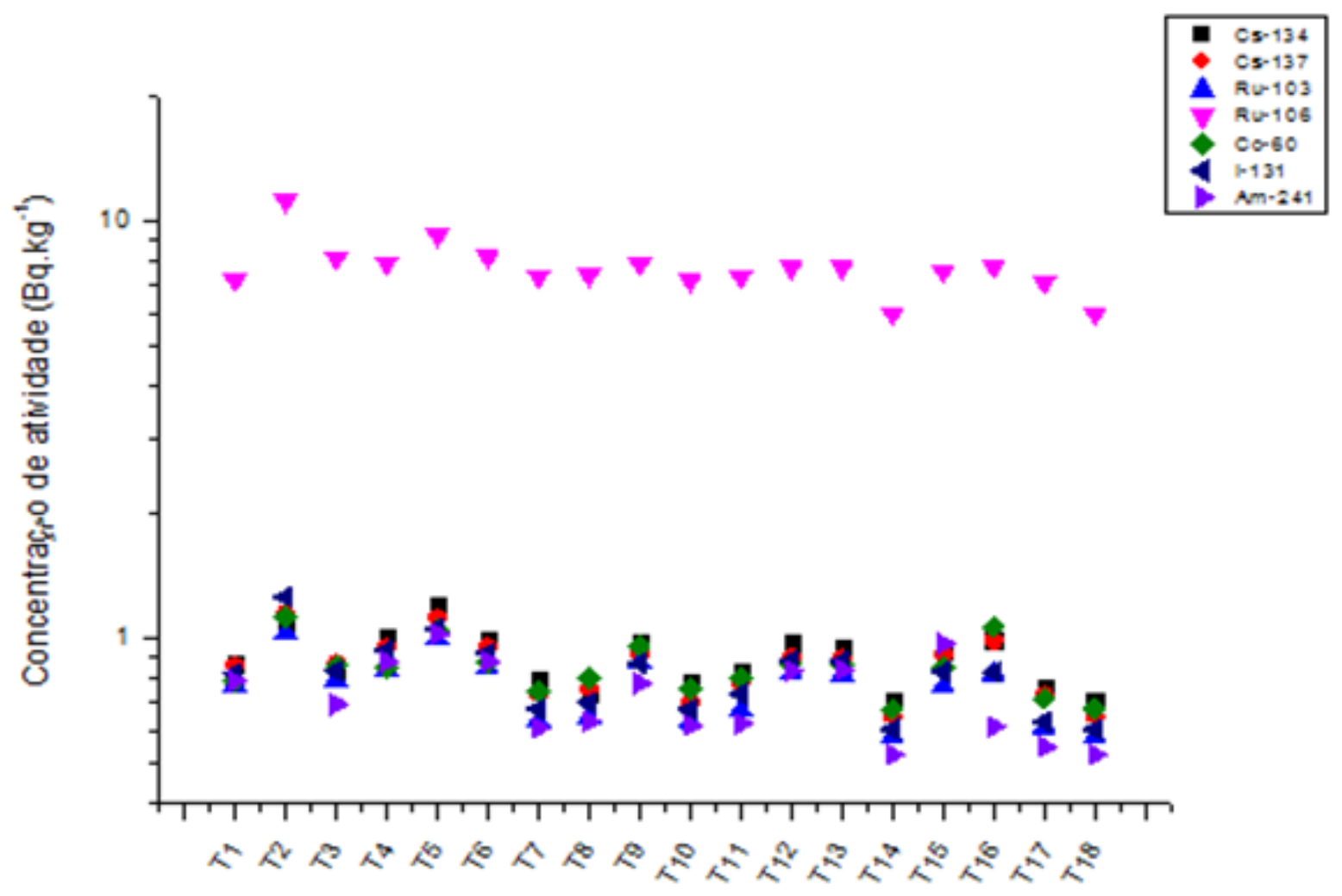

Figura 23. Concentração mínima detectável de ${ }^{134} \mathrm{Cs},{ }^{137} \mathrm{Cs},{ }^{103} \mathrm{Ru},{ }^{106} \mathrm{Ru},{ }^{60} \mathrm{Co},{ }^{131} \mathrm{I}$ e ${ }^{241} \mathrm{Am}$ para as farinhas de milho.

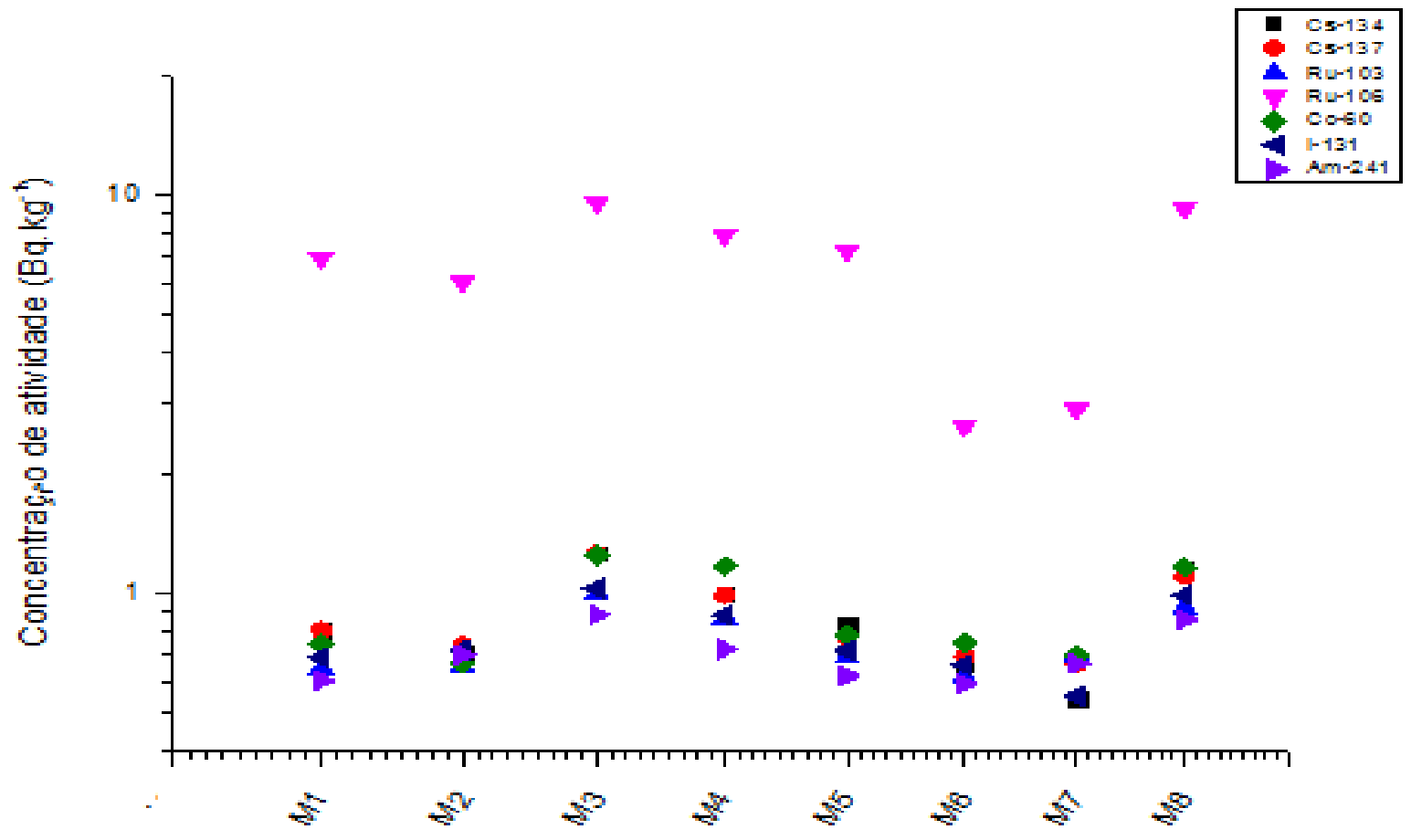


Figura 24. Concentração mínima detectável de ${ }^{134} \mathrm{Cs},{ }^{137} \mathrm{Cs},{ }^{103} \mathrm{Ru},{ }^{106} \mathrm{Ru},{ }^{60} \mathrm{Co},{ }^{131} \mathrm{I}$ e ${ }^{241} \mathrm{Am}$ para as farinhas de soja.

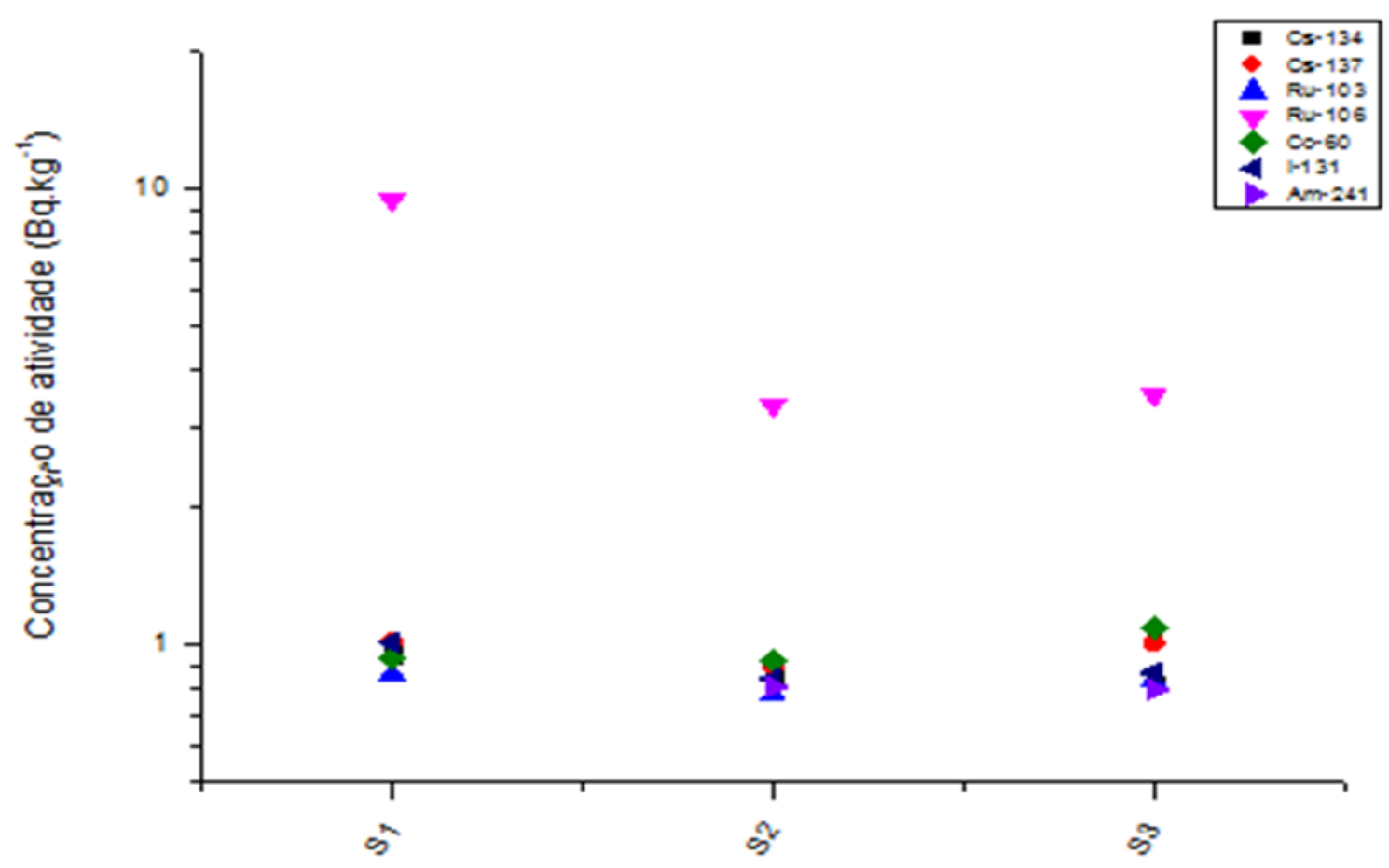

Figura 25. Concentração mínima detectável de ${ }^{134} \mathrm{Cs},{ }^{137} \mathrm{Cs},{ }^{103} \mathrm{Ru},{ }^{106} \mathrm{Ru},{ }^{60} \mathrm{Co},{ }^{131} \mathrm{I}$ e ${ }^{241} \mathrm{Am}$ para as farinhas de mandioca.

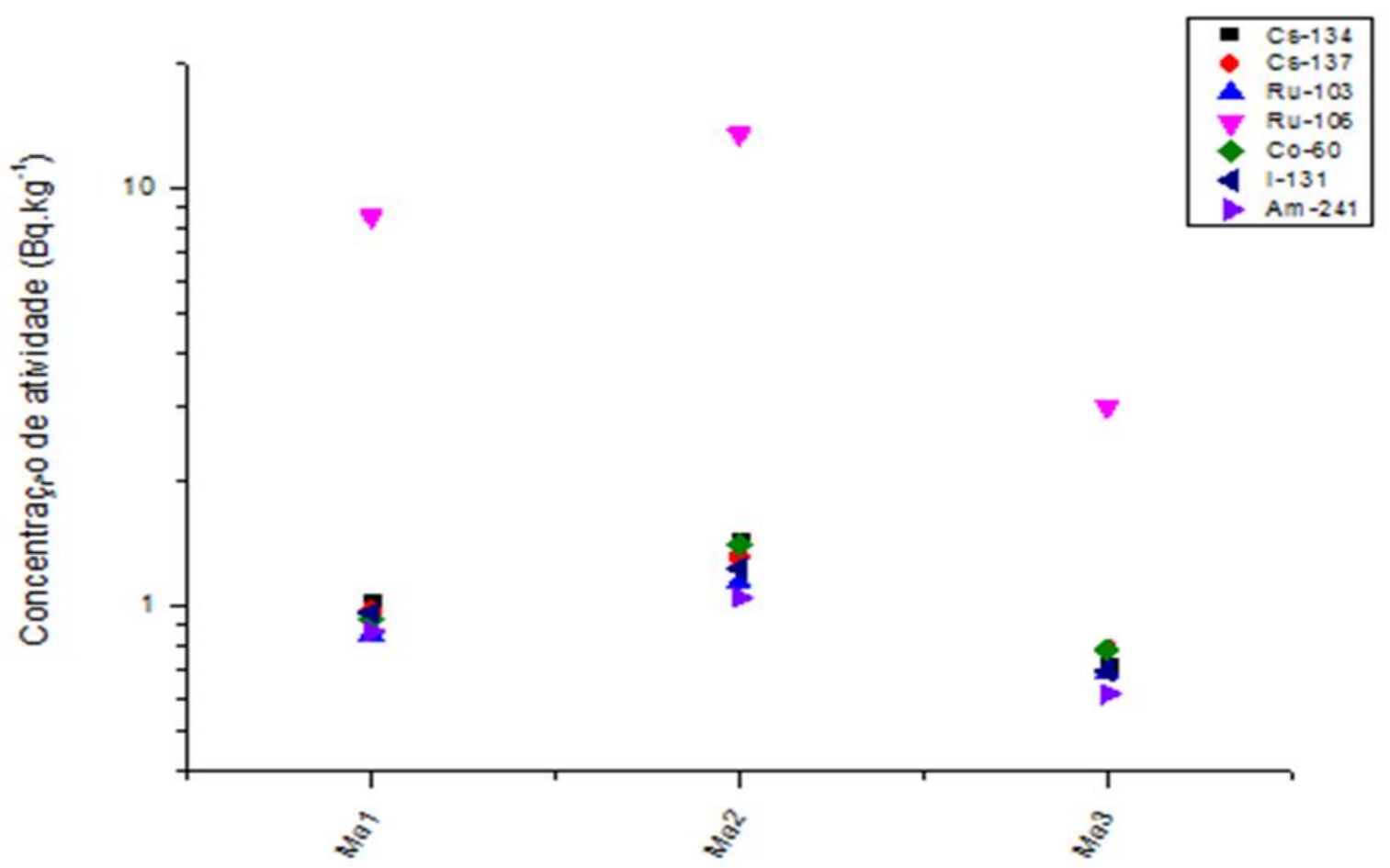


Figura 26. Concentração mínima detectável de ${ }^{134} \mathrm{Cs},{ }^{137} \mathrm{Cs},{ }^{103} \mathrm{Ru},{ }^{106} \mathrm{Ru},{ }^{60} \mathrm{Co},{ }^{131} \mathrm{I} \mathrm{e}$ ${ }^{241} \mathrm{Am}$ para as farinhas de arroz.

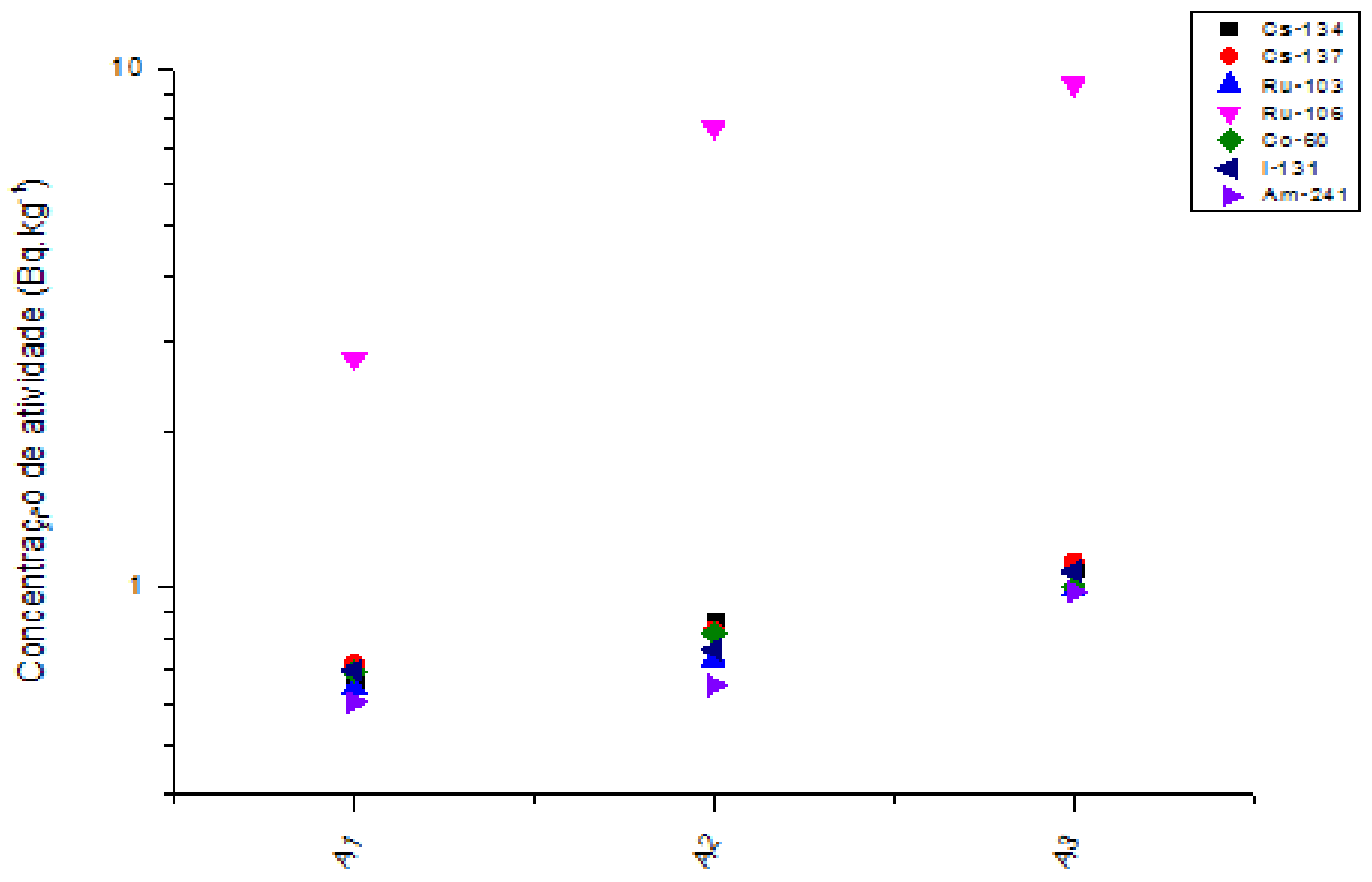

Figura 27. Concentração mínima detectável de ${ }^{134} \mathrm{Cs},{ }^{137} \mathrm{Cs},{ }^{103} \mathrm{Ru},{ }^{106} \mathrm{Ru},{ }^{60} \mathrm{Co},{ }^{131} \mathrm{I} \mathrm{e}$ ${ }^{241} \mathrm{Am}$ para as farinhas de aveia, centeio e rosca.

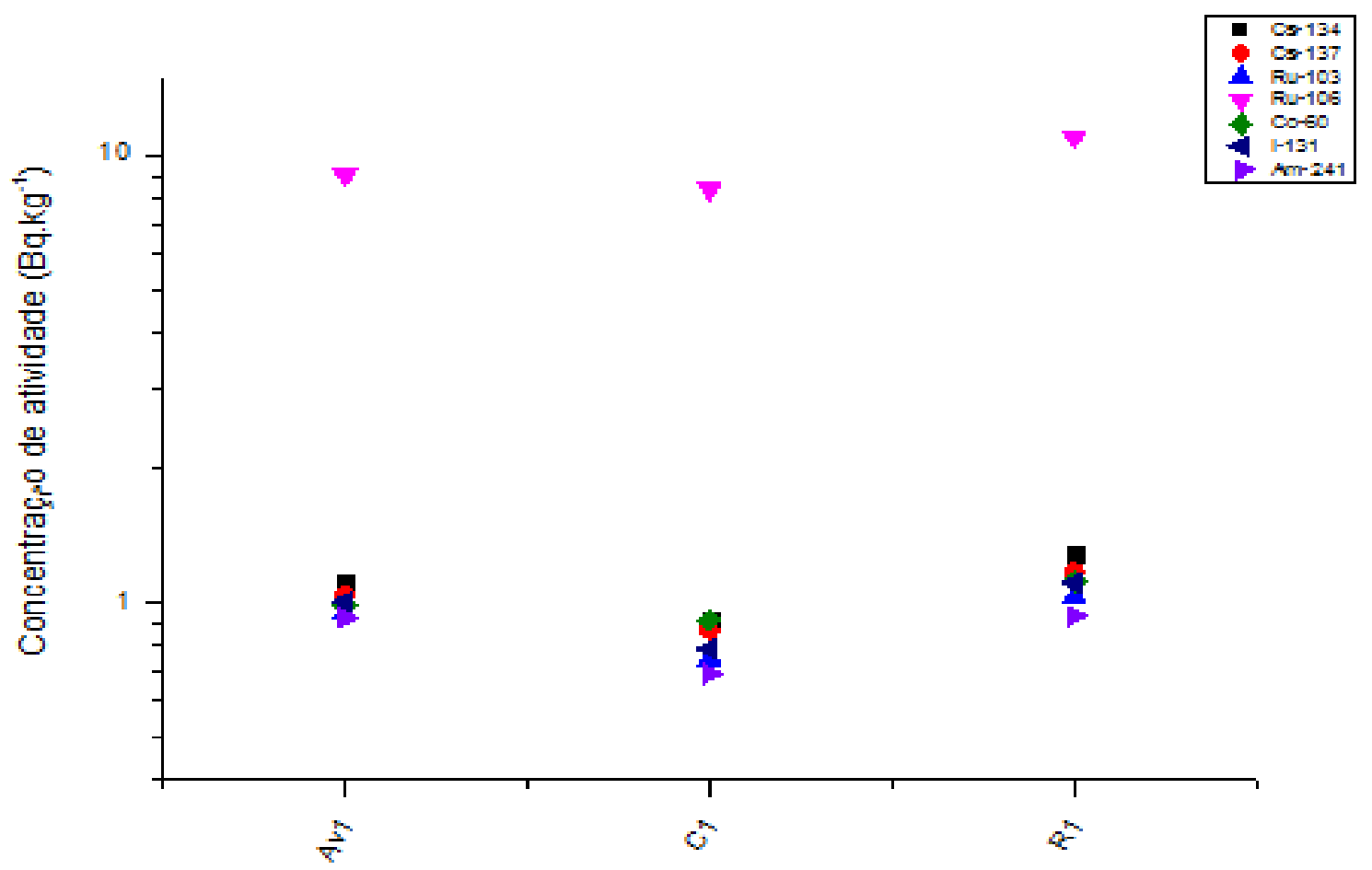




\subsection{Dose Efetiva}

\subsubsection{Dose efetiva para radionuclídeos naturais}

A dose efetiva foi calculada segundo a equação 5 do item 3.7, utilizando os valores de concentração de atividade obtidas com as análises e, quando isso não foi possível, foram utilizadas as concentrações mínimas detectáveis (CMD) para o cálculo da dose para indivíduos do público adultos e público infantil.

\subsubsection{Dose efetiva para indivíduos do público adulto}

Os valores de dose efetiva para indivíduos do público adulto são apresentados na Figura 28.

Figura 28. Valores de dose efetiva obtidos utilizando as concentrações de atividade e as concentrações mínimas detectáveis para as amostras de trigo (T), milho (M), $\operatorname{arroz}(A)$, mandioca $(M a)$, soja $(S)$, aveia $(A v)$, centeio $(C)$ e rosca $(R)$, para público adulto.

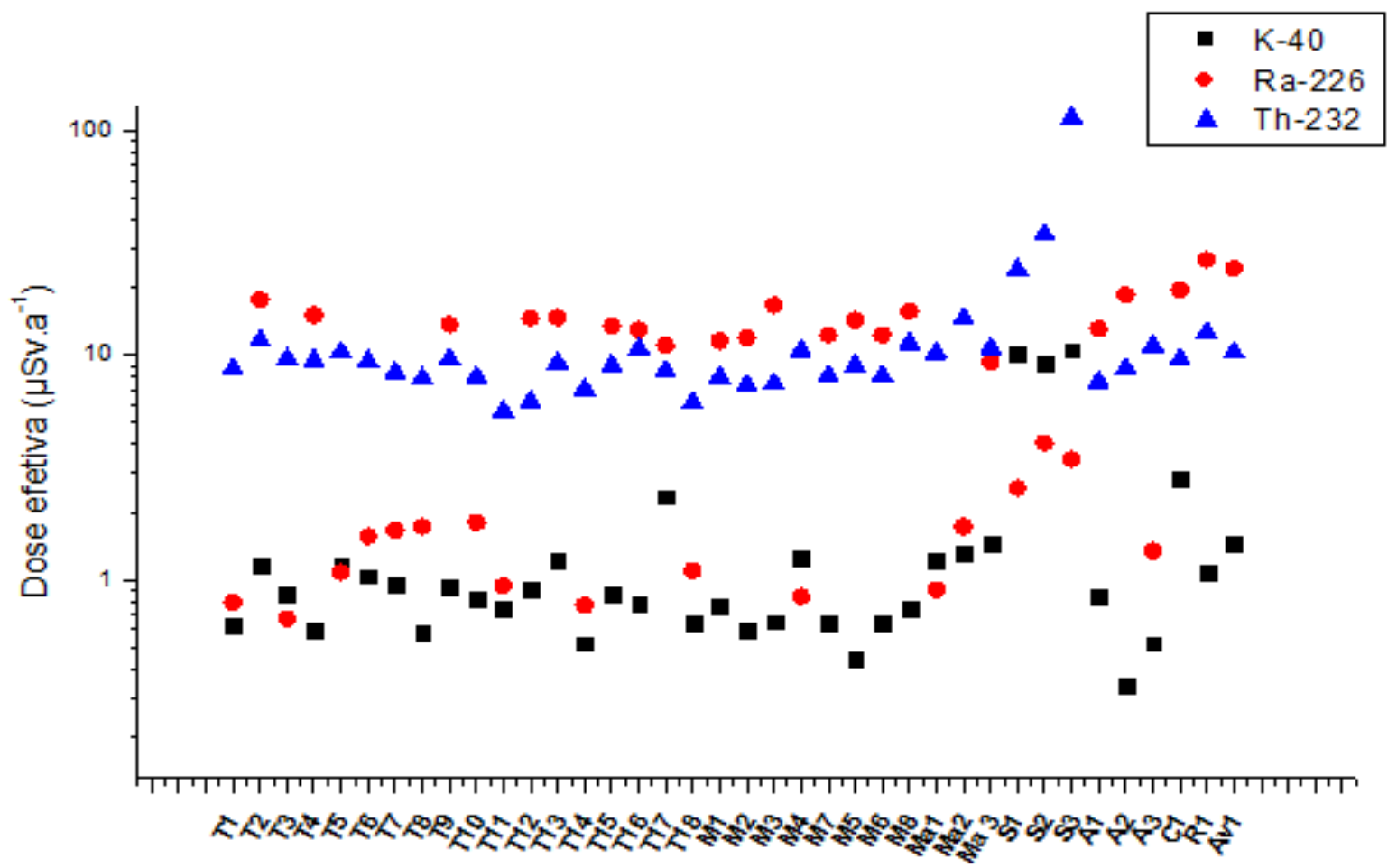


Os intervalos dos valores obtidos são apresentados na Tabela 13.

Tabela 13. Faixa de valores de dose efetiva calculada para ${ }^{40} \mathrm{~K},{ }^{226} \mathrm{Ra}$ e ${ }^{232} \mathrm{Th}$ para público adulto.

\begin{tabular}{|c|c|c|c|c|c|c|c|c|c|}
\hline \multicolumn{10}{|c|}{ Dose efetiva } \\
\hline & \multicolumn{9}{|c|}{$\mu S v \cdot a^{-1}$} \\
\hline & \multicolumn{3}{|c|}{${ }^{40} \mathrm{~K}$} & \multicolumn{3}{|c|}{${ }^{226} \mathrm{Ra}$} & \multicolumn{3}{|c|}{${ }^{232} \mathrm{Th}$} \\
\hline Trigo & 0,5 & - & 2,3 & 0,6 & - & 17,6 & 5,6 & - & 11,6 \\
\hline Milho & 0,4 & - & 1,2 & 0,8 & - & 16,7 & 7,3 & - & 11,3 \\
\hline Arroz & 0,3 & - & 0,8 & 0,9 & - & 12,8 & 7,6 & - & 10,9 \\
\hline Mandioca & 1,2 & - & 1,4 & 0,9 & - & 9,3 & 10,2 & - & 10,7 \\
\hline Soja & 9,1 & - & 10,5 & 2,5 & - & 4,1 & 24 & - & 114 \\
\hline Aveia & \multicolumn{3}{|c|}{1,4} & \multicolumn{3}{|c|}{16,8} & \multicolumn{3}{|c|}{10,3} \\
\hline Centeio & \multicolumn{3}{|c|}{2,8} & \multicolumn{3}{|c|}{13,5} & \multicolumn{3}{|c|}{9,5} \\
\hline Rosca & \multicolumn{3}{|c|}{1,1} & \multicolumn{3}{|c|}{18,3} & \multicolumn{3}{|c|}{12,5} \\
\hline
\end{tabular}

A dose efetiva por ingestão recomendados pela IAEA e UNSCEAR para público infantil e adulto são de 0,11 mSv. $\mathrm{a}^{-1}$ e 0,20 $\mathrm{mSv}^{-\mathrm{a}^{-1}}$, respectivamente, e de 140 $\mu$ Sv. $a^{-1}$ segundo a UNSCEAR (IAEA, 2016, UNSCEAR, 2000).

Os valores mais elevados de dose efetiva foram obtidos para as farinhas de soja, centeio e mandioca, seguido pelas farinhas de rosca e aveia. As farinhas de e milho apresentaram os menores valores de dose efetiva por ingestão para público adulto.

Os valores de dose efetiva obtidos para os radionuclídeos ${ }^{40} \mathrm{~K}$ e ${ }^{226} \mathrm{Ra}$ são bem próximos, mesmo conhecendo que as concentrações de atividade para o ${ }^{40} \mathrm{~K}$ são mais elevados, deve-se considerar a toxicidade do radionuclídeo e seu comportamento químico, com isso os valores aproximados deve-se ao coeficiente de conversão de dose para o radionuclídeo ${ }^{226} \mathrm{Ra}$ que pondera esses fatores, tento um peso maior e consequentemente um valor de dose efetiva mais elevado, diferentemente do ${ }^{40} \mathrm{~K}$ que é um elemento essencial no controle homeostático dos seres humanos. 


\subsubsection{Dose efetiva para indivíduos do público infantil}

Os valores de dose efetiva para indivíduos do público infantil são apresentados na Figura 29.

Figura 29. Valores de dose efetiva obtidos utilizando as concentrações de atividade e as concentrações mínimas detectáveis para as amostras de trigo (T), milho (M), arroz $(A)$, mandioca $(\mathrm{Ma})$, soja $(\mathrm{S})$, aveia $(\mathrm{Av})$, centeio $(\mathrm{C})$ e rosca $(\mathrm{R})$, para público infantil.

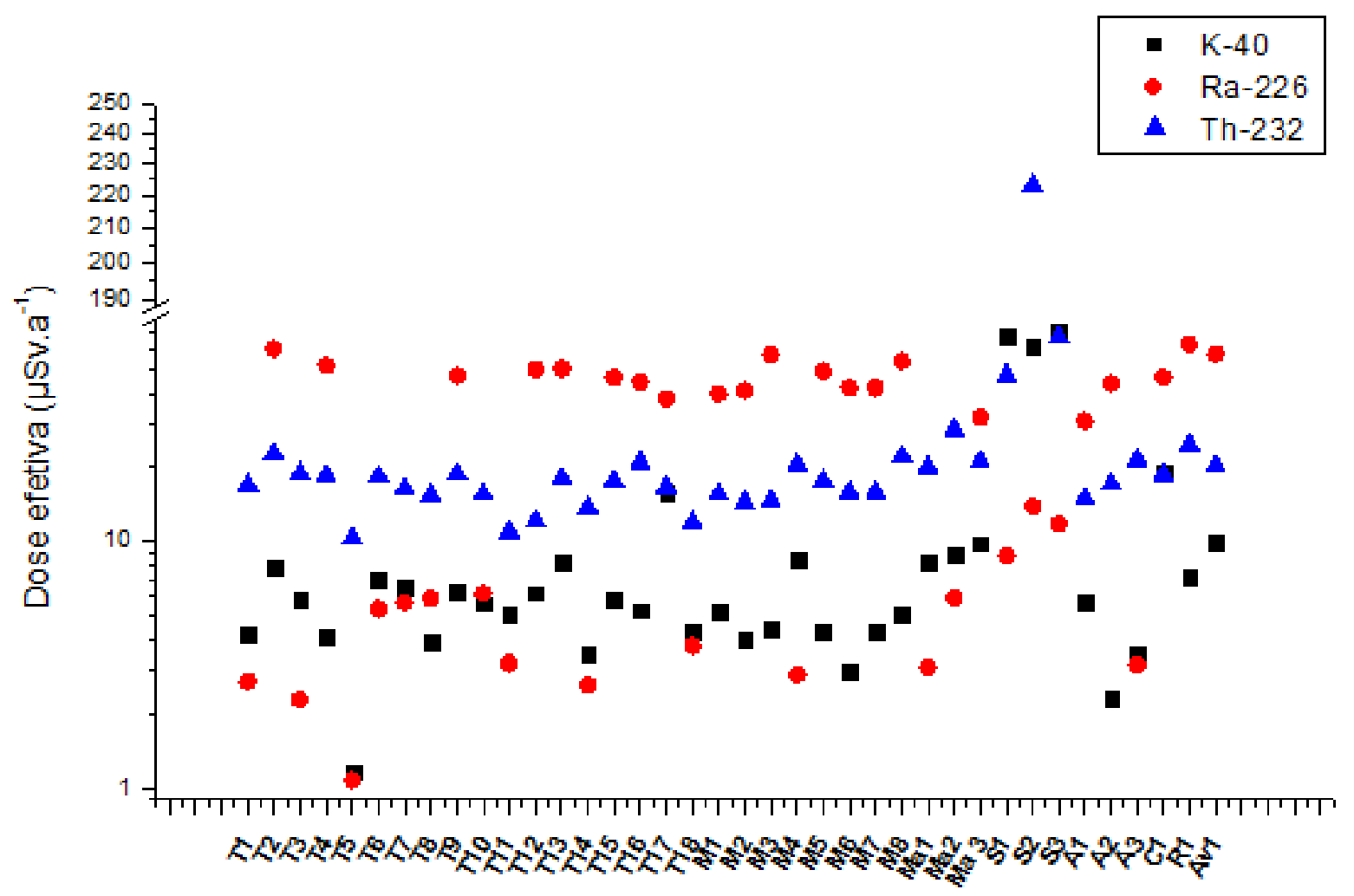

Os intervalos dos valores obtidos são apresentados na Tabela 14. 
Tabela 14. Faixa de valores de dose efetiva calculada para ${ }^{40} \mathrm{~K},{ }^{226} \mathrm{Ra}$ e ${ }^{232} \mathrm{Th}$ para público infantil.

\begin{tabular}{|c|c|c|c|c|c|c|c|c|c|}
\hline \multicolumn{10}{|c|}{ Dose efetiva } \\
\hline & \multicolumn{9}{|c|}{$\mu S v \cdot a^{-1}$} \\
\hline & \multicolumn{3}{|c|}{${ }^{40} \mathrm{~K}$} & \multicolumn{3}{|c|}{${ }^{226} \mathrm{Ra}$} & \multicolumn{3}{|c|}{${ }^{232} \mathrm{Th}$} \\
\hline Trigo & 1,1 & - & 15,8 & 1,1 & - & 60,5 & 10,3 & - & 22,7 \\
\hline Milho & 3,1 & - & 8,4 & 2,8 & - & 57,2 & 14,4 & - & 22,1 \\
\hline Arroz & 2,3 & - & 5,6 & 3,1 & - & 43,9 & 14,9 & - & 21,5 \\
\hline Mandioca & 0,00 & - & 9,8 & 0,00 & - & 31,9 & 0,00 & - & 28,5 \\
\hline Soja & 9,8 & - & 71,5 & 8,7 & - & 13,9 & 47,0 & - & 223 \\
\hline Aveia & \multicolumn{3}{|c|}{9,9} & \multicolumn{3}{|c|}{57,7} & \multicolumn{3}{|c|}{20,1} \\
\hline Centeio & \multicolumn{3}{|c|}{18,9} & \multicolumn{3}{|c|}{46,3} & \multicolumn{3}{|c|}{18,7} \\
\hline Rosca & \multicolumn{3}{|c|}{7,2} & \multicolumn{3}{|c|}{62,9} & \multicolumn{3}{|c|}{24,6} \\
\hline
\end{tabular}

Os valores de dose efetiva calculada para o público infantil para 0 radionuclídeo ${ }^{40} \mathrm{~K}$ ficaram entre $15,89 \mu \mathrm{Sv} . \mathrm{a}^{-1}$ para a farinha de trigo e $71,5 \mu \mathrm{Sv} . \mathrm{a}^{-1}$ para farinha de soja.

Os valores mais elevados de dose efetiva dentre as farinhas analisadas para o radionuclídeo ${ }^{40} \mathrm{~K}$ foram para as farinhas de trigo, soja e centeio.

Os valores de dose efetiva calculada para o público infantil para o radionuclídeo ${ }^{226} \mathrm{Ra}$ ficaram entre $13,9 \mu \mathrm{Sv} . \mathrm{a}^{-1}$ para a farinha de soja e $62,9 \mu \mathrm{Sv} . \mathrm{a}^{-1}$ para farinha de rosca.

Os valores mais elevados de dose efetiva dentre as farinhas analisadas para o radionuclídeo ${ }^{226} \mathrm{Ra}$ foram para as farinhas de trigo, milho, aveia e rosca.

Os valores de dose efetiva calculada para o público infantil para 0 radionuclídeo ${ }^{232}$ Th ficaram entre $18,7 \mu \mathrm{Sv} . \mathrm{a}^{-1}$ para a farinha de centeio e $223 \mu \mathrm{Sv} . \mathrm{a}^{-1}$ para farinha de soja. 


\subsubsection{Dose efetiva para radionuclídeos artificiais}

A dose efetiva foi calculada segundo a equação 4 do item 3.7, utilizando os valores de concentrações mínimas detectáveis (CMD) para o cálculo da dose para indivíduos do público adultos e público infantil.

\subsubsection{Dose efetiva para indivíduos do público adulto}

Os valores de dose efetiva para os radionuclídeos artificiais para indivíduos do público adulto são apresentados na Figura 30.

Figura 30. Valores de dose efetiva obtidos utilizando as concentrações mínimas detectáveis para as amostras de trigo $(\mathrm{T})$, milho $(\mathrm{M})$, arroz $(\mathrm{A})$, mandioca $(\mathrm{Ma})$, soja $(S)$, aveia $(A v)$, centeio $(C)$ e rosca $(R)$, para público adulto.

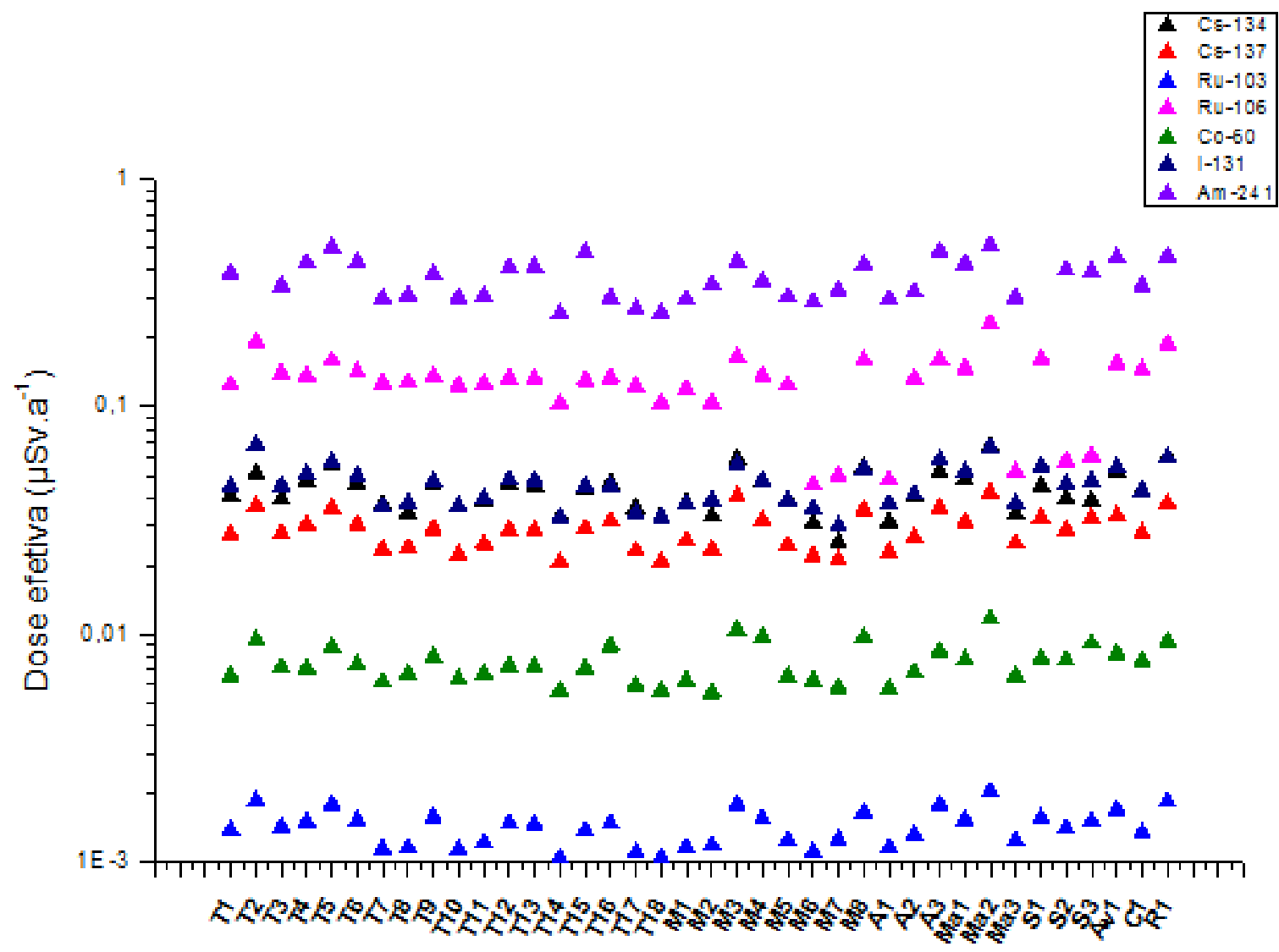


Os valores de dose efetiva recomendados para público adulto pela ingestão de alimentos contendo radionuclídeos artificiais são de ${ }^{134} \mathrm{Cs} 1 \mathrm{mSv} \cdot \mathrm{a}^{-1}, 0,7 \mathrm{mSv} \cdot \mathrm{a}^{-1}$, 0,04 mSv. $\mathrm{a}^{-1}, 0,04 \mathrm{mSv} \cdot \mathrm{a}^{-1}, 0,2 \mathrm{mSv} \cdot \mathrm{a}^{-1}, 0,1 \mathrm{mSv} \cdot \mathrm{a}^{-1}$, e $0,1 \mathrm{mSv} \cdot \mathrm{a}^{-1}$, para os radionuclídeos, ${ }^{134} \mathrm{Cs},{ }^{137} \mathrm{Cs},{ }^{103} \mathrm{Ru},{ }^{106} \mathrm{Ru},{ }^{60} \mathrm{Co},{ }^{131} \mathrm{I}$ e ${ }^{241} \mathrm{Am}$, respectivamente (CODEX, 2009).

Para $0{ }^{134} \mathrm{Cs}$ os valores de dose efetiva ficaram entre $0,025 \mu \mathrm{Sv} \cdot \mathrm{a}^{-1} \mathrm{e}$ $0,067 \mu \mathrm{Sv} \cdot \mathrm{a}^{-1}$, para ${ }^{137} \mathrm{Cs}$ os valores obtidos ficaram entre $0,021 \mu \mathrm{Sv} \cdot \mathrm{a}^{-1}$ e 0,042 $\mu S v \cdot a^{-1}$, o ${ }^{106} \mathrm{Ru}$ apresentou valores entre $0,045 \mu \mathrm{Sv} \cdot \mathrm{a}^{-1}$ e $0,194 \mu \mathrm{Sv} \cdot \mathrm{a}^{-1},{ }^{103} \mathrm{Ru}$ os valores ficaram entre $0,0010 \mu \mathrm{Sv} . \mathrm{a}^{-1}$ e $0,0020 \mu \mathrm{Sv}^{-a^{-1}}$, os valores obtidos para o ${ }^{60} \mathrm{Co}$ ficaram entre $0,0056 \mu S v \cdot a^{-1}$ e $0,0117 \mu S v \cdot a^{-1}$, para o ${ }^{131}$ I os valores foram de 0,030 $\mu S v \cdot a^{-1}$ e $0,068 \mu S v . a^{-1}, o^{241} \mathrm{Am}$ os valores ficaram entre $0,258 \mu S v \cdot a^{-1}$ e $0,514 \mu S v . a-$ 1. Dentre os radionuclídeos artificiais o valor de dose efetiva mais elevado foi de 0,514 $\mu \mathrm{Sv} . \mathrm{a}^{-1}$ do ${ }^{241} \mathrm{Am}$ para a farinha de mandioca.

Os valores de dose efetiva para os radionuclídeos artificiais ficaram entre $0,0010 \mu \mathrm{Sv} \cdot \mathrm{a}^{-1}$ e $0,514 \mu \mathrm{Sv} \cdot \mathrm{a}^{-1}$ para as farinhas de trigo e mandioca, respectivamente.

Os valores médios obtidos para os radionuclídeos ${ }^{134} \mathrm{Cs},{ }^{137} \mathrm{Cs},{ }^{106} \mathrm{Ru}$, ${ }^{103} \mathrm{Ru},{ }^{60} \mathrm{Co},{ }^{131} \mathrm{I}$ e ${ }^{241} \mathrm{Am}$, foram de 0,043 $\mu \mathrm{Sv} \cdot \mathrm{a}^{-1}, 0,029 \mu \mathrm{Sv} \cdot \mathrm{a}^{-1}, 0,128 \mu \mathrm{Sv} \cdot \mathrm{a}^{-1}$, $0,0014 \mu S v \cdot a^{-1}, 0,0075 \mu S v \cdot a^{-1}, 0,046 \mu S v \cdot a^{-1}$ e $0,349 \mu S v \cdot a^{-1}$, respectivamente.

\subsubsection{Dose efetiva para indivíduos do público infantil}

Os valores de dose efetiva para indivíduos do público infantil são apresentados na Figura 31. 
Figura 31. Valores de dose efetiva obtidos utilizando as concentrações mínimas detectáveis para as amostras de trigo $(T)$, milho $(M)$, arroz $(A)$, mandioca $(M a)$, soja $(S)$, aveia $(A v)$, centeio $(C)$ e rosca $(R)$, para público infantil.

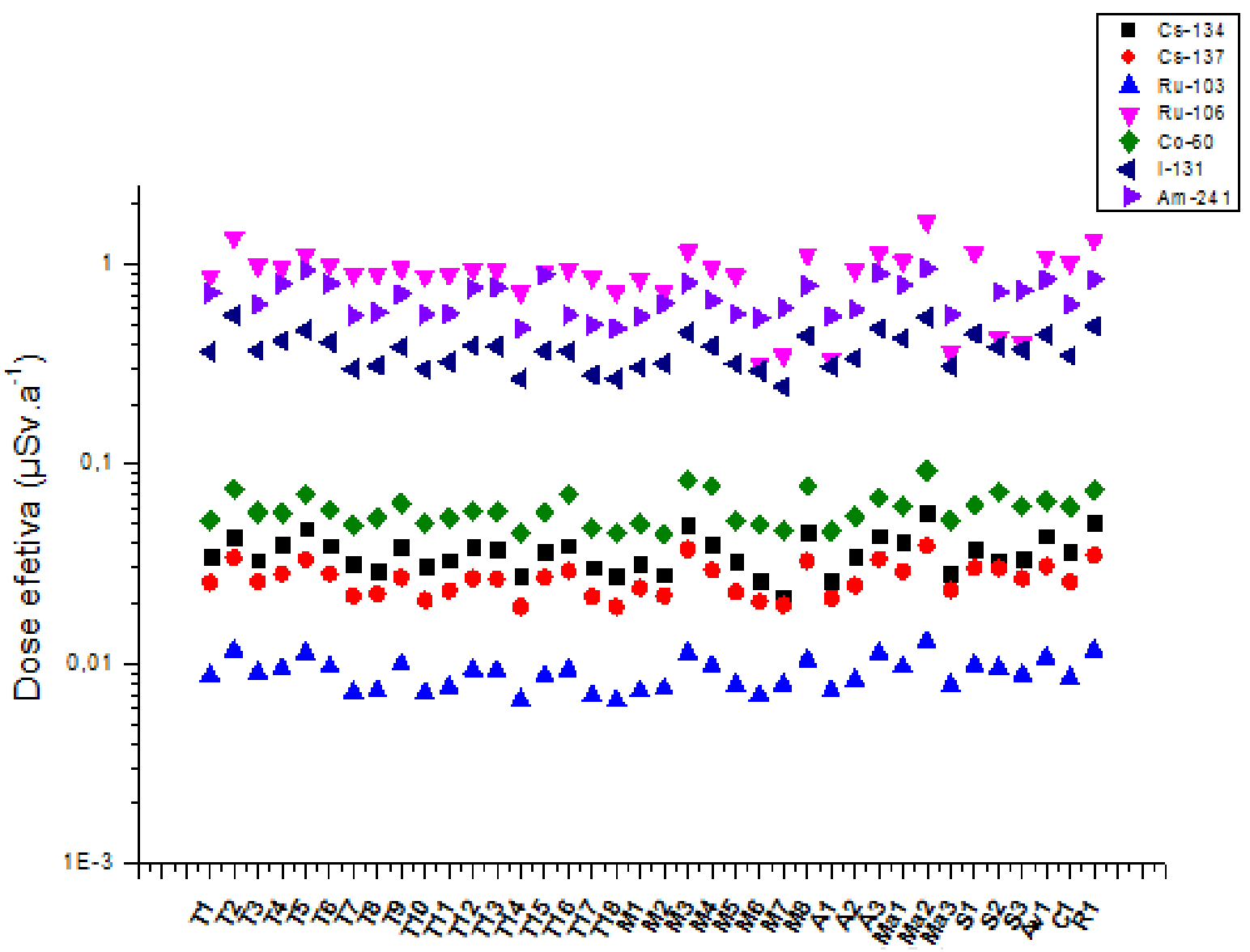

Os valores de dose efetiva recomendados para público infantil são de $0,5 \mathrm{mSv} \cdot \mathrm{a}^{-1}$ para ${ }^{134} \mathrm{Cs}, 0,4 \mathrm{mSv} \cdot \mathrm{a}^{-1}$ para ${ }^{137} \mathrm{Cs}, 0,1 \mathrm{mSv} \cdot \mathrm{a}^{-1}$ para ${ }^{103} \mathrm{Ru}, 0,2 \mathrm{mSv} \cdot \mathrm{a}^{-1}$ para ${ }^{106} \mathrm{Ru}, 0,4 \mathrm{mSv} \cdot \mathrm{a}^{-1}$ para ${ }^{60} \mathrm{Co}$, e $0,07 \mathrm{mSv} \cdot \mathrm{a}^{-1}$ para os radionuclídeos ${ }^{131} \mathrm{I}$ e ${ }^{241} \mathrm{Am}$, pela ingestão de alimentos que contenham esses radionuclídeos (CODEX, 2009).

Para o ${ }^{134} \mathrm{Cs}$ os valores de dose efetiva foi de $0,02 \mu \mathrm{Sv} \cdot \mathrm{a}^{-1}$ para a farinha de milho, e de $0,06 \mu \mathrm{Sv} \mathrm{a}^{-1}$ para farinha de mandioca, para o ${ }^{137} \mathrm{Cs}$ os valores obtidos foram de $0,09 \mu \mathrm{Sv} \cdot \mathrm{a}^{-1}$ para farinha de trigo e $0,04 \mu \mathrm{Sv} \cdot \mathrm{a}^{-1}$ para a farinha de mandioca.

$\mathrm{O}{ }^{106} \mathrm{Ru}$ apresentou valores entre $0,4 \mu \mathrm{Sv} \cdot \mathrm{a}^{-1}$ a $1,4 \mu \mathrm{Sv} \cdot \mathrm{a}^{-1}$ para as farinhas de mandioca e trigo, respectivamente. $\mathrm{O}{ }^{103} \mathrm{Ru}$ os valores ficaram entre $0,01 \mu \mathrm{Sv} \cdot \mathrm{a}^{-1}$ para farinha de trigo e de $0,01 \mu \mathrm{Sv} \cdot \mathrm{a}^{-1}$ para farinha de rosca. 
Os valores obtidos para o ${ }^{60} \mathrm{Co}$ ficaram entre $0,04 \mu \mathrm{Sv} . \mathrm{a}^{-1}$ a $0,08 \mu \mathrm{Sv} . \mathrm{a}^{-1}$, para o ${ }^{131}$ I os valores foram de $0,24 \mu S v \cdot a^{-1}$ a $0,6 \mu S v . a^{-1}$, o ${ }^{241} \mathrm{Am}$ os valores ficaram entre $0,5 \mu S v . a^{-1}$ a $0,9 \mu S v . a^{-1}$.

Dentre os radionuclídeos artificiais o valor de dose efetiva mais elevado foi de $1,4 \mu \mathrm{Sv} . \mathrm{a}^{-1}$ do ${ }^{106} \mathrm{Ru}$ para a farinha de trigo.

Os valores médios obtidos para os radionuclídeos ${ }^{134} \mathrm{Cs},{ }^{137} \mathrm{Cs},{ }^{106} \mathrm{Ru}$, ${ }^{103} \mathrm{Ru},{ }^{60} \mathrm{Co},{ }^{131} \mathrm{I}$ e ${ }^{241} \mathrm{Am}$, foram de 0,04 $\mu \mathrm{Sv} . \mathrm{a}^{-1}, 0,03 \mu \mathrm{Sv} . \mathrm{a}^{-1}, 0,01 \mu \mathrm{Sv} . \mathrm{a}^{-1}$, $0,9 \mu S v . a^{-1}, 0,1 \mu S v . a^{-1}, 0,4 \mu S v . a^{-1}$ e $0,6 \mu S v . a^{-1}$, respectivamente.

\section{DISCUSSÃO}

As variações observadas da concentração de atividade e consequentemente, a dose efetiva entre os radionuclídeos considerados e as amostras analisadas provavelmente são decorrentes dos diferentes níveis de radiação de fundo, clima e condições agrícolas em que os grãos são cultivados (EISENBUD, 1987; UNSCEAR, 2000; AROGUNJO et al., 2005; ASADUZZAMAN et al., 2014).

Os dados obtidos na literatura apresentam valores de concentração de atividade mais elevados para ${ }^{40} \mathrm{~K}$, por se tratar de um nutriente essencial para as plantas (VENTURINI, L. e SORDI, 1999; SANTOS et al., 2002b; SCHEIBEL, 2006;) justificando os valores de concentrações obtidos. Além disso, o condicionamento do solo por meio de fertilizantes pode acarretar o aumento de ${ }^{40} \mathrm{~K}$ nas plantas e isso explicaria os valores obtidos neste trabalho e verificados em estudos anteriores, principalmente para os derivados da soja (VENTURINI, L. e SORDI, 1999; SCHEIBEL, 2016). Mesmo com esse incremento, o condicionamento do solo e o uso fertilizantes não contribui significativamente nos níveis de transferência dos radionuclídeos do solo para as plantas (MAZZILLI, 2013), assim as concentrações de ${ }^{40} \mathrm{~K}$ mais elevadas poderiam ser características de mobilidade e disponibilidade desse radionuclídeo no meio ambiente (PAIVA, 2008). 
AROGUNJO (2005), obteve valores médios de concentração de atividade de $130 \pm 8,1 \mathrm{~Bq} \cdot \mathrm{kg}^{-1}$ para o ${ }^{40} \mathrm{~K}, 11,5 \pm 3,8 \mathrm{~Bq} \cdot \mathrm{kg}^{-1}$ para o ${ }^{238} \mathrm{U}$ e de $6,7 \pm 2,1 \mathrm{~Bq} \cdot \mathrm{kg}^{-1}$ para o ${ }^{232}$ Th em amostras de cereais e tubérculos, na região da Nigéria.

Outro estudo realizado na década de 1990 nessa mesma região, apresentou valores médios de concentração de atividade de $6,1 \mathrm{~Bq} \cdot \mathrm{kg}^{-1}, 6,8 \mathrm{~Bq} \cdot \mathrm{kg}^{-1} \mathrm{e}$ 11,8 Bq. kg ${ }^{-1}$ em cereais, e 5,6 Bq. kg ${ }^{-1}, 5,5$ Bq. $\mathrm{kg}^{-1}$ e 10,4 Bq. $\mathrm{kg}^{-1}$ em tubérculos, para os radionuclídeos ${ }^{238} \mathrm{U},{ }^{232} \mathrm{Th}$ e ${ }^{40} \mathrm{~K}$, respectivamente (OLOMO, 1990), no qual os valores obtidos para ${ }^{238} \mathrm{U}$ e ${ }^{232}$ Th são bem próximos aos encontrados por AROGUNJO, entretanto, os valores para o ${ }^{40} \mathrm{~K}$ são bem superiores aos valores obtidos por OLOMO (1990), e observou-se um aumento considerável na concentração de ${ }^{40} \mathrm{~K}$ nesses alimentos, esse aumento, pode ser atribuído ao uso de fertilizantes utilizado na maioria das regiões do país ao longo dos anos.

ROSA (2018) observou que na maioria dos grupos alimentares analisados, as concentrações de atividade eram superiores para o ${ }^{228} \mathrm{Ra}$ em relação ao ${ }^{226} \mathrm{Ra}$. O rádio apresenta uma elevada mobilidade no solo, se comparado ao tório. Uma vez que a química do tório no ambiente é completamente controlada pelas limitações de solubilidade e reações de sorção, este elemento encontra-se, preferencialmente, ligado à fase sólida do solo, apresentando baixa mobilidade (PAIVA, 2008; NISTI, 2016). Já seu produto de decaimento, o rádio, tem alta mobilidade nos compartimentos ambientais e grande abundância natural, consequentemente sua disponibilidade será maior que a de tório, sendo possível inferir que no processo de lixiviação, o que fica disponível na solução do solo é o rádio. Com o equilíbrio interrompido por diversos processos e especialmente pelo processo de lixiviação, o que será disponibilizado para as plantas através da solução do solo é o rádio, que absorvido pelo sistema radicular das plantas, será transferido para os grãos. Com a absorção de rádio pelos grãos, é possível inferir sua concentração de atividade pelo actínio, uma vez que ambos estão em equilíbrio. (RIBEIRO, 2004; SCHEIBEL, 2006; NISTI, 2016; ROSA, 2018; IAEA, 2019).

Em um estudo desenvolvido para avaliação da exposição interna de ${ }^{40} \mathrm{~K}$ em residentes da cidade do Rio de Janeiro, foi observado que entre os alimentos analisados, os que apresentaram maior concentração de atividade foram feijão preto, carne bovina, batata e arroz, com concentrações variando entre 20 Bq. $\mathrm{kg}^{-1}$ à 544 
Bq. $\mathrm{kg}^{-1}$ para ${ }^{40} \mathrm{~K}$ (arroz $47 \mathrm{~Bq} \cdot \mathrm{kg}^{-1}$, mandioca $56 \mathrm{~Bq} \cdot \mathrm{kg}^{-1}$, farinha de trigo $62 \mathrm{~Bq} \cdot \mathrm{kg}^{-1}$, farinha mandioca $87 \mathrm{~Bq} \cdot \mathrm{kg}^{-1}$, fubá $60 \mathrm{~Bq} \cdot \mathrm{kg}^{-1}$ ), com uma dose efetiva estimada de 138 $\mu \mathrm{Sv} \cdot \mathrm{a}^{-1}$, evidenciando que a maior contribuição para dose por ingestão é do ${ }^{40} \mathrm{~K}$ (SANTOS, et al., 2002b).

Outro estudo realizado na cidade do Rio de Janeiro, avaliou a ingestão diária de ${ }^{232} \mathrm{Th},{ }^{238} \mathrm{U},{ }^{226} \mathrm{Ra},{ }^{228} \mathrm{Ra}$ e ${ }^{210} \mathrm{Po}$, presentes em feijão, farinha de trigo, farinha de mandioca, cenoura, arroz, tomate e batata, com concentrações de atividade de 1,9 mBq. $\mathrm{kg}^{-1}, 2,0$ mBq. $\mathrm{kg}^{-1}, 19 \mathrm{mBq} \cdot \mathrm{kg}^{-1}, 26 \mathrm{mBq} \cdot \mathrm{kg}^{-1}$ e $47 \mathrm{mBq} \cdot \mathrm{kg}^{-1}$, respectivamente. A estimativa de dose efetiva decorrente da ingestão desses alimentos foi de 14,5 $\mu$ Sv.a ${ }^{-1}$ (SANTOS, et al., 2002a). A Tabela 15 apresenta os valores de concentração de atividade encontrados no presente trabalho, junto com alguns valores da literatura. 
Tabela 15. Faixas de variação e valores da concentração de atividade dos radionuclídeos naturais ${ }^{40} \mathrm{~K},{ }^{232} \mathrm{Th}$ e ${ }^{226} \mathrm{Ra}$ no presente trabalho e na literatura, no Brasil e na Nigéria. (Entre parênteses, incertezas, quando disponíveis).

\begin{tabular}{|c|c|c|c|c|c|}
\hline Região & Autor & Amostra & $40 \mathrm{~K}$ & 232Th & ${ }^{226} \mathrm{Ra}$ \\
\hline \multirow{8}{*}{ São Paulo (Brasil) } & \multirow{8}{*}{$\begin{array}{c}\text { GMSilva } \\
\text { Presente trabalho }\end{array}$} & farinha de trigo & $34[5]-153$ [17] & $10[3]-15[3]$ & $1[0,4]-2,6[0,4]$ \\
\hline & & farinha de milho & $29[4]-81[10]$ & $19[4]$ & $1,1[0,4]-1,2[0,4]$ \\
\hline & & farinha de mandioca & $80[10]-95[10]$ & $19[4]$ & N.D \\
\hline & & farinha de soja & $598[65]-663[71]$ & 42 [6] - 201 [22] & $3,9[0,3]-4,5[0,3]$ \\
\hline & & farinha de arroz & $25[4]-54[7]$ & N.D & $1,3[0,5]$ \\
\hline & & farinha de aveia & $95[11]$ & N.D & N.D \\
\hline & & farinha de centeio & $183[20]$ & N.D & N.D \\
\hline & & farinha de rosca & $69[9]$ & N.D & N.D \\
\hline Nigéria & OLOMO, 1990 & $\begin{array}{l}\text { cereais } \\
\text { tubérculos }\end{array}$ & $\begin{array}{l}11 \\
10\end{array}$ & $\begin{array}{l}6,8 \\
5,5\end{array}$ & $\begin{array}{l}\text { N.D } \\
\text { N.D }\end{array}$ \\
\hline \multirow{3}{*}{$\begin{array}{l}\text { Rio de Janeiro } \\
\text { (Brasil) }\end{array}$} & \multirow{3}{*}{$\begin{array}{c}\text { *SANTOS et al., } \\
2002^{\mathrm{a}} \\
\left({ }^{232} \mathrm{~T}^{226} \mathrm{Ra}\right) \\
\text { SANTOS, et al., } \\
2002^{\mathrm{b}} \\
\left({ }^{40 \mathrm{~K})}\right. \\
\text { (todas as amostras } \\
\text { úmidas) }\end{array}$} & $\begin{array}{c}\text { arroz } \\
\text { farinha de trigo } \\
\text { farinha de mandioca }\end{array}$ & $\begin{array}{l}47 \\
62 \\
1,5\end{array}$ & $\begin{array}{c}0,7-7,9 \\
0,51-4,3 \\
4,2-393\end{array}$ & $\begin{array}{c}5-27 \\
11-64 \\
30-372\end{array}$ \\
\hline & & mandioca & N.D & $2,5-13$ & $28-282$ \\
\hline & & farinha de milho & 60 & $0,49-4,1$ & $6-36$ \\
\hline
\end{tabular}




\begin{tabular}{|c|c|c|c|c|c|}
\hline Nigéria & AROGUNJO (2005) & cereais e tubérculos & $130[8,19]$ & $6,78[2,13]$ & N.D \\
\hline \multirow{7}{*}{ Londrina (Brasil) } & \multirow{7}{*}{ SCHEIBEL (2006) } & farinha de trigo & $73[2]$ & N.D & N.D \\
\hline & & fubá & $54[1]$ & N.D & N.D \\
\hline & & farinha de mandioca & $121[4]$ & N.D & N.D \\
\hline & & farinha de arroz & 56 [2] & N.D & N.D \\
\hline & & farinha de soja & 1469 [17] & N.D & N.D \\
\hline & & farinha de centeio & $191[5]$ & N.D & N.D \\
\hline & & farinha de aveia & $235[6]$ & N.D & N.D \\
\hline $\begin{array}{l}\text { Poços de Caldas } \\
\text { (Brasil) }\end{array}$ & ROSA (2018) & mistura de farinhas & $16[4]$ & $0,01[0,004]$ & $0,18[0,06]$ \\
\hline \multirow{4}{*}{ São Paulo (Brasil) } & \multirow{4}{*}{$\begin{array}{l}\text { VENTURINI \& } \\
\text { SORDI (1999) }\end{array}$} & trigo & $96[5]$ & N.D & $<0,23$ \\
\hline & & mandioca & $120[6]$ & N.D & $0,64[7]$ \\
\hline & & arroz & $15[7]$ & N.D & $<0,11$ \\
\hline & & aveia & 119 [6] & N.D & $0,75[15]$ \\
\hline
\end{tabular}

${ }^{*}$ Resultados originais do autor em mBq. $\mathrm{kg}^{-1}$.

N.D - Não determinado. 
Estudo realizado na cidade de Erbil, no Iraque, apresentou dados do fator de transferência dos radionuclídeos presentes no solo para culturas de plantas, em que o fator de transferência do solo para as plantas, são mais elevados para tório quando comparado ao rádio, o que também foi observado na literatura, e consequentemente os valores de dose efetiva também são mais elevados para o para o tório quando se comparado ao rádio. Contudo, o fator de transferência dos radionuclídeos do solo para as plantas, não apresenta influência significativa nesse processo, evidenciando que o fator de transferência é afetado principalmente pelas características físico-químico do solo em questão, assim como pelas características de cada espécie de plantas cultivadas (AZEEZ, et al., 2019).

Apesar de não ser possível verificar a origem dos insumos utilizados para confecção das farinhas, os valores de concentração de atividade e dose efetiva obtidos neste trabalho são bem próximo aos valores encontrados na literatura para os radionuclídeos naturais considerados.

\section{CONCLUSÕES}

Para os radionuclídeos naturais considerados ${ }^{40} \mathrm{~K},{ }^{226} \mathrm{Ra}$ e ${ }^{232} \mathrm{Th}$, foram obtidas concentrações de atividade na faixa entre $25 \mathrm{~Bq} \cdot \mathrm{kg}^{-1}$ a $663 \mathrm{~Bq} \cdot \mathrm{kg}^{-1}$ para o ${ }^{40} \mathrm{~K}$, de 0,97 Bq. kg-1 a 4,47 Bq. $\mathrm{kg}^{-1}$ para o ${ }^{226} \mathrm{Ra}$ e de 9,91 Bq. $\mathrm{kg}^{-1}$ a 42,41 Bq. $\mathrm{kg}^{-1}$ para o ${ }^{232} \mathrm{Th}$, inferiores aos limites anuais recomendados pela UNSCEAR de $22 \mathrm{~Bq} \cdot \mathrm{kg}^{-1}$ para o ${ }^{226} \mathrm{Ra}$ e de 1,7 22 Bq. $\mathrm{kg}^{-1}$ para o ${ }^{232} \mathrm{Th}$ (UNSCEAR, 2008). Para o ${ }^{40} \mathrm{~K}$ não apresentam valores de concentração de atividade por se tratar de um macronutriente essencial ao metabolismo humano. As doses efetivas obtidas estão entre 0,34 $\mu$ Sv.a' ${ }^{1}$ e $10,56 \mu S v . a^{-1}$ para o ${ }^{40} \mathrm{~K}$, entre $0,67 \mu S v . a^{-1}$ e $18,35 \mu S v . a^{-1}$ para o ${ }^{226}$ Ra e entre $5,62 \mu \mathrm{Sv} . \mathrm{a}^{-1}$ a $114,02 \mu \mathrm{Sv} . \mathrm{a}^{-1}$ para o ${ }^{232} \mathrm{Th}$. Os valores de dose efetiva recomendados pela UNSCEAR e IAEA por ingestão de alimentos contendo radionuclídeos naturais são de $140 \mu \mathrm{Sv} \cdot \mathrm{a}^{-1}$ e de $1 \mathrm{mSv} \cdot \mathrm{a}^{-1}$, respectivamente, para os indivíduos do público (UNSCEAR, 2008; IAEA, 2016). A dose efetiva anual devido à exposição às fontes naturais de radiação é de $2,4 \mathrm{mSv} \cdot \mathrm{a}^{-1}$, desse valor $0,29 \mathrm{mSv} \cdot \mathrm{a}^{-1}$ é devido à ingestão.

Os radionuclídeos artificiais ${ }^{134} \mathrm{Cs},{ }^{137} \mathrm{Cs},{ }^{106} \mathrm{Ru},{ }^{103} \mathrm{Ru},{ }^{60} \mathrm{Co},{ }^{131} \mathrm{I}$ e ${ }^{241} \mathrm{Am}$, apresentaram valores de concentração de atividades abaixo da concentração mínima 
detectável (CMD). Os valores médios obtidos para ${ }^{134} \mathrm{Cs},{ }^{137} \mathrm{Cs},{ }^{106} \mathrm{Ru},{ }^{103} \mathrm{Ru},{ }^{60} \mathrm{Co},{ }^{131}$ I $\mathrm{e}^{241} \mathrm{Am}$, foram de 0,04 $\mu \mathrm{Sv} . \mathrm{a}^{-1}, 0,03 \mu \mathrm{Sv} . \mathrm{a}^{-1}, 0,13 \mu \mathrm{Sv} . \mathrm{a}^{-1}, 0,001 \mu \mathrm{Sv} . \mathrm{a}^{-1}, 0,01 \mu \mathrm{Sv} . \mathrm{a}^{-}$ $1,0,05 \mu S v . a^{-1}$ e $0,4 \mu S v . a^{-1}$, respectivamente, para público adulto. Para público infantil os valores médios obtidos para os radionuclídeos artificiais recomendados foram de $0,04 \mu S v . a^{-1}, 0,03 \mu S v . a^{-1}, 0,01 \mu S v . a^{-1}, 0,9 \mu S v . a^{-1}, 0,1 \mu S v . a^{-1}, 0,4 \mu S v . a^{-1}$ e 0,6 $\mu \mathrm{Sv} . \mathrm{a}^{-1}$, para os radionuclídeos ${ }^{134} \mathrm{Cs},{ }^{137} \mathrm{Cs},{ }^{106} \mathrm{Ru},{ }^{103} \mathrm{Ru},{ }^{60} \mathrm{Co},{ }^{131} \mathrm{I}$ e ${ }^{241} \mathrm{Am}$, respectivamente.

Para os radionuclídeos artificiais considerados, tanto concentrações de atividade, quanto os valores de dose efetiva são inferiores aos níveis de referência de $1 \mathrm{mSv} \cdot \mathrm{a}^{-1}$ para os radionuclídeos artificiais em alimentos destinados ao consumo humano (crianças e adultos) e comercializados internacionalmente, (CNEN, 2005; CODEX, 2009).

Todas as amostras apresentaram valores de concentração de atividade e dose efetiva inferiores aos níveis recomendados, não apresentando riscos à saúde a partir da ingestão das farinhas analisadas.

\section{Sugestão para futuros trabalhos}

$\checkmark$ Aumentar o número de amostras, principalmente para soja, aveia, centeio e rosca.

$\checkmark$ Tentar relacionar os tipos de trigo (ver item 3.1, Tabela 5), com as concentrações de atividade obtidas, para verificar se, eventualmente, há influência do processamento do insumo utilizado para produção das farinhas de trigo. 


\section{REFERÊNCIAS}

ABITRIGO. Associação Brasileira da Indústria do Trigo. Estatísticas - Trigo e Farinha no Mundo. Julho, 2019. Disponível em < http://www.abitrigo.com.br/wpcontent/uploads/2019/08/Producao mundial de trigo 20152019 .pdf >. Acesso: julho, 2020.

ABIMILHO. Associação Brasileira das Indústrias do Milho. Riqueza/Produtividade, 2019. Disponível em: < http://www.abimilho.com.br/milho/produtividade>. Acesso em julho. 2020.

ACIOLI, M. R. Efeitos das variáveis de extrusão e da incorporação de glúten, amilase e farinha de milho na qualidade tecnológica da farinha de rosca extrusada em base de trigo. Dissertação (mestrado) - Universidade Estadual de Campinas. Faculdade de Engenharia de Alimentos. Campinas, SP: [s.n[, 2000.

AROGUNJO, A.; OFUGA, E.E.; AFOLABI, M.A. Levels of natural radionuclides in some Nigerian cereals and tubers. Journal of Environmental Radioactivity. 82(1):16 DOI: 10.1016/j.jenvrad.2004.10.010. February 2005.

ÁLVARES, VIRGÍNIA DE SOUZA. Manual de classificação de farinha de mandioca / Virgínia de Souza Álvares. - Brasília, DF: Embrapa, 2014.

ANVISA. Agência Nacional de Vigilância Sanitária. Gerência-Geral Alimentos Resolução - CNNPA no 12, de 1978 D.O. de 24/07/1978.

ANVISA. Agência Nacional de Vigilância Sanitária. REGULAMENTO TÉCNICO PARA FORTIFICAÇÃO DAS FARINHAS DE TRIGO E DAS FARINHAS DE MILHO COM FERRO E ÁCIDO FÓLICO. Resolução de Diretoria Colegiada - RDC № 344, D.O.U de 18/12/2002.

AQUINO, Reginaldo Ribeiro. Avaliação da radioatividade em mármores e granitos comerciais do estado do Espírito Santo. Tese (Doutorado - Programa de PósGraduação em Tecnologia Nuclear). São Paulo 2015.

ARAÚJO, J. M. A. Química de alimentos: teoria e pratica. 2. ed. Viçosa: UFV, 1999. 416 p.:11.

AROGUNJO, A. M.; OFUGA, E. E.; AFOLABI M. A. Levels of natural radionuclides in some Nigerian cereals and tubers. Journal of Environmental Radioactivity 82 (2005) 1-6.

ASADUZZAMAN, K. H.; KHANDAKER, M. U.; AMIN, Y.M.; BRADLEY, D.A.; MAHAT, R.H.; NOR, R.M. Soil-to-root vegetable transfer factors for ${ }^{226} \mathrm{Ra},{ }^{232} \mathrm{Th},{ }^{40} \mathrm{~K}$, and ${ }^{88} \mathrm{Y}$ in Malaysia, Journal of Environmental Radioactivity, Volume 135, 2014.

AWUDU, A. R.; FAANU, A.; DARKO, E. O.; EMI-REYNOLDS, G.; ADULKPO, O. K.; KPEGLO, D. O.; OTOO, F.; LAWLUVI, H.; KPODZRO, R.; LI, I. D.; OBENG, M. K.; 
AGYEMAN, B. Preliminary studies on ${ }^{226} \mathrm{Ra},{ }^{228} \mathrm{Ra},{ }^{228} \mathrm{Th}$ and ${ }^{40} \mathrm{~K}$ concentration in foodstuffs consumed by inhabitants of Accra metropolitan area, Ghana. Journal of Radioanalytical and Nuclear Chemistry. V. 291, p. 635-641, 2012.

AZEEZ, H. H.; MANSOUR, H. H.; AHMAD, S. T. Transfer of natural radioactive nuclides from soil to plant crops. Elsevier, Applied Radiation and Isotopes 147 (2019) 152-158.

BARROS, L. F. e PECEQUILO, B. R. S. Self-Attenuation factors in gamma-ray spectrometry of select sand samples from Camburi Beach - Vitória, Espírito Santo, Brazil, Radiation physics and Chemistry. v. 95, p. 339-341, 2014.

BARTABURU, Xavier. Do grão ao pão: farinha de trigo: história da moagem no Brasil. São Paulo. Editora Origem, 2016. Disponível em < http://www.abitrigo.com.br/wp-content/uploads/2019/08/Livro-ABITRIGO.pdf>.

Acesso em julho de 2020.

BELIK, WALTER. Perspectiva para segurança alimentar e nutricional no Brasil. Saúde e Sociedade. v.12, n.1, p.12-20, jan-jun 2003. Disponível em < http://www.scielo.br/pdf/sausoc/v12n1/04.pdf>. Acesso em dez. 2019.

BERGAMASCHI, H.; BERLATO, M. A.; MATZENAUER, R.; FONTANA, D. C.; CUNHA, G. R.; SANTOS, M. L. V; FARIAS, J. R.B.; BARNI, N. A. Agrometeorologia aplicada a irrigação. 2. Ed. Porto Alegre: Ed. Universidade/UFRGS, 1999. 125 p.

BORGES, J. T. S.; CARDOSO, W. S.; MACHADO, F. de P.; PINHEIRO, F. de A.; RIOS, S. de A. Indústria do milho. In: BORÉM, A.; RIOS, S. de A. (Ed.). Milho biofortificado. Visconde do Rio Branco: Suprema, 2011. p. 173-195.

BRASIL. Decreto-Lei no 986, de 12 de outubro de 1969. Institui Normas Básicas sobre alimentos. Diário Oficial da União, Brasília, 21 de outubro de 1969.

BRASIL. Ministério da Agricultura, Pecuária e Abastecimento. Instrução Normativa no 354, 18/06/1996. Diário Oficial da União. Brasília, 22 de setembro de 1996.

BRASIL. Ministério da Agricultura, Pecuária e Abastecimento. Instrução Normativa № 8 de 2 de junho de 2005. Aprova o Regulamento Técnico de Identidade e Qualidade da Farinha de Trigo. Diário Oficial da União, Brasília - DF, 2 de junho de 2005.

BRASIL. Ministério da Agricultura, Pecuária e Abastecimento. Instrução Normativa 52/2011 de novembro de 2011. Brasília, 2011. Regulamento Técnico da Farinha de Mandioca.

BRASIL. Ministério da Saúde. Resolução da Diretoria Colegiada ํo 42 de 29 de agosto de 2013. Regulamento Técnico MERCOSUL sobre limites máximos de Contaminantes Inorgânicos em Alimentos. Diário Oficial da União. Brasília - DF, 30 agosto de 2013.

BRASIL. Ministério da Saúde. Guia alimentar para a população brasileira. $2^{a}$ Ed. Brasília - DF, 2014. Disponível em: < >. Acesso em 30 dez. 2019. 
BRASIL. Ministério da Saúde. PNAN - Plano Nacional de Alimentação e Nutrição 2015 - 2020, 2015. Disponível em:

<http://www.minsaude.gov.cv/index.php/documentossite/331-plano-nacional-

alimentacao-e-nutricao-2015-2020/file> Acesso em 30 dez. 2019.

CAISAN. Câmara Interministerial de Segurança Alimentar e Nutricional. II PLANO NACIONAL DE SEGURANÇA ALIMENTAR E NUTRICIONAL PLANSAN 20162019. Brasília, fevereiro de 2018.

CARNEIRO, F F; PIGNATI, W; RIGOTTO, R M; AUGUSTO, L G S. RIZOLLO, A; MULLER, N M; ALEXANDRE, V P. FRIEDRICH, K; MELLO, M S C. Dossiê ABRASCO -Um alerta sobre os impactos dos agrotóxicos na saúde. ABRASCO, Rio de Janeiro, abril de 2012. 1a Parte. 98p.

CÂMARA, G. M. S.; GODOY, O. P.; MARCOS, F.o, J.; LIMA, U. A Tecnologia da produção. In: CÂMARA, G. M. S.; GODOY, O. P.; MARCOS, F.o, J.; LIMA, U. A. Mandioca: produção, pré-processamento e transformação agroindustrial. (Série Agroindustrial no 4). São Paulo: Secretaria da Ind., Com., Ciênc. e Tec., 1982. p. 1-44. (Câmara, 1982)

CANBERRA. Germanium detectors. Acesso em: abril, 2019. Disponível em: <http://www.canberra.com/products/detectors/germanium-detectors.asp.>

CAVALCANTE, FERNANDA. Avaliação da Radioatividade Natural e Artificial em Rações Comerciais para Animais Domésticos. Tese (Doutorado - Programa de Pós-Graduação em Tecnologia Nuclear). São Paulo, 2017. 113 f.:

CODEX. Codex General Standard for Contaminants and Toxins in Food and Feed. Revision 4 - 2009, Amendment 2 - 2010, n. 193, 2009.

COSTA, M. G. et al. Qualidade tecnológica de grãos e farinhas de trigo nacionais e importados - Ciência e Tecnologia de Alimentos, Campinas, p. 220-225, jan.-mar. 2008. Disponível em: <http://www.scielo.br/pdf/cta/v28n1/30.pdf>. Acesso em 14 dez. 2017.

CNEN. Posição regulatória 3.01 / 006:2001 - Medidas de Proteção e Critérios de Intervenção em Situação de Emergência. Comissão Nacional de Energia Nuclear, 2005.

CNEN. Comissão Nacional de Energia Nuclear, 2014. CNEN - NN 3.01 - Diretrizes Básicas de Radioproteção, Rio de Janeiro: DOU 11 de março de 2014.

CNEN. Comissão Nacional de Energia Nuclear, 1988. Norma CNEN NN 6.02Licenciamento de Instalações Radiativas, Resolução CNEN 261/20 maio, 2020.

CHUZEL, G.; VILPOUX, O.; CEREDA, M. P. Le Manioc Au Brésil. Importance sócio-économique et diversité. In: EGBE, T. A.; BRAUMAN, A.; GRIFFON, D.; TRECHE, S. (Eds.). Transformation alimentaire du manioc. Paris: Orstom, 1995. p. $571-579$. 
CURRIE, L. A. Limits for Qualitative Detection and Quantitative Determination: Application to Radiochemistry, Anal. Chemistry, v.40, p. 586-593, 1968.

DE MORI, C.; IGNACZAK, J. C.; GARAGORRY, F. L.; CHAIB FILHO, H. Dinâmica da produção de centeio no Brasil no período de 1975 a 2003. Passo Fundo: Embrapa Trigo, 2007. 37 p. Disponível em <https://core.ac.uk/download/pdf/18498275.pdf >. Acesso em julho 2020.

DIAS, A R. G. Efeito de oxidantes, de ácidos orgânicos e da fração solúvel em água na propriedade de expansão do amido de mandioca fermentado. Campinas. 2002. 149 p. Tese (Doutor em Tecnologia de Alimentos) - Faculdade de Engenharia de Alimentos, Universidade Estadual de Campinas.

EISENBUD, M. Environmental Radioactivity. 3nd ed. Academic Press, 1987.

EMBRAPA. Empresa Brasileira de Pesquisa Agropecuária. Farinhas de mandioca seca e mista. Embrapa Informação Tecnológica, Brasília, (Agroindústria Familiar). DF. 2006. 44 p.

EMBRAPA. Empresa Brasileira de Pesquisa Agropecuária. Eco fisiologia da soja. Circular técnica 48, ISSN 1516 - 7860. Londrina, PR, setembro, 2007. Disponível em: <https://www.embrapa.br/soja/busca-de-

publicacoes//publicacao/470308/ecofisiologia-da-soja>. Acesso em: julho de 2020.

EMBRAPA. Empresa Brasileira de Pesquisa Agropecuária. Qualidade comercial do trigo brasileiro: Safra 2007. Embrapa Trigo, documento online, dezembro, 2010. Disponível em: <http://www.cnpt.embrapa.br/biblio/do/p do126.pdf>. Acesso em: julho de 2020.

EMBRAPA. Empresa Brasileira de Pesquisa Agropecuária. Árvore do conhecimento. Tecnologia de alimentos - Aveia. EMBRAPA. Disponível em: < http://www.agencia.cnptia.embrapa.br/gestor/tecnologia de alimentos/arvore/CONT 000girlwnqt02wx5ok05vadr1pof7xln.html>. Acesso em julho de 2020.

EVANS, R. D. The Atomic Nucleus. McGraw Hill, New York, 1972.

FERREIRA, A. O. Avaliação da radioatividade natural em algumas rochas graníticas do estado do Paraná e sua utilização civil. Tese (Doutorado - Programa de PósGraduação em Tecnologia Nuclear). São Paulo, 2013.

GILMORE, G. and HEMINGWAY, J.D. Pratical gamma-ray spectrometry. John Wiley, 1995.

GUTKOSKI, L. C.; Bonamigo, J. M. A.; Teixeira, D. M. F.; Pedó, I. Desenvolvimento de barras de cereais à base de aveia com alto teor de fibra alimentar. Ciência e Tecnologia de Alimentos, v. 27, n. 2, p. 787-792, 2007.

HE, F. J. and CHEN, J. Q. Consumption of soybean, soy foods, soy isoflavones and breast cancer incidence: Differences between Chinese women and women 
in Western countries and possible mechanisms. Food Science and Human Wellness, v. 2, p.146-161, 2013.

HORTON, SRJ \& ROSS, J. The Economics of Iron Deficiency. Food Policy, 2003. 28. 51-75. 10.1016/S0306-9192 (02) 00070-2.

IAEA. International Atomic Energy Agency. International Basic Safety Standards for Protection against lonizing Radiation and for the Safety of Radiation Sources. Safety series $n^{\circ} 115,1996$.

IAEA. International Atomic Energy Agency. Criteria for Radionuclide Activity Concentrations for Food and Drinking Water. IAEA-TECDOC-1788. Vienna, 2016.

IAEA. International Atomic Energy Agency. World Thorium Occurrences, Deposits and Resources. IAEA-TECDOC-1877. Vienna, 2019.

IAEA. International Atomic Energy Agency. Isotopes Table, 2020. Disponível em: $<$ https://nds.iaea.org/relnsd/vcharthtml/VChartHTML.htm >.

ICRP. International Commission on Radiological Protection - 1990 Recommendations of the International Commission on Radiological Protection. ICRP Publication 60. Pergamon Press, Oxford. 1991.

INTERWINNER TM 6.0 MCA, 2004. Emulation, Data Acquisition and Analysis software for Gamma and Alpha Spectroscopy IW-B32. ORTEC. Oak Ridge, TN, USA.

IBGE. INSTITUTO BRASILEIRO DE GEOGRAFIA E ESTATíSTICA. Pesquisa de Orçamentos Familiares 2008/2009. Rio de Janeiro: 2010.

ISMAEL, L. A. S. Consumo do trigo na alimentação brasileira e sua projeção na estratégia de fortificação de farinhas de trigo. 2011. 105p. [Programa de PósGraduação Interunidades em Nutrição Humana Aplicada - PRONUT - Faculdade de Ciências Farmacêuticas, Faculdade de Economia, Administração e Contabilidade e Faculdade de Saúde Pública da Universidade de São Paulo].

KENNEDY, G.; BURLINGAME, B.; NGUYEN, N. Nutrient impact assessment of rice in major rice-consuming countries. International Rice Commission Newsletter, Roma, v. 51, p. 33-42, 2002.

KNOLL, G. P. Radiation Detection and Measurement, John Wiley, New York, $3^{\text {rd }}$ ed. 2000.

LIMA, U. A. Industrialização da mandioca. Mandioca: produção, préprocessamento e transformação agroindustrial. São Paulo: Secretaria da Ind., Com., Ciênc. e Tec., 1982.

LOPES, JOSÉ MARQUES. Dose Efetiva Comprometida Devida aos Radionuclídeos ${ }^{40} \mathrm{~K}$, ${ }^{226} \mathrm{Ra},{ }^{228} \mathrm{Ra}$ e ${ }^{228} \mathrm{Th}$ Contidos nos Alimentos da Dieta da População do Estado do Rio de Janeiro. Tese (Doutorado) UFRJ/COPPE/Programa de Engenharia Nuclear. Rio de Janeiro, 2018. 
LNHB. Laboratorie National Henri Becquerel. Acesso em dez. 2019. Disponível em: $<$ http://www.nucleide.org/DDEP WG/DDEPdata.htm $>$.

MÁDUAR, M. F. Desenvolvimento de um código computacional aberto de análise quantitativa para determinação de radionuclídeos por espectrometria gama com detectores semicondutores. Tese (Doutorado - Programa de Pós-Graduação em Tecnologia Nuclear). São Paulo, 2010.

MAZZILLI, B. P.; MÁDUAR, M. F.; CAMPOS, M. P. Radioatividade no Meio Ambiente e Avaliação de Impacto Radiológico Ambiental. Instituto de Pesquisas Energéticas e Nucleares (IPEN), Notas de aula. Universidade de São Paulo, São Paulo, 2013.

MELQUIADES, F. L.; APPOLONI, C. R. Radioatividade natural em amostras alimentares. Cad. Brás. Ens. Fís. 2004.

NEVES, LETÍCIA CORASSA. Farinha de trigo: consumo da população brasileira e sua implicação na ingestão de ferro e ácido fólico. - versão revisada de acordo com a resolução CoPGr 6018 de 2011. - - Piracicaba, 2017. 76 p. Dissertação (Mestrado) - USP / Escola de Agricultura "Luiz de Queiroz").

NISTI, M. B.; SANTOS, A. J. G; PECEQUILO, B. R. S.; MADUAR, M. F.; ALENCAR, M. M.; MOREIRA, S. R. D. Fast methodology for time counting optimization in gammaray spectrometry based on preset minimum detectable amounts. J. Radioanal. Nucl. Chem., v. 281. N. 2, p. $283-286,2009$.

NISTI, M. B.; CAMPOS, M. P.; MAZZILLI, B. P. Natural radioactivity and ${ }^{222} \mathbf{R n}$ exhalation rate from Brazilian phosphogypsum building materials. 7th International Symposium on Naturally Occurring Radioactive Material, 2013, Beijing. Proceedings of $7^{\text {th }}$ International Symposium on Naturally Occurring Radioactive Material (Supplementary Material), International Atomic Energy Agency, Vienna (2013), p.1-6.

NISTI, M. B. Lixiviação de metais e radionuclídeos em solos tropicais condicionados com fosfogesso. Tese (Doutorado - Programa de Pós-Graduação em Tecnologia Nuclear). São Paulo, 2016.

NYGREN, C.; HALLMANS, G.; LITHNER, F. Effect of high-bran bread on blood glucose control in insulindependent diabetic patients. Diabète \& Métabolisme, Paris, v. 10, n. 1, p. 39-43, jan. 1984.

OLOMO, J. B. The natural radioactivity in some Nigerian foodstuffs. Nuclear Instruments and Methods in Physics Research A299, 666 - 669, 1990.

PAIVA, CHRISTIANNE TORRES DE. Estudo da mobilidade e dispersão de ${ }^{238} \mathrm{U}$, ${ }^{232} \mathrm{Th},{ }^{40} \mathrm{~K},{ }^{226} \mathrm{Ra} \mathrm{e}{ }^{222} \mathrm{Rn}$ e metais pesados no sistema solo-rocha do depósito de U-ETR de São José de Espinharas (PB) - Recife: O Autor, 2008. 223f., il., figs., tabs., gráfs. 
PNI - Programa Nacional de Intercomparação de Resultados de Análises de Radionuclídeos em Amostras Ambientais. IRD, Rio de Janeiro. Rodadas de abril/2008 a agosto/2019. Relatório interno LRA.

POLANCO, I.; MOLINA, M.; PIETRO, G.; CARRACO, S.; LAMA, R. Dieta y enfermidad celíaca. Alimentaria, v.33, n.264, p.91-93, 1995.

RIBEIRO, FERNANDO CARLOS ARAUJO. Manejo agrícola e teores de radionuclídeos naturais em vegetais cultivados no Rio de Janeiro. Rio de Janeiro: IRD, 2004. Xii, 61 p. 29,7 cm: il. Graf., tab. Dissertação (mestrado) - Instituto de Radioproteção e Dosimetria - Rio de Janeiro, 2004.

ROSA, M. M. L. Estudo de dieta total aplicado na avaliação de ingestão de elementos essenciais, tóxicos e radionuclídeos naturais nas populações urbana e rural de Poços de Caldas. 2018. 148p. Tese (Doutorado em Tecnologia Nuclear), Instituto de Pesquisas Energéticas e Nucleares, IPEN-CNEN/SP, São Paulo.

SANTOS, E. E.; LAURIA, D. C.; AMARAL, E. C. S.; ROCHEDO, E. R. Daily ingestion of ${ }^{232} \mathrm{Th},{ }^{238} \mathrm{U},{ }^{226} \mathrm{Ra},{ }^{228} \mathrm{Ra}$ and ${ }^{210} \mathrm{~Pb}$ in vegetables by inhabitants of Rio de Janeiro city. J. Environ. Radioactiv. Vol. 62, pág. 75-86, 2002a.

SANTOS, E. E., LAURIA D. C., AMRAL, E. C. S., CARVALHO, L. L. Avaliação da exposição interna a K-40 dos residentes da cidade do Rio de Janeiro. Instituto de Radioproteção e Dosimetria (IRD), Rio de Janeiro - RJ, 2002b.

SCHEIBEL, VIVIANE. Determinação das doses efetivas por ingestão de farinhas de cereais através da espectrometria de raios gama. Tese (Doutorado em Física) - Universidade Estadual de Londrina, 2006.

SHWEIKANI, R.; HASAN, M. Determination of the optimal measurement counting time and detection limit for gamma-ray spectrometry analysis. Accredit Qual Assur, v. 20, n. 6 , p. 501, 504, 2015.

SIVARAMAKRISHNAN, H. P.; SENGE, B.; CHATTOPADHYAY, P. K. Rheological properties of rice dough for making rice bread. Journal of Food Engineering, Meppel, v. 62 , n. 1, p. 37-45, 2004.

SINDUSTRIGO. Sindicato Indústria Trigo Estado São Paulo. Estatísticas - Consumo per capita - Consumo per capita Estado de São Paulo, 2019. Disponível em: $<$ http://www.sindustrigo.com.br/recursos/files/Consumo-Per-Capita-de-Farinha-de-

Trigo-SP-17-18.pdf>. Acesso em 09/12/2019.

SILVA, E. M. M. Produção de macarrão pré-cozido à base de farinha mista de arroz integral e milho para celíacos utilizando o processo de extrusão. $118 \mathrm{f}$. Dissertação (Mestrado em Ciência) - Instituto de Tecnologia, Universidade Rural do Rio de Janeiro, Rio de Janeiro, 2007.

TOME, F. V.; BLANCO RODRÍGUEZ, M. P.; LOZANO, J. C. Soil-to-plant transfer factors for natural radionuclides and stable elements in a Mediterranean area. Journal of Environmental Radioactivity 65 (2003) 161-175. 
TORRES, R.L.; GONZÁLES, R.J.; SÁNCHEZ, H.D.; OSELLA, C.A.; TORRES, M.A.G. Comportamiento de variedades de arroz en la elaboración de pan sin gluten. Archivos Latinoamericanos de Nutrición, v.9, n.2, p. 162-165, 1999.

UNSCEAR. United Nations Scientific Committee on the Effects of Atomic Radiation. Sources and Effects of Ionizing Radiation. Report Vol. I. United Nations, New York, 2000.

UNSCEAR. United Nations Scientific Committee on the Effects of Atomic Radiation. Sources and Effects of lonizing Radiation, Scientific Annex B: Exposure of the public and workers from various sources of radiation. The, New York, 2008a.

UNSCEAR. The United Scientific Committee on the Effects of Atomic Radiation. Sources and Effects of lonizing Radiation, Scientific Annex F: Effective doses coefficients for ingestion of radionuclides for members of the public. New York, 2008b.

VASCONCELLOS, R. M.; METELO, M. J.; MOTA, A. C. M.; GOMES, R. D. Geofísica em Levantamentos Geológicos no Brasil, CPRM, Serviço Geológico do Brasil, Rio de Janeiro, 1994, $165 \mathrm{p}$.

VENTURINI, L.; SORDI, A. A. Radioactivity in and committed effective dose from some Brazilian foodstuffs. Health Phys. Vol. 76 (3), pag. 311, 1999.

WEBER, F. H.; GUTKOSKI, L. C.; ELIAS, M. C. Caracterização química de cariopses de aveia (Avena sativa, L.) da cultivar UPF 18. Ciência e Tecnologia de Alimentos, v. 22, n. 1, p. 39-44, 2002.

WHO. World Health Organization. Iron deficiency anaemia. Assessment, prevention, and control. A guide for programme managers. Geneva. 132 p. 2001.

WHO. World Health Organization. Guideline: Potassium intake for adults and children. Geneva. 2012.

WHO. World Health Organization. Guideline: fortification of maize flour and corn meal with vitamins and minerals. Geneva: 2016.

ZARDO, F. P. Análises Laboratoriais para o Controle de Qualidade da Farinha de Trigo. Instituto Federal de Ciência e Tecnologia do Rio Grande do Sul, Bento Gonçalves, 2010. Disponível em:

<http://www.bento.ifrs.edu.br/site/midias/arquivos/2012429101512203fernandazardo. pdf>. Acesso em 14 dez. 2017. 
INSTITUTO DE PESQUISAS ENERGÉTICAS E NUCLEARES

Diretoria de Pesquisa, Desenvolvimento e Ensino

Av. Prof. Lineu Prestes, 2242 - Cidade Universitária CEP: 05508-000

Fone/Fax(0XX11) 3133-8908

SÃO PAULO - São Paulo - Brasil

http://www.ipen.br

O IPEN é uma Autarquia vinculada à Secretaria de Desenvolvimento, associada à Universidade de São Paulo e gerida técnica e administrativamente pela Comissão Nacional de Energia Nuclear, órgão do

Ministério da Ciência, Tecnologia, Inovações e Comunicações. 